\title{
Students’ Perspectives on Bullying
}

\author{
Camilla Forsberg
}

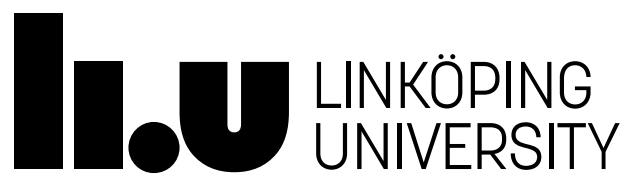

Linköping Studies in Behavioural Science No. 193

Faculty of Educational Sciences

Linköping 2016 
Linköping Studies in Behavioural Science $\cdot$ No. 193

Distributed by:

Department of Behavioural Sciences and Learning Linköping University

SE-581 83 Linköping

Camilla Forsberg

Students' Perspectives on Bullying

Edition 1:1

ISBN 978-91-7685-874-5

ISSN 1654-2029

(c) Camilla Forsberg 2016

Department of Behavioural Sciences and Learning, 2016

Printed by: Liu-tryck, Linköping, Sweden, 2016 


\section{Förord}

Att vara doktorand eller inte. Det är den stora frågan. För en måste traska igenom, vad som i doktorandtermer kan benämnas som, "The Valley of Shit". Ni vet, den där mörka, geggiga fasen, där en säger till sig själv "Nej, det här kommer aldrig blir färdigt och bra".

Under sådana processer behövs någon annan som kan ge stöd, vägledning och analytisk skärpa på ens arbete. Just detta har jag många olika personer att tacka för. Alldeles i synnerhet mina två handledare. Min huvudhandledare, Robert Thornberg, du har bidragit med ovärderliga kunskaper och analytiska idéer, vägledning och engagemang under hela processen. Marcus Samuelsson, min biträdande handledare, du har kommit med kloka råd och uppmuntran och bidragit med en analytisk blick som fört mig och avhandlingen framåt. Ett Stort och innerligt tack till er båda! Tack även till Gunnel Colnerud som inledningsvis var min biträdande handledare. Din vishet och ditt engagemang gör dig till en oerhörd förebild.

Tack även till mina fantastiska kollegor och vänner vid PeDi för uppmuntran, engagemang och social samvaro. Jag är väldigt tacksam över att jag har fått lära känna er och arbeta tillsammans med er. Tack särskilt till doktorandgruppen. Ett extra tack till Elisabeth Eriksson. Du har inte bara stått ut med att dela kontor och ha mig inneboende utan även varit mig följsam och behjälplig genom hela processen. Ett stort tack även till Tove Mattsson, Björn Sjögren, Jessica Elofsson och Joakim Strindberg för insatser i ett kritiskt skede av arbetet.

Jag vill även tacka Elisabet Näsman som var granskare vid mitt slutseminarium. Du hade noggrant läst mitt arbete och kom med konstruktiva kommentarer som jag hade stor nytta av i det fortsatta arbetet med avhandlingen. Värdefulla kommentarer har jag även fått ifrån Susanne Kreitz-Sandberg och Håkan Löfgren som tillsammans med mina handledare utgjorde min läsgrupp. Tack för att ni engagerade er i min text och gav mig synpunkter som vägledde mig in i mål! 
Tack även till mina vänner och kollegor vid Pedvux, särskilt för att ni så varmt tog emot mig när jag lånade ett kontor uppe hos er. Ett särskilt tack till Song-ee Ahn för alla skratt och klokheter. Och tack Elli, my companion in all of this, vad skulle jag göra utan dig?

Jag vill även tacka alla i den f.d. FOG-gruppen som jag har haft många roliga och givande stunder tillsammans med.

Tack även till Confero, jag är så glad att jag fått vara en del av denna tidskrift. Det har lärt mig och gett mig mycket. Ni är alla bäst!

För gott samarbete vill jag tacka Paul Horton, Jelmer Brüggeman och Lisa Kilman. Det har varit väldigt spännande och utvecklande att få samarbeta med er alla.

The research team at Georgia State University: Thank you all for our collaboration!

Det är så många som har bidragit till att denna avhandling nu ser sitt gryningsljus. Inte minst vill jag tacka alla elever som jag har fătt möjlighet att intervjua, utan er hade det inte blivit någon avhandling. Tack även till alla skolor och lärare som varit med och möjliggjort att jag fått träffa just era elever.

Till mina vänner och min familj, ni har fått stå ut med att ibland inte träffa mig på flera månader och fått möta en socialt förvirrad person i upptagenhet av tankar på avhandlingen. Tack för att ni har påmint mig om livet bortom avhandlingen och för att ni finns i mitt liv. Nu ska vi nog kunna ses lite oftare. Välkommen till världen Lovelia, släktens nya tillskott!

Sist men inte minst vill jag tacka Martin. Du har tagit hand om mig och stöttat mig igenom det slitiga slutåret. $\mathrm{Nu}$ lovar jag, inga fler svarta avhandlingshål. Tack för att du finns.

Linköping i december 2015

Camilla Forsberg 


\section{CONTENT}

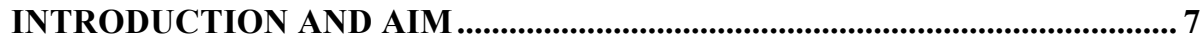

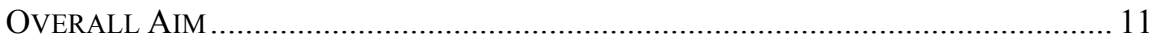

2. DEFINITIONS, PERSPECTIVES AND RESEARCH ON BULLYING ........ 13

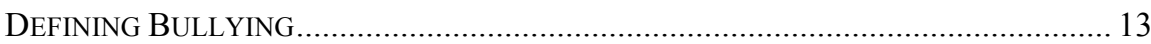

Repetition, Intention and Power Imbalance ……………………………........ 14

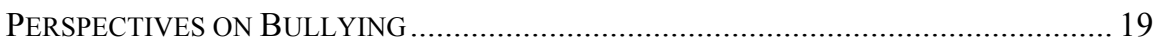

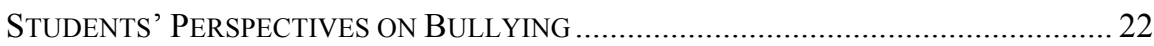

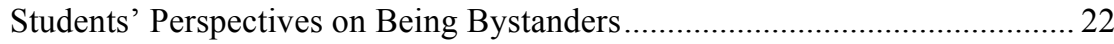

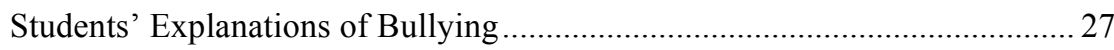

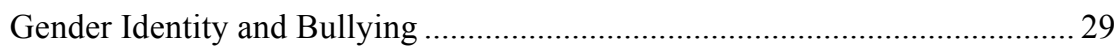

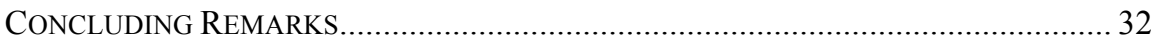

3. PHILOSOPHICAL AND THEORETICAL FRAMEWORK..............................33

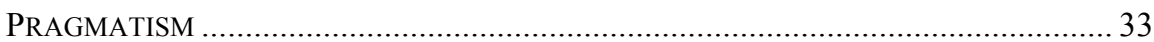

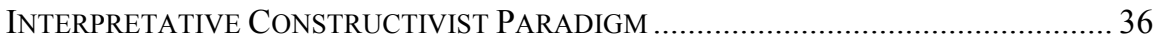

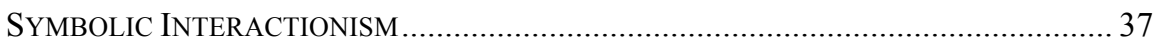

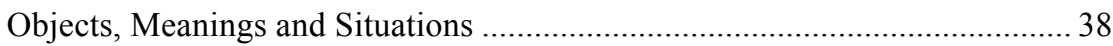

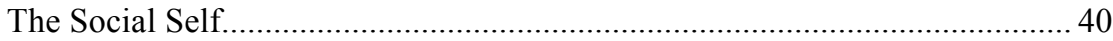

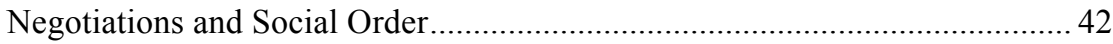

A Symbolic Interactionist Perspective on Bullying ........................................... 42

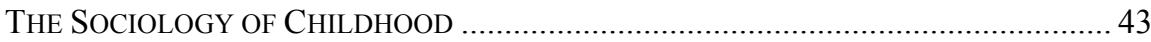

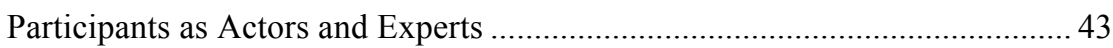

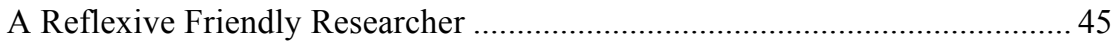

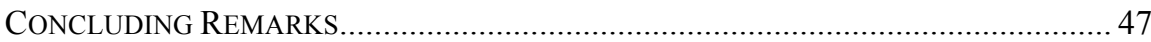

4. METHODOLOGICAL FRAMEWORK AND METHODS...............................48

A CONSTRUCTIVIST GROUNDED THEORY APPROACH............................................ 48

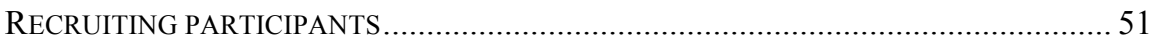

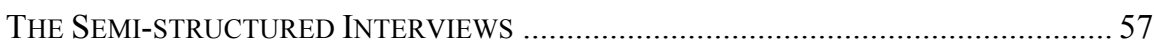

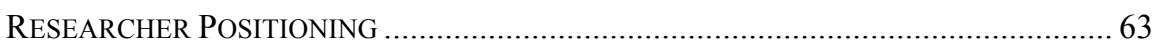

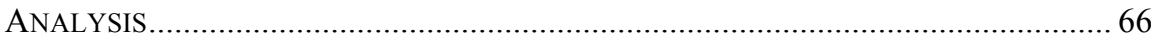

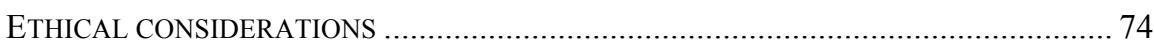

5. SUMMARY OF PAPERS …............................................................................ 78 


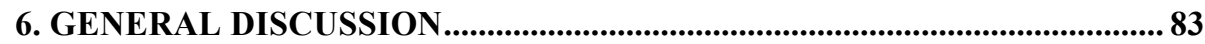

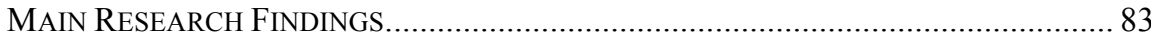

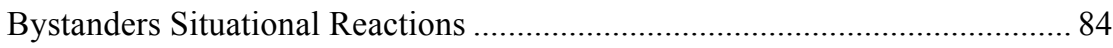

The Social Ordering of Belonging Producing Bullying .................................. 87

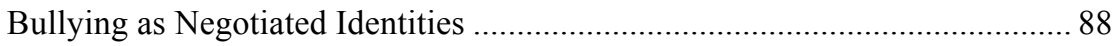

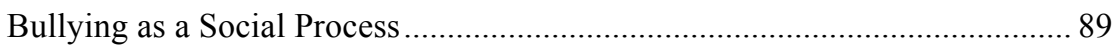

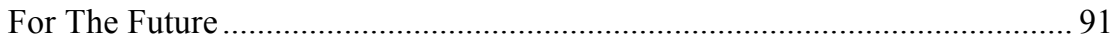

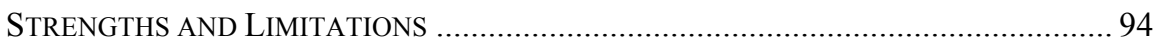

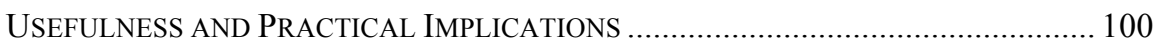

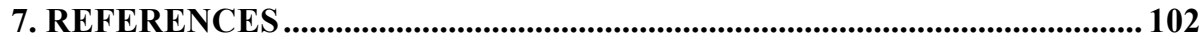




\section{Introduction and Aim}

This thesis is about bullying, reactions to bullying and processes in bullying, as it takes shape in interaction and interpretations of $133^{1}$ interviews with students from fourth-to eighth grade. One of the students I met stated the following.

So I, I think it is like this, adults need to listen more to the children and try to see things from different perspectives. It's the same thing when the police try to solve a crime, they can't just say to someone "you have done this and this and you're going to prison for a year", they need to collect evidence as well. And at the same time, teachers, they don't see everything, or adults in general, but they believe they do and they construct their own opinion about what's going on and act as if they are right, like, "I don't care what you are saying". But, they don't react to small things either, and that's what makes bullying emerge" (a girl in grade 5).

From this excerpt it is possible to make a few interpretations of how several rationales have been constructed as important for her perspective on bullying. Firstly, she has met several adults who have handled bullying with varying success and she holds a sceptical view of some adults' ways of approaching bullying and children, where the adults' actions have been problematised as ineffective and offensive for overlooking children's perspectives. Secondly, she suggests that adults should take a more open approach to bullying and investigate what has happened. Especially she wants adults to listen to children to better understand what is going on. Thirdly, she compares this to how the police work to solve crimes, which here seems to function as a way of strengthening her argument of not foreclosing the interpretations of what has happened too soon, but rather investigating this. Fourthly, she adds that adults do not react to small things and thereby as not taking

\footnotetext{
${ }^{1}$ For this thesis eighty-seven Swedish students participated. However, as will be noted later, 46 US students participated in paper II. These students were recruited and interviewed by the US research team, but with these students included, 133 students participated.
} 
the opportunity to prevent bullying from emerging.

The excerpt above illustrates perspectives that were discussed among the participants during our interviews. I have studied students' perspectives on bullying, since I view students' perspectives as crucial for our further understanding of this phenomenon. Children ${ }^{2}$ have the right to make their voices heard on issues that concern them according to Article 12 of the UN Convention on the Rights of the Child (e.g., Utrikesdepartementet, 2008; Näsman \& von Gerber, 2002). I have assumed that students have something to say about bullying and view the participants as expert commentators of their social worlds (Prout \& James, 1997). Firstly, I assumed students have something to say about bullying as it is considered to be a prevalent problem in schools (Borntrager, Davis, Bernstein, \& Gorman, 2009), where approximately 7-8 per cent of Swedish students between 10 and 15 are bullied in school (Flygare et al., 2011). Secondly, bullying involves a lot of people as it takes place in a peer context often including witnesses, referred to as bystanders (Craig \& Pepler, 1997; Craig, Pepler, \& Atlas, 2000). Bystanders are usually present when bullying takes place but seldom intervene (Craig \& Pepler, 1997; Craig et al., 2000) by either taking a stand in the situation or telling a teacher or an adult (Rigby, 2008). Thirdly, the school could be defined as an arena where bullying takes place (e.g., Eriksson, Lindberg, Flygare, \& Daneback, 2002) involving several formal and informal activities for organising social relations among students (e.g., Bliding, 2004).

Bullying is largely connected to the school context. Schools in Sweden have to be goal oriented in their work against bullying, prevent bullying from occurring, as well as put together yearly a comprehensive plan regarding their arrangements to counteract bullying. Bullying is prohibited in schools; all school staff are subscribed the responsibility to counteract such incidents (SFS: 2010:800). I have collected my data in the school context. This context is convenient, for it gathers large groups of individuals but students' perspectives might also shed new light on factors that could be included in some of the schools' bullying prevention and intervention

\footnotetext{
2 I will mostly use the concepts "students" or "participants" throughout this thesis. However, when referring to theories or documents where the concept "child" or "children" is used, this concept will be used instead. Additionally, the concept child was used in my third paper to fit the scientific journal.
} 
efforts. This seems important as most definitions on bullying are formulated by adults (e.g., Frånberg \& Wrethander, 2011) and students seldom have influence over bullying interventions in schools (e.g., Osbeck \& Söderström, 2014). Discrepancies are also found among students' and adults' perspectives on bullying. Compared to adults, students are found more seldom to address repetition and power imbalances as part of their bullying definition (Cheng, Chen, Ho, \& Cheng, 2011; Frisén, Holmqvist, Oscarsson, 2008; Naylor, Cowie, Cossin, Bettencourt, \& Lemme, 2006). Hence, Compton, Campbell, \& Mergler (2014) found that teachers ignored power imbalance in their definition, whereas both students and teachers disregarded repetition as crucial. The value of my research lies in its usability for researched practice (Dewey, 1925; Peirce, 1940) and my intended audiences include schools, school professionals and prospective teachers, and how the conceptualisations made in this study could be used as tools for reflecting, interpreting and improving bullying prevention and intervention efforts. However, my audience - and the value of my research - also includes the bullying research community, and others interesting in research on bullying, where the findings could contribute with important nuances and insights to the growing body of research. Since bullying is associated with health consequences such as depression, social isolation, lower academic achievement and mental health problems for everyone involved (Farrington \& Ttofi, 2011; Rivers, Poteat, Noret, \& Ashurst, 2009; Stavrinides, Georgiou, Nikiforou, \& Kiteri, 2011), there should be a lot of audiences interested in this kind of research.

A great many studies have contributed with important insights on bullying, including both quantitative and qualitative research designs. Thus, students' perspectives on bullying are not commonly heard in research (Patton, Hong, Patel, \& Kral, 2015) and less research has been conducted with a qualitative approach. By using a qualitative approach I hope to contribute with important nuances - or processes- of students' perspectives on bullying (Mishna, Saini, \& Solomon, 2009). Even though quantitative research can give important insights into some of the students' perspectives on bullying, "it does not give children an opportunity to discuss their own understanding of bullying experiences in their own voices", as argued by Bosacki, Marini, and Dane (2006, p. 232). 
But how do you study someone's perspectives? I view the students' perspectives as constructed through social interaction through which they construct a set of assumptions about the world. From these constructed perspectives they define, make sense of and approach the world (Blumer, 1969; Charon, 2009). Furthermore, this means that I do not claim to have found "the truth". Different aspects - such as the social context of the interviews, me as a researcher and different discourses about bullying-most likely influence the perspectives the students used and articulated. Nevertheless, these are the perspectives articulated and used. By way of this starting point I have also subscribed to a constructivist view on perspectives that acknowledges the researcher as a constructor of perspectives and my knowledge claims as provisional due to the angle I approach the world from; "researcher and research participants make assumptions about what is real, possess stocks of knowledge, occupy social statuses, and pursue purposes that influence their respective views and actions in the presence of each other" (Charmaz, 2006, p.15). We construct and interpret meaning and consequently act, and view the world, from these perspectives (Blumer, 1969; Mead, 1934). It would be naïve to think that the students' perspectives are just out there waiting to be discovered by me and not affected by me as a researcher. I have come from somewhere, with assumptions, knowledge's and experiences. This of course raises new questions about how I treat my earlier knowledge in conjunction with wanting to learn about the participants' perspectives.

Before I entered this research field I was trained to use different theoretical concepts and theories, but I have come to use mainly microand macro-sociological theories, since these were important perspectives throughout my interdisciplinary undergraduate programme. I have always been interested in social norms, social identities, group processes and gender. In this study I therefore have chosen to work with a theoretical framework that offers me theoretical and methodological tools that help me to stay reflexive (e.g., Alvesson \& Sköldberg, 2009) and focused on the participants' perspectives. I have tried to remain reflexive about what is going on in my data by paying attention to what the participants have been talking about, and this has been important during the whole research process. Thus, "staying grounded" in data (Thornberg, 2012). "Being reflexive" refers 
to paying attention to my role as a knowledge constructor and reflecting on the different steps taken during the research process towards the construction of my findings. For me, this means that my analysis, along with carefully listening to the participants during our social interactions to try to understand their perspectives (Blumer, 1969) by probing for their understandings, together form the knowledge construction. I have also tried to remember what we share as humans partaking in a social life of interactions, in which I too was once a child and of which I also have experience, as well as trying to remember that children might position me as an adult in a desirable position (Näsman, 1995).

My thesis does not cover all perspectives, angles or theories that could be used to approach and understand bullying, but contributes to the research by presenting possible conceptualisations of the participants' perspectives (e.g.,Thornberg, 2015b). More specifically, this thesis addresses the perspectives of students between the fourth and eighth grades, as previous research has addressed how bullying appears to decline with age (Craig et el., 2009; Flygare et al., 2011), mainly occurring when students are 10-15 years old (Flygare et al., 2011; Nansel et al., 2001).

\section{Overall Aim}

I moved into this research area with a foreshadowed problem (e.g. Malinowski, 1922), which means that I started somewhere and ended up partly somewhere else. I identified a research area that I wanted to understand from the students' perspectives. Overall I was interested in finding out how they viewed bullying and how they reacted on bullying. During the research process, and in accordance with its ongoing analysis, interviews with the participants guided me to articulate more specific research aims in the studies that followed. According to this, my final aims throughout my papers were constructed during the research process where the discussions of the participants informed what to focus on in the upcoming data collection. The interviews, and what was addressed in them, gave me direction for what they wanted to discuss, which gave me ideas for what my specific research aims would be. I started to conduct interviews on students' 
definitions on bullying and reactions to bullying. My first two studies addressed students' perspectives on bystander reactions. When conducting interviews for these two papers, the students were talking about the reasons to why bullying happens. I therefore added this theme to my interview protocol to explore students' perspectives on why bullying emerges as this appeared as important and became a suitable focus for my third paper. A similar process evoked when conducting interviews for my third paper, when the participants described how their bullying experiences and social organisation of friendships were gendered. These issues were especially discussed among the girls and they also spoke about indirect bullying. I decided to focus on these processes in my fourth paper. My aim has been to listen to, examine and conceptualise fourth and eighth grade students' perspectives on bullying and bystander reactions. Based on my analyses and interactions with students, this thesis came to focus interactions, processes and negotiations as important themes. My specific aims was:

\section{Paper I}

The aim was to investigate bystander actions in bullying situations as well as reasons behind these actions as Swedish students from fourth to seventh grade articulated them.

\section{Paper II}

The aim was to focus on how Swedish and US students articulate and discuss what factors influence their own and other students' decisions to defend or not defend victims when witnessing bullying.

\section{Paper III}

The aim with this study was to listen to how children themselves discuss, reason on and make sense of how and why bullying emerges to extend our knowledge of what social processes that are made important among the children.

\section{Paper IV}

The aim with the present study was to take an explorative approach towards junior-high school girls' subjective perspectives of bullying by carefully listen to how girls themselves discuss and reason on bullying. 


\section{Definitions, Perspectives and Research on Bullying}

In the following chapter I will give an introduction to how bullying has been defined, some of the ongoing debates regarding bullying as a concept and the different theoretical perspectives on bullying. At the end of this chapter I will focus more specifically on students' perspectives on bullying.

\section{Defining Bullying}

Bullying is usually described to include different expressions, or types, of bullying, defined as physical, verbal or indirect bullying (e.g., Borntrager et al., 2009; Cowie \& Jennifer, 2008; Rigby, 2008) and can be summarised as traditional bullying or cyber-bullying. Whereas traditional bullying has been associated with physical acts (e.g., hit, kicks), verbal acts (degrading comments) and indirect acts (exclusion, rumours), cyber-bullying tends to be associated with verbal or indirect acts involving mobile phones, text messages and Internet forums (Tokunaga, 2010). The most common definition of bullying used among researchers has been formulated by Olweus and includes the following:

A student is being bullied or victimized when he or she is exposed, repeatedly and over time, to negative actions on the part of one or more students and the student who is exposed to negative actions has difficulty defending him- or herself (Olweus, 1993, p. 4).

Olweus's definition, including repetition, the intentional act of the bully and the power imbalance, was established in the 1970s, but Heinemann introduced the concept of bullying prior to this definition in a newspaper debate. Heinemann viewed bullying as a form of collective aggressiveness that was discharged when an individual or a group provoked or attracted this aggressiveness and the group then turned against the individual or the group (Heinemann, 1972). 
Heinemann described how different processes in groups, such as isolation, no communication among groups and a view of one's own group as innocent, could evolve into bullying. Of importance in Heinemann's definition is the group and the group's loaded aggression that culminates against an individual or a group when the group feels threatened (Heinemann, 1972; Larsson, 2008). Heinemann also linked these group processes with other social issues in society such as racism and genocide (Larsson, 2008). Of less importance were the actions of the individuals; this was instead of importance in Olweus's definition: the actions and characteristics of the individual bully and the victim. The victim is described as either passive or provocative and the bully as physically stronger, impulsive and prone to using violence (Olweus, 1993). Even though researchers commonly have used Olweus's definition, it has undergone debate and critique. Up until today there exists no common definition of bullying that all scholars agree upon, but rather different perspectives that take different approaches towards this phenomenon. We see the beginning of these two perspectives already inherent in the positions taken by Heinemann and Olweus. However, Olweus and Heinemann both addressed bullying as aggressive behaviour, where the power imbalance between the target and perpetrator(s) was essential, to which Olweus added intention and repetition. Similar criteria have been used for defining concepts that are sometimes interlinked with bullying, such as violence and harassment (Smith, 2014).

\section{Repetition, Intention and Power Imbalance}

One of the debated aspects of Olweus's definition of bullying concerns the criteria of repetition. The issue of repetition has received increased attention as cyber-bullying, considered to be the new arena of bullying, has evoked discussions of the similarities and differences between traditional and cyber-bullying (e.g., Beckman, 2013). In cyber-bullying the issue of repetition is questioned, since cyber acts do not necessarily involve repetition. However, one cyber act might reach a larger crowd of bystanders once performed and be just as hurtful (Kowalski, Limber, \& Agatson, 2012). From the cyber target's perspective, repetition could be viewed in a different way, since the target might be exposed to the same picture or comment several times by revisiting a 
social network or confronting a posted picture numerous times. On the issue of cyber-bullying and repetition as a criterion for defining bullying, Olweus (2013) calls for further research. However, Smith Salmivalli, \& Cowie (2012) concluded that Olweus's three criteria might be used for defining cyber-bullying even though repetition might work in a different way for cyber-bullying (Smith, 2014). Others ask how many repetitions of an action are needed for it to count as bullying (Walton, 2005) and whether actions happening only once can be viewed as bullying because they could be just as hurtful (Smith, 2014). Some have suggested that instead of focusing on repetition, the frequency and intensity of victims' experiences should be the criteria used (Volk, Dane, \& Marini, 2014).

A second debate concerning Olweus's definition addresses the presence of the intentional act in bullying episodes. The inclusion of the intentional might dismiss the importance of the social processes of inclusion and exclusion as part of the construction of peer friendship groups, where exclusion is found to be part of these two parallel processes rather than being based on an intentional act (Beckman, 2013; Bliding, 2004; Rigby, 2008). The question of how to determine someone's intentions has also been debated and raises questions such as whether one can always assume that an intention to cause harm is relevant, or whether other forms of intention might be at stake, e.g. aiming for higher status (May Schott, 2014; Volk, Dane, \& Marini, 2014). Rigby (2008) tries to offer a solution by suggesting a division between intentional (malign) and unintentional (non-malign) acts. In that sense Rigby suggests that bullying sometimes includes an intention and sometimes not. Another attempt to solve the critical aspect of the intentional act, but with smaller adjustments, to maintain the Olweus definition were articulated by Volk et al. (2014): "Bullying is goal-directed behaviour that harms another individual within the context of a power imbalance" (p. 328). In their definition the intentional act was defined as different kinds of goal-directed behaviours, more or less known to the person using them, but which could include all sort of things such as social dominance, striving for higher status or the social benefits of bullying. Bullying is sometimes defined as a type of violence; a similar discussion has occurred around the concept of violence where it has been suggested that the effect on the target is independent of the intention of the perpetrator(s) (Iadicola 
\& Shupe, 2012). However, taking the targets' experiences as a criterion instead of repetition and intention could be difficult as few want to subscribe to a victim position (Iadicola \& Shupe, 2012; Smith, 2014). Furthermore, the social context might affect how actions are viewed and how targets of these actions respond to these actions. Making distinctions as to whether different actions are bullying or not could therefore be difficult, as these actions are part of their social worlds and can construct their social life in multiple ways (Iadicola \& Shupe, 2012; Osbeck, Holm, \& Wernersson, 2003, Osbeck, 2006) and can be viewed as routine phenomena, which have been referred to as habituation to bullying (Thornberg, et al., 2012).

Intention is further discussed when considering the third criteria in power imbalance. In Olweus's definition, a power imbalance is said to exist between the target and the perpetrator(s) where the target finds it difficult to defend himself or herself (Olweus, 1993). Power imbalance is viewed as crucial in defining bullying (Volk et al., 2014), but has seldom been specified (Horton, 2011). It has been suggested that certain mechanisms evoke a power imbalance where the possible mechanisms behind the power imbalance could be social dominance, striving for higher status or the social benefits of bullying; behaviours that are goal-directed and have the effect of constructing a power imbalance, but which are not always known to the person responsible for these acts (Volk, Dane, \& Marini, 2014). Olweus's definition may position victims as powerless and without strength, which could make it problematic to define someone as a victim and the incidents as bullying if the target responds by hitting the bully back or saying something verbally. In this sense, some incidents may not be viewed as bullying and some targets may not be viewed as helpable (Søndergaard, 2012, 2015). Focusing on mechanisms such as Volk et al. (2014) suggest might better identify how this power imbalance refers to social patterns rather than the actual physical or verbal reaction of the victim. However, Horton (2011) states: "Bullying may say less about the aggressive tendencies of those involved than it does about the relations of power within which it occurs" (p. 54) and reveals how power is used rather then held. This view on power relations opens up the possibility of more fluid positions on how power is constituted differently in different situations. Such a view on power does not ascribe power to certain individuals, nor does it regard 
striving for a powerful position as an individual striving, but rather regards it as an example of power relations among people (Walton, 2005). However, this could articulate how more power could be ascribed to different positions in a group in order to define others and act against others as being less valuable; where what is fundamental for violence such as bullying to occur is the process by which some people are defined and acted against as less valuable than ourselves, and therefore this is a question of inequality in a broader sense (Iadicola \& Shupe, 2013). In this way, power imbalance includes people's opportunities to resist or construct a more positive social identity in a specific context - a social identity that is not based on being perceived as odd, deviant or not fitting in the group (Iadicola \& Shupe, 2013; Hunter, Boyle, \& Warden, 2007), or as meek (Horton, Kvist-Lindholm, \& Nguyen, 2015). This does not exclude a power imbalance that may sometimes refer to difficulties in defending oneself physically or verbally (or in performing actions where one defends oneself physically or verbally), but it includes people believing that they are different or odd themselves or having difficulties in changing the interpretation of themselves as such.

In Sweden, the Swedish National Agency for Education [Skolverket] has abandoned bullying as a concept and replaced it with the concept of degrading treatment [kränkande behandling] (Flygare et al., 2011). Bullying seemed unclear and was perceived as being both too narrow and too broad. Degrading treatment thus appears more appropriate as it includes isolated actions and actions that are performed due to social relations formations among students rather than with a specific intention to harm (e.g., Frånberg \& Wrethander, 2011). Degrading treatment is defined as "an action that, without being discriminatory, aims at degrading someone's dignity" (SFS: 2010: 800 , p. 23). Bullying, from the perspective of the Swedish National Agency for Education, should then be understood as repeated degrading treatment actions. However, harassment (e.g., sexual harassment, racial harassment) is not included in the concept of degrading treatment in the Swedish school legislation. Harassment is

\footnotetext{
${ }^{3}$ My translation. In Swedish it says: “Kränkande behandling är ett uppträdande som, utan att vara diskriminering enligt diskrimineringslagen, kränker barns eller elevers värdighet.
} 
instead interlinked with discrimination acts related to, for instance, gender or ethnicity (SFS: 2010:800), which might make degrading treatment more narrow compared to the concept of bullying, when excluding what has been referred to as the normative bullying embedded in and supporting racism, homophobia, disability and gender stereotypes (e.g., Cowie \& Jennifer, 2008; Davies, 2011; Duncan, 1999; Ellwood \& Davies, 2010; Rigby, 2008).

There are several different positions made regarding what concepts to use and what to include and exclude within these concepts. In certain circumstances bullying seems to be broader and include more aspects than degrading treatment, and bullying and harassment do seem to be interlinked on occasion (Cascardi, Brown, Iannarone, \& Cardona, 2014), which may point towards using the same concept or at least being clear about "what is what". Conversely, Brown, ChesneyLind, and Stein (2007) state that by including, for example, sexual harassment within bullying, this might "psychopathologize gender violence while simultaneously stripping girl victims of powerful legal rights and remedies" (p. 1251), which instead would favour the Swedish school legislation that separates bullying and (sexual) harassment, even though this would not resolve the possible intersections of these two phenomena. This risk of psychopathologising gender violence or issues concerning racism or homophobia seems overwhelming when bullying is individuated, because it excludes the role of social oppression (Walton, 2005).

It has to be recognised, with reference to the literature, that a specific act in a particular social context could be identified as sexual harassment and bullying at the same time, because these concepts are not mutually exclusive and in some parts they overlap (Brinkman \& Manning, 2015; Meyer, 2008; Smith, 2014). When comparing the concept of bullying with interlinked concepts such as violence, it is obvious that these concepts share some of the definitional problems. There have been problems with the definition of violence being too broad and the gendered aspects sometimes disappearing, which has had consequences for female victims of gendered partner violence where the patterned violence has not been addressed when every incident is viewed separately and the pattern regularities of previous experiences are dismissed (Durfee, 2012; Enander, 2011). This is similar to the critique of the power imbalance in the bullying 
discourse, where the positioning of victims might hide previous actions of importance for understanding an incident (Søndergaard, 2012). However, in the research on violence one issue appears to be that one incident are viewed as serious and the pattern regularities of gendered violence are forgotten. In comparison with the separation of degrading treatment into one or repeated actions, this could be a strength, but the separation of discrimination acts, some of which may address normative orders that are incorporated in bullying, can give us new headaches. This is especially interesting to remember as these issues can be overlapping (Meyer, 2008; Smith, 2014).

Even though degrading treatment is now the concept used in the school legislation, bullying is still the more common concept in the international research field and hitherto the most common concept used in school practice. I have therefore mostly used bullying as a concept in this thesis and in my interactions with the students, as well as in my findings. The participants have not been provided with any definition of bullying; rather, I asked for their definitions and explored the concept from their perspectives. Hence, I have not used any particular definition of bullying but explored bullying as a sensitising concept (Blumer, 1969, p. 148). A sensitizing concept gives the researcher guidance and a starting point in exploring their topic but not any fixed directions of what to see (Blumer, 1969; Charmaz, 2014).

\section{Perspectives on Bullying}

The debate on the definition of bullying could be referred to as involving different perspectives on bullying. Heinemann, as described above, focused on the group, whereas Olweus focused on the individual bully and victim. Olweus (2013) finds it crucial to use the traditional definition of bullying, as well as the importance of working with clear concepts, but has never denied the importance of the group. When research on bullying acknowledged that it usually involves several participants and not just the bully and the victim, the group and its influence received increased attention. Several participants with different roles tend to be involved in bullying (Salmivalli, Lagerspetz, Bjorkqvist, Osterman, \& Kaukiainen, 1996, Salmivalli, 1999). Various emphases of the individual and the group could be understood as 
developed within different perspectives on bullying, referred to as the individual psychological perspective and social psychology perspectives (Thornberg, 2013b). Social psychology perspectives here include both micro-social and macro-social perspectives (i.e., theories on how social influences, processes, structures and discourses on various levels contribute to explain or understand everyday reasoning, meaning-making, behaviour, and interaction patterns), even though some may make further distinctions between social psychology perspectives and sociological perspectives on bullying (May Schott, 2014). Note that Heinemann represented the social psychology perspective and the actions of the group, but a review of the research on bullying shows that most of the studies in this area have been conducted from an individual psychology perspective and influenced by the common definition of Olweus. Compared to the individual psychological perspective, the social psychology perspective has conceptualised bullying as a social process and includes studies on group processes, interactional patterns and social norms (e.g., Bliding, 2004; Dixon, Smith, \& Jenks, 2004; Duffy \& Nesdale, 2009; Lahelma, 2004; Salmivalli \& Voeten, 2004; Thornberg, 2015b; Thornberg, Halldin, Bolmsjö, \& Petersson, 2013a), which in turn emphasises that bullying often includes bystanders (Craig \& Pepler, 1997; Craig et al., 2000). Salmivalli (2010) stressed the importance of placing bullying in a group context, since this will give insights into bystander actions, the motivation to bully and what happens during bullying processes. Compared to the individual psychological perspective, placing bullying in a group context suggest that the actions of the whole group, not just the bully and the victim, need to be targeted to counteract bullying (Salmivalli et al., 1996; Salmivalli, 1999). Furthermore, the different participant roles inherent in the group perspective of bullying view these roles as ongoing and not stable.

Moreover, within the social psychological perspective, group processes that address social status, group norms and peer actions are crucial in order to understand bullying (Adler \& Adler, 1998; Burns, Maycock, Cross, \& Brown, 2008a; Cadigan, 2002; Caravita, Blasio, \& Salmivalli, 2009; Dixon et al., 2004; Eder, Evans, \& Parker, 1995; Gini, 2005; Hamarus \& Kaikkonen, 2008; Kinney, 1993; Kless, 1992; Merton, 1997; Pellegrini, 2002; Phillips, 2003). Group processes have been associated with social norms on whether or not to tell adults 
about bullying (Rigby, 2008) and with peer pressure that evokes fear of intervening and supporting a target (Bosacki et al., 2006; Cowie \& Jennifer, 2008; Rigby, 2008; Salmivalli, 2010). It has also been found that in the social organising of peer friendships, inclusion and exclusion practices might occur (Adler \& Adler, 1998; Bliding, 2004), and bystander responses appear to be associated with the relationships with the people involved (Brinkman \& Manning, 2015). A common finding is the social construction of the target as odd and responsible for the bullying (Bibou-Nakou, Tsiantis, Assimopoulos, Chatzilambou, \& Giannakopoulou, 2012; Frisén et al., 2008; Hamarus \& Kaikkonen, 2008; Lahelma, 2004; Teräsahjo \& Salmivalli, 2003; Thornberg, 2010, 2015a; Thornberg \& Knutsen, 2011; Varjas, et al., 2008) being a part of labelling and stigma processes in groups that evoke bullying (Dixon et al., 2004; Thornberg, 2015a; Thornberg et al., 2013a).

What has been added from the sociological approaches to bullying is a focus on institutional factors, power relations, gender and other normative stereotypes as part of bullying, which indicates issues such as sexual bullying, normative bullying and homophobic bullying (e.g., Duncan, 1999; Osbeck et al., 2003; Rivers \& Duncan, 2013). Normative power structures based on gender, (hetero)sexuality, ethnicity and social class are suggested (Ringrose, 2008; Ringrose \& Renold, 2009), as well as how different positions within these structures address how the power relations are formed and involved in bullying. The issue of power is mentioned in the Olweus definition, but power relations as such have not been explored to a large extent (Horton, 2011; Walton, 2005) and especially not in respect of how schooling in itself contributes to bullying (Horton, 2011; Walton, 2005, 2011; Yoneyama \& Naito, 2003). The strong emphasis on the individual is said to neglect the importance of institutional factors that might support and reinforce aggression (Walton, 2005, 2011). Bullying might potentially being evoked as a reaction to institutional factors in the school (Horton, 2011). Institutional aspects and the importance of context are aspects that were incorporated later when the ecological approach towards bullying was introduced. In the ecological framework perspective, bullying is approached as emerging from individual, physical milieu, social, institutional, local community, cultural and societal factors (Swearer \& Doll, 2001). The ecological framework attempts to combine multiple components to understand 
bullying, including individual and social psychological factors (Espelage \& Swearer, 2011). It is important to note that these aspects included in the ecological approach were already a part of the schooling concept developed in Japan (Yoneyama \& Naito, 2003), but for some reason seem to have been neglected in the Western discourse on bullying.

\section{Students' Perspectives on Bullying}

Following on from the social perspectives on bullying is the attention on students' own perspectives on bullying explored using qualitative research approaches. Today there is a small but growing body of qualitative research conducted with the students' perspectives at the forefront of the exploration (Patton et al., 2015). Teräsahjo and Salmivalli (2003) have stressed the need to conduct research using qualitative research methods and focus on how the meaning and understanding of bullying are constructed among students. One of the starting points in this thesis is that a focus on students' perspectives in the landscape of different perspectives and discussions on these issues, mostly formulated by adults, can reveal important aspects of how students themselves understand and experience bullying (Bosacki et al, 2006; Mishna et al., 2009). The research conducted hitherto on students' perspectives has uncovered a complex set of factors in their understanding of bullying. The selection of areas below to some extent shares the attention on students' perspectives, but more importantly they became key themes among the students during my data collection. The following areas will be explored below: (a) students as bystanders, (b) explanations of bullying and (c) gender identity and bullying.

\section{Students' Perspectives on Being Bystanders}

In a few observational studies it has been revealed that bullying incidents mostly involve witnesses, referred to as bystanders. Furthermore, video-recorded observational studies have demonstrated that students who end up in the role of bystander seldom intervene to help the target of bullying (Craig \& Pepler, 1997; Craig et al., 2000; O'Connell, Pepler, \& Craig, 1999). At the same time, a study on 
bystander reactions reveals that bystanders who intervene are usually successful in their attempts to reduce bullying (Hawkins, Pepler, \& Craig, 2001). Bullying and bystander reactions are commonly viewed as a group process in which different participant roles are identified among bystanders (Salmivalli et al., 1996). In two studies Salmivalli et al. (1996) and Salmivalli (1999) reveal how students adopt a range of participants' roles. These participants' roles are conceptualised to include at least four possible participant roles: (a) assistant (join the bully), (b) reinforcer (support the bully), (c) defender (defend the victim), and (d) outsider (leave the situation or act passively) (Salmivalli, 1999). In a broader sense the different participant roles are defined as intervening, non-intervening or co-bullying. In a couple of studies students' own perspectives on bystander behaviours have been explored (Bellmore, Ma, You, \& Huhges, 2012; Brinkman \& Manning, 2015; Patterson, Allan \& Cross, 2015; Rigby \& Johnson, 2005; Thornberg et al., 2012). From the students' perspectives it appears as if bullying evokes many emotional responses in which students in general tend to express the view that they want to intervene and defend the target because the bullying is perceived as something wrong and evokes feelings of sympathy towards the victim and angriness towards the bully (Bellmore et al., 2012; Brinkman \& Manning, 2015; Rigby \& Johnson, 2005; Thornberg et al., 2012). Contrarily, in Patterson's et al. (2015) investigation of bystander responses to cyber-bullying, using a vignette to discuss adolescents' bystander responses, students said that most bystanders would ignore the situation.

Several factors are of importance when students discuss how they come to assume different bystander roles. These include both individual and situational factors, but group processes among the students appears to be a crucial consideration. Brinkman and Manning (2015) use the metaphor of barriers to explain factors that affect students' bystander reactions, as a consequence of which they do not follow their moral voice to intervene and help the victim. Different groups construct different social norms and appropriate behaviours for its members (Becker, 1963; Goffman, 1963). For example, groups might have a formal norm of perceiving bullying as something wrong, but informal norms might make bullying accepted and difficult to act against (Fors, 1995). In terms of bystander responses, this is prevalent 
when students regard social hierarchies as an important barrier affecting their bystander responses. Social hierarchies position students in social status positions, and certain agency opportunities or constraints are attributed to these positions. For example, students state that they have difficulty intervening if they have lower status than the bully, which in turn has been found to evoke self-protecting and passive bystander responses rather than intervening to help the victim (Bellmore et al., 2012; Rigby \& Johnson, 2005; Thornberg, 2010; Thornberg et al., 2012). Thornberg et al. (2012) and Thornberg (2010) find that having high status among their peers makes students more able to defend a victim. Students seldom intervene by telling the teacher about bullying because doing so is viewed not only as uncool (Rigby, 2008), but also as possibly dangerous, as teachers are sometimes viewed as making things worse (Patterson et al., 2015). It is reasonable to assume that social hierarchical processes are involved in this decision as well, where it is more important to evoke selfprotecting strategies because of the fear of being defined as uncool or called a snitch. The interplay between social hierarchies and group process among students might illustrate power relations among them (Horton, 2011), which may be of interest to explore further.

Another key barrier affecting the students' bystander responses, identified by the students themselves, is their lack of knowledge of bullying and bystander responses (Rigby \& Johnson, 2005; Thornberg et al., 2012). This uncertainty has been found to be associated with interpreting the actual situation in terms of whether it is harmful, in terms of the type of bullying and in terms of what is known about the people involved (Bellmore et al., 2012; Thornberg, 2010; Thornberg et al., 2012) or associated with seeking clues for whether it is harmful, e.g. how the victim reacts (Patterson et al., 2015).

The concept of self-efficacy (Bandura, 1997), referring to the beliefs one has in the ability to handle a situation in a way that will resolve it, are associated with bystander responses (Thornberg et al., 2012), and appears to be involved when students describe barriers to their bystander responses. This was apparent when Brinkmann and Manning (2015) found that students perceived it difficult to manifest the bystander responses that they wanted, such as standing up to the bully, because they did not feel confident enough. Similar process may have been involved when students discussed difficulties in interpreting 
the situation and not knowing how to react or what to do and the issue of social hierarchies. However, lack of knowledge may also be an example of institutional factors, which says something about how schools discuss with their students what bullying is and how to respond to it. Adults and students sometimes have different views of what counts as bullying (Cheng et al., 2011; Compton et al., 2014), but there may also be a lack of attention in school to social issues affecting students' knowledge about bullying. It is also possible that some actions are viewed as routine phenomena (Thornberg et al., 2012) and therefore not as bullying.

The quality of friendship has been described as making it easier for students to intervene as bystanders. Being friends is viewed as an essential prerequisite to helping' (Bellmore et al., 2012; Brinkman \& Manning, 2015; Rigby \& Johnson, 2005; Thornberg, 2010; Thornberg et al., 2012). However, Thornberg et al. (2012) recognise that friendships can function as a barrier if friends are acting as bullies. In these situations students have come to articulate a loyalty towards their friends, which has actually made them consider co-bullying or avoiding defending the victim. This attributes a significant role to friendship in the students' social worlds.

While friendship and emotional reactions to bullying may make students see themselves as responsible for doing something about bullying, students further articulate that they themselves are not always responsible for this, which affects their bystander reactions (Bellmore et al., 2012; Thornberg, 2010; Thornberg et al., 2012). Students regard others as being responsible, in particular teachers and the victim, and see themselves as less responsible (Bellmore et al., 2012; Thornberg, 2010). A situation where bullying is interpreted as being caused by the victim, and where, because the victim is constructed as deviant, odd and responsible, students feel less motivated to defend the victim and instead either do not intervene or else co-bully, has been recognised as a moral disengagement process (e.g., Bandura, 1999, 2002). In such processes the victim is dehumanised. When regarding the victim as responsible, students view the bullying as caused by the victim and attribute blame to the victim (Thornberg et al., 2012, Thornberg, 2015a), which makes them less likely to take on the role of defender. These processes of transferring responsibility have been understood through the concept of diffusion of responsibility. Diffusion of 
responsibility involves diluting one's personal responsibility due to the presence or involvement of other people (e.g., Bandura 1999, 2002; Latené \& Darley, 1970) and may be linked with not knowing what to do (e.g., Bandura, 1997), as well as a transfer of responsibility to teachers, perceived friends of the victims and higher-status students (Thornberg, 2010).

It appears as if the line of arguments and considerations students encounter when being bystanders to bullying will serve as guidance as to whether they intervene or not, or co-bully. This body of qualitative research on students' perspectives on bystander actions and reactions is still very limited and in need of further empirical and theoretical exploration. Of the studies mentioned, only Thornberg et al. (2012) have taken an explorative approach towards students' understanding of bystander reactions to bullying; this study was conducted with US students. Bellmore et al. (2012) as well as Rigby and Johnson (2005) have used questionnaires to investigate bystander responses to bullying, but these have not been followed up to gather further data. Brinkman and Manning (2015) have taken a similar approach when using a hypothetical scenario and have asked students about their responses to a particular type of bullying - gender-based bullying; their study included victim responses as well. Patterson et al. (2015) have used a vignette to investigate bystander responses to cyberbullying, and Thornberg (2010) has used both observations and interviews, but has not studied solely bullying situations but bystander situations more generally in which students are in distress.

A few things appear to be of interest for further exploration. Firstly, a qualitative study with a focus on students' perspectives on bystander reactions in a Swedish context; this would add something that has not yet been explored. Secondly, a further exploration of how different bystander reactions may vary; it is rather unclear what distinctions are being made when referring to different factors affecting students' bystander responses. For example, when do the different types of defending reactions occur? Rigby and Johnson (2005), for example, make a distinction between ignoring and assisting the bully as two different types of non-helping behaviours. Whereas reasons given for ignoring the bully are "it is none of my business", fear of the consequences, the victim is (or may be) responsible, action may be counterproductive or futile and enjoyment of the spectacle, 
reasons given for assisting the bully are that it is the safer option, admiration for the aggressors and feelings of hostility. Thirdly, I have suggested some theoretical ways of understanding bystander responses, but what is needed is further elaboration on which processes are of importance among students when being bystanders.

\section{Students' Explanations of Bullying}

When students have been asked to give their explanations as to why bullying occurs, the issue of peers and social hierarchies are again identified as crucial. However, in the students' statements, bullying is to some extent associated with status and coolness and therefore is sometimes justified (Thornberg, 2010). It appears as if ongoing group processes and social hierarchies make bullying the norm, and when intended students want to fit in among their peers, they come to engage in bullying (Burns et al., 2008a; Erling \& Hwang, 2004). As such, bullying can be pinpointed as a group process where friendship and social hierarchies create bullying (e.g., Bliding, 2004; Cadigan, 2002; Eder et al., 1995). The two most common explanations for bullying, however, do not explain bullying as a matter of peer pressure or social hierarchies but rather define bullying as occurring (a) because of the victim or (b) the bully (for a review, see Thornberg, 2011b). When attributing the cause of bullying to the victim, students describe the victim as odd, different or deviant, and view this as an explanation for why bullying occurs (e.g., Bibou-Nakou et al., 2012; Cheng et al., 2011; Frisén et al., 2008; Teräsahjo \& Salmivalli, 2003; Thornberg, 2010, 2015a; Varjas et al., 2008). This is called the "odd student repertoire" a concept developed by Terasärjho \& Salmivalli (2003), to describe how students tend to construct the victim as being deviant and responsible for the bullying. As previously mentioned as part of the students' way of describing the victims' responsibility as being linked with their own bystander responses, when victims are made responsible, bullying can be justified (Eriksson, Barajas, \& Lindgren, 2009; Lahelma, 2004; Osbeck et al., 2003; Salmivalli, 2010; Teräsahjo \& Salmivalli, 2003; Thornberg, 2010, 2015a; Varjas et al., 2008).

These explanations of bullying strengthen how bullying might be portrayed as a social process that applies to the use of labelling and stigma theory (e.g., Thornberg, 2011b) and how the construction of 
deviance (e.g., Becker, 1963; Goffman, 1963) is part of the students' repertoire of bullying. When focusing on the "odd student repertoire", students' inclination to blame the victim may be an example of an interactional pattern of inhumanity and power abuse (Thornberg, 2011b). Furthermore, students' explanations may be understood as a collective action where the labelling of the victim as odd and responsible justifies the social act of bullying, in which the bullies at the same time are constructed as the "normal us" (Thornberg, 2015a). In this way the victim, described as the "odd student", is viewed as challenging a social order that needs to be re-established through bullying (Teräsahjo \& Salmivalli, 2003; Thornberg, 2010). Social order among students as an explanation for bullying may therefore constitute normative moral orders (Ellwood \& Davies, 2010), which refers to processes by which certain norms are constructed among students.

The issue of social order as a process may be of relevance when students explain bullying as occurring because of the bully. The bully is described as someone striving for social status by bullying others (e.g., Frisén et al., 2008; Phillips, 2003; Swart \& Bredekamp, 2009; Thornberg, 2010; Thornberg \& Knutsen, 2011a; Varjas et al., 2008). However, students hold an individualistic view of the bully, describing the actions of the bully as being caused by social problems at home, poor self-esteem or being an insecure or distressed person (e.g., Frisén et al., 2008; Thornberg, 2010; Thornberg \& Knutsen, 2011a; Varjas et al., 2008), or simply describe the bully as just a bad or mean person (e.g., Thornberg, 2010). Morover, while bullies can function as protectors of moral orders (Davies, 2011) and therefore be associated with social value, the victims are positioned as always undesirable and as being viewed as representing deviance.

Furthermore, there are students who reason that bullying can take place because it is fun and because students are bored (e.g., Hamarus \& Kaikkonen, 2008; Owens, Shute, \& Slee, 2000), or that bullying sometimes may be something that just happens without any specific reason or intent, - an student explanation that can be understood as "thoughtless bullying" (e.g., Thornberg, 2010).

From these qualitative studies on students' explanations for why bullying occurs, we have gained crucial insights into some of the factors that students regard as important explanations for why bullying 
emerges. Even so, we still have limited insight into how students articulate how, when and why bullying processes emerge. For example, in what circumstances is something considered to be deviant and in what situations, and what nuances of deviance constructions do they articulate?

\section{Gender Identity and Bullying}

As mentioned earlier, bullying includes several different expressions: physical (hits, kicks), verbal (degrading comments, nicknames) and indirect (social exclusion or rumours) (e.g., Borntrager et al, 2009; Cowie \& Jennifer, 2008; Olweus, 1993; Rigby, 2008). When investigating the students' own perspectives on bullying, students tend to associate indirect bullying with girls and physical bullying with boys (Giles \& Heyman, 2005; Gini \& Pozzoli, 2009). Girls also have been found to view indirect aggression as more harmful compared to boys (Murray-Close, Crick, \& Galotti, 2006). Indirect bullying is sometimes labelled as relational or social bullying, but tends to cover the same aspects (Archer \& Coyne, 2005). Indirect bullying more specifically involves acts that attempt to manipulate social relationships through different actions such as rumours, gossip or social exclusion. Indirect bullying is associated with children's social organising, in which manipulation and exclusion practices recurrently occur (Goodwin, 2002; Svahn \& Evaldsson, 2011), and manipulation of friendship repeatedly takes place (Adler \& Adler, 1995; Besag, 2006; Eder, 1985). Furthermore, Adler and Adler (1995) and Eder (1985) have addressed how inclusion and exclusion might occur due to status hierarchies among children. These dynamics of organising friendship have actually been found among both genders (Adler \& Adler, 1995; Goodwin, 2002), but Goodwin (2002), for example, chooses to focus on the girls' disputes.

In the research on different types of bullying, boys have been found to be more likely to engage in bullying as bullies and bullyvictims (Flygare et al., 2011; Wang, Iannotti, \& Nansel, 2009), and especially to engage in and experience physical bullying, whereas girls are considered to be involved in, and more often experience, indirect bullying (Flygare et al, 2011; Vaillancourt et al., 2010; Wang et al., 2009). Hence, gender differences have been questioned because of 
mixed findings in the literature (Olweus, 2009), where in some cases girls have been found to use physical bullying (Duncan, 1999; Philips, 2003), while others have found no gender differences in traditional bullying but emphasise that girls are more likely to be cyber victims (Beckman et al., 2013). An evaluation of anti-bullying methods used in Swedish schools from a range of perspectives clearly indicates that gender differences are apparent both in how girls and boys are bullied and bully others, and how anti-bullying factors may work differently based on gender (Flygare et al., 2011).

A number of studies incorporate theoretical orientations of gender stereotypes or norms that are said to play a role in bullying (Rivers \& Duncan, 2013; Duncan, 1999), some of which have incorporated feminist post-structural perspectives to examine bullying among girls (Currie, Kelly, \& Pomerantz, 2007; Ringrose, 2008; Ringrose \& Renold, 2009). Feminist post-structural perspectives address how normative (hetero)sexual and gendered discourses of femininity construct subjectivities that affect female bullying acts and identities (Currie et al., 2007; Ringrose, 2008; Ringrose \& Renold, 2009). These theoretical perspectives theorise female bullying in the context of sexualised and gendered practices (Jennifer, 2013); as such, it is not neglected as an individual girl issue but as embedded in these structural practices. Studies with this theoretical orientation focus on how the appearance of girls is crucial (Besag, 2006; Owens et al., 2000), as different heterosexual positionings based on girls' appearance function as a factor in defining their popularity and attractiveness (Duncan, 2004; Duncan \& Owens, 2011) and are used among girls to position each other (Renold, 2005). Furthermore, Ringrose (2008) reveals how girls' friendship groups and conflicts are characterised by "dynamics of (hetero)sexualized, classed, racialized and culture-bound" discourses (p. 519). These issues of normative power structures have, according to Ringrose (2008), been overlooked in the educational discourse on bullying. With this starting point, normative power structures based on gender norms construct girls' friendships and furthermore their bullying practices (Ringrose, 2008).

A few studies have examined girls' perspectives on indirect bullying. Owens et al. (2000) have contributed an interview study based on both individual and focus group interviews with girls. Their findings articulate both what kind of bullying behaviours the girls 
engaged in as well as their explanations for enacting these kinds of behaviours. Owens et al. (2000) reveal that the girls themselves said that they used indirect forms of bullying and explained their choice of doing so in terms of friendship and membership processes, selfprotection, jealousy or boredom, or as an attempt for acceptance. Besag (2006) later replicated the findings of Owens et al. (2000). Duncan (2004) has adopted the same vignette and find that girls' relationships are constructed around popularity and sexuality, where close friendships are crucial and gossiping about others can increase popularity. Popularity itself is an indicator of who is or isn't popular with the boys. Duncan (1999) has also studied sexual bullying from the perspective of both boys and girls and found that gendered identities are at play both in same-sex and intersexual relationships. Duncan's findings reveal complex interplays of gendered identities and the possibility of hegemonic masculinities and femininities. In a recent study (Jamal, Bonell, Harden, Lorenc, 2015), a social ecology approach has been used to explore girls' perspectives on the context of school bullying and gender. This study revealed that traditional gender and sexual discourses structured the girls' identities and positions towards bullying. However, this study did not merely focus on bullying.

Gender differences have been investigated and contested in previous research, but research has rarely examined girls' perspectives with an explorative approach. Overall, regardless of whether indirect bullying appears to be more common among girls in the few studies that exist, students themselves seem to distinguish between different bullying acts in terms of gender. In the studies mentioned above, qualitative studies have further revealed these patterns through observation studies. In other studies it has been assumed that girls engage more in indirect bullying, and these studies have conducted research from this point of view, while others have analysed this within a feminist theoretical framework. Social norms and identities seem to be constructed and a part of bullying, which is revealed in some of the studies above. By investigating girls' subjective perspectives, by exploring and carefully listening to their perspectives, this might add important insights into the processes that girls themselves associate with bullying. 


\section{Concluding Remarks}

From the literature review on bullying and students' perspectives on bullying, we can conclude that bullying can be viewed as a complex phenomenon understood as emerging from different factors and which needs to be addressed from several perspectives (e.g., Cowie \& Jennifer, 2008; Espelage \& Swearer, 2011; Granström, 2007). Bullying as a concept, even if it has been abandoned by the Swedish National Agency for Education, is a widely acknowledged concept, particularly in an international research context. I have therefore used this concept in my interactions and interviews with the students and have had them define actions in terms of whether or not they are bullying. I did not provide the students with a definition of bullying; rather, I explored the students' perspectives on this concept. This means that the eventual distinctions between different sorts of actions (e.g., bullying, teasing, degrading treatment) are built on the participants' perspectives. I have been interested in exploring how they define their social worlds as a place where bullying is said to take place. This section ends with an acknowledgment that most of the existing perspectives on bullying are not students' perspectives; our definitions of bullying have to a large extant been formulated by adults, and students' perspectives may not be the same as those of adults, as Frånberg and Wrethander (2011) remind us. As previous research has revealed, students may define these issues differently (Cheng et al., 2011; Frisén et al., 2008; Purcell, 2012). The literature reviewed on students' perspectives clearly indicates the need for more research in this area-research that takes the opportunity to address students' perspectives on bystander behaviours, bullying causes and articulated processes of importance for understanding bullying from students' perspectives. 


\section{Philosophical and Theoretical Framework}

In this chapter I address my philosophical and theoretical framework, the interlinked positions that together stand as a theory/methods package in my thesis (e.g., Charmaz, 2014; Clarke, 2005; Leigh-Star \& Griesemer, 1989). These are: (a) pragmatism, (b) a constructivist interpretative paradigm, (c) symbolic interactionism and (d) sociology of childhood.

\section{Pragmatism}

I have aimed to study students' perspectives on bullying. In taking this as my starting point, I have needed to reason on how I came to conceptualise their perspectives the way I have. Since I do not view researchers as unbiased, I have had to find an approach that acknowledges the acts of the researcher while at the same time still attempting to give insights into the participants' perspectives. I have found this in the philosophical heritage of pragmatism. Pragmatism is an American philosophical tradition that is usually described as having evolved among philosophers and sociologists at the University of Chicago in the beginning of the twentieth century and which initially included scholars such as Peirce, Dewey, Mead and James (Charmaz, 2014; Thayer, 1982). My use of pragmatism will focus on some of the concepts and ideas developed by some of these men, but I want to note that the heritage of pragmatism is far more complex and did not emerge only among these men in academia. Pragmatism emerged in complex ways and involved a large network of organisations, activists and others, and also women such as Jane Addams (e.g., Deegan, 1986).

One of the basic ideas in pragmatism is a focus on how people handle problems they encounter, the perspectives from which people act against these problems and how the consequences of acting from such perspectives against a certain problem work in practice (Charmaz, 2014; Dewey, 1925). Bullying can be an example of a problem that people act against or an example of how people try to handle other 
problems by acting against bullying based on a certain perspective, and pragmatism would here pay attention to the consequences that an act based on a certain definition has in practice. If we assume that people act towards bullying based on the idea that bullying occurs because bullies have problematic backgrounds, because this has been a factor in all the bullying incidents they have encountered, bullying interventions might be handled with this perspective in mind. This interpretation and way of acting towards the situation may work in practice to solve this problem, but what if a new bullying incident occurs where no clear linkage exists between the bully and a problematic background? In that case people might need to construct a modified or new perspective on how to act towards bullying. This assumes a view of people as being active and constantly reflecting on and interpreting how to act towards problems (Dewey, 1925; Mead, 1938). Dewey (1925) claimed that humans through ongoing reflections strive to construct, in the end, a better world. Striving for a better world through reflection may sound naïve, and it assumes that people have an intention of being good, which is clearly not always the case, but the alternative is to give up (Arneback, 2012). Rorty (1999), subscribing to pragmatism himself, asks, with reference to Dewey, what kind of "better world" is assumed, in response to which Dewey and his pragmatism can only refer to progress and reflection. Rorty (1999), however, assumes that progress towards a better world refers to social processes among people and our abilities to co-operate with and trust each her.

In pragmatism, actions are viewed as interpretations that people make about the world, which arise through the actions humans take part in (Charmaz, 2014; Dewey, 1925). The philosophical position of pragmatism further informs an interpretative way of understanding the world and claims that knowledge is always provisional and stems from our social experiences and social interactions (Mead, 1934). Our perspectives, which arise through our actions, are social; they are constructed in a specific context and through social interaction. Social interaction is therefore fundamental for our construction of perspectives and for our understanding of our social worlds. The concept of signs has been used to describe the process of how people come to construct perspectives about the world. Signs are objects, made up through social interaction that people interpret and act against based on that interpretation. Signs have a symbolic value; we act 
against the world based on these signs (Mounce, 1997; Peirce, 1940). Knowledge is therefore situated, contextualised, social, provisional and fallible. There exist no unbiased positions (Dewey, 1925; Peirce, 1940; Thayer-Bacon, 1996). How the world appears is dependent on the researcher (Charmaz, 2014; Corbin \& Strauss, 2008; Mounce, 1997; Peirce, 1940; Thayer-Bacon, 1996), and, I would add, dependent on the researcher and the participants as they co-construct data that the researcher then has to interpret further (e.g., Charmaz, 2006, 2014; Corbin \& Strauss, 2008).

These ideas presented from the tradition of pragmatism mean that I have subscribed to the idea that perspectives can only be understood in practice (Mounce, 1997; Peirce, 1940) by asking questions on how they are derived (Thayer-Bacon, 1996). In that sense the trustworthiness of my research analysis has to be evaluated through its usefulness, but in this thesis the analysis also has to work in practice and "respect the nature of the empirical world" (Blumer, 1969, p. 28), where my analysis is judged by the way it conceptualises the actors' perspectives (e.g., Blumer, 1969; Peirce, 1940). Conceptualisations are trustworthy as long as they are useful in defining the actors' social worlds (e.g., Charon, 2009). By taking as a starting point the assumption that people reflect on the problems they face, I, as researcher, have to reflect on how I handle the problem of interpreting the participants' perspectives and how I respect the empirical world of my participants. Pragmatism uses the concept of abduction to address how this reflective process may look from a researcher's perspective (Peirce, 1940). Abduction informs an imaginative approach based on openness and curiosity during data collection and analyses, to account for surprising data that occur during data collection and analyses. Surprising data can be referred to as cases that deviate, or one can actively ask questions of the data to reveal possible nuances and try out different kinds of interpretations. Abduction is further involved in making inferences where the researcher formulates a set of conceptual hypotheses to further explore, while constantly asking new questions and accounting for possible new surprising data (e.g., Charmaz, 2014; Thornberg \& Charmaz, 2014). However, the final theoretical conceptualisations are viewed as constructed and provisional (Mounce, 1997; Peirce, 1940) until they no longer work in practice. If other interpretations are made that contradict or extend these 
conceptualisations, they are no longer working in practice. The intention of the researcher is to explore the perspectives that the participants use to approach, in my case, bullying. How I have tried to account for this will become evident when we delve into my analysis.

\section{Interpretative Constructivist Paradigm}

While digging deep into my data I do not uncritically report what the participants have been talking about during the interviews. Their perspectives are instead, and in accordance with interpretative constructivism (Lincoln, Lynham, \& Guba, 2011), viewed as interpreted and analytically conceptualised. Interpretations are involved in the beginning of my data collection process, when I transcribe my interviews, analyse the transcriptions and write up the finished papers. I construct the research product (Charmaz, 2014). An important starting point in this study is therefore that all constructions of the world take place in situated social and historical contexts in which particular constructions of knowledge, assumptions and perspectives are available, and these arrive through engaging in social interaction (Berger \& Luckmann, 1966, Charon, 2011; Mead, 1934). We can recognise that this position has already been acknowledged in the pragmatism position, but I think it is important to name the action of the researcher more specifically as an act of the data, an interpretation.

As Peirce (1940) claims of pragmatism, theoretical conceptualisations about the world are provisional as well as biased. My theoretical conceptualisations still have to make sense of the participants' perspectives, highlighting the importance of striving to produce interpretations that reflect their perspectives (Lincoln, Lynham, \& Guba, 2011) but they cannot and will not be an exact picture. This further addresses the importance of staying reflexive during the research process (Alvesson \& Sköldberg, 2009). Reflexivity includes interpreting interpretations and reflecting on how the researcher is involved in the constructing of the finished research product (Alvesson \& Sköldberg, 2009). I have tried to focus on the statements of the participants when collecting and interpreting my data (Charmaz, 2006, 2014), which may be interpreted as respect towards 
the participants' reflected perspectives (Charmaz, 2006, 2014). I have tried to adopt a non-judgemental approach that promotes the researcher to probe for the participants' perspectives. The researcher neither judges the participants' perspectives nor forecloses the interpretations made from these perspectives too soon (Charmaz, 2014). However, researchers accept multiple realities and interpretative theories as provisional due to the constructed character of interpretations (Charmaz, 2006, 2014; Corbin \& Strauss, 2008). This includes both my interpretations and those made by the participants, since we all engage in interpreting each other's and our own social worlds (Charmaz, 2006, 2014).

\section{Symbolic Interactionism}

I have adopted symbolic interactionism as a theoretical perspective in this study. This perspective is the lens from which I have approached my understanding and interpretations of the participants' perspectives. As with all perspectives, symbolic interactionism is one angle, one perspective, and as such is both limiting and enriching (Charon, 2009). I have taken this perspective as my starting point as it seems suitable due to my interest in exploring perspectives. It gives me tools both for exploring perspectives and for conceptualising interpretations of the same, since it engages in an open exploration of the participants' ways of constructing social meaning of processes and actions. At the same time it offers a framework of sensitising concepts (Blumer, 1969), where earlier knowledge's can be used as possible theoretical lenses. Symbolic interactionism is not an explanatory theory but a perspective (Charmaz, 2014). Symbolic interactionism has mostly been referred to by Blumer (1969) and Mead (1934), but also Cooley, Thomas, Becker and Goffman. It is pragmatic ideas that have informed the symbolic interactionist perspective (Charmaz, 2014; Corbin \& Strauss, 2008); it is therefore obvious that some of the ideas presented previously, when discussing pragmatism, are also a part of symbolic interactionism. The central ideas in symbolic interactionism articulate that humans are social, interactional, reflective actors who interact with others and with themselves and act towards objects (e.g., things, people, places) in the world according to the meaning it has for them (Blumer, 1969). Hence, 
individuals, perspectives and our social world are viewed as constructed in social interaction (Charon, 2009), but also as changeable and tentative and able to vary in different situations (Blumer, 1969). What the symbolic interactionism perspective offers, based on the ideas presented on pragmatism, is a perspective on how the reflective, interpretative social process of the self and on how interactional processes among people work. While pragmatism offers philosophical ideas that are incorporated in the methodology in this study, symbolic interactionism uses these ideas to reveal how our perspectives, social worlds and identities are constructed. I will now outline some of these ideas and how they are incorporated in my study.

\section{Objects, Meanings and Situations}

In the pragmatist position, the concept of signs is used to illustrate how people use signs to interpret and act in the world. In symbolic interactionism signs are referred to as objects. Objects consist of anything that is referred to, and their meaning is constructed in social interaction (Blumer, 1969). Objects can be other people, places or things (Blumer, 1969; Mead, 1934). To learn about the participants' perspectives, how and on what objects they construct their perspectives is pivotal. Perspectives and the way they are constructed become important to study on their own. In this study I have therefore aimed to examine the objects my participants have addressed and what meaning they have attributed to them. Meaning can be both shared and nonshared, because people may act towards a situation in different ways or act towards an object in similar ways if they come to share a socially agreed meaning of an object (Blumer, 1969). Mead (1934, 1938) introduced the concept "generalised other" to describe how the perspectives of the social groups to which an individual belongs influence the actions of that member as these perspectives are internalised. Generalised others function as a necessity in the process of constructing shared perspectives. A generalised other can be a peer group, school class or a social category such as gender. In this study it is of interest to explore the way in which generalised others, and which generalised others, may be of importance for the participants.

Two further points need to be made; one is that perspectives can change in different situations as they are derived from ever ongoing 
social interaction and reflections. In my study this means that I can only say something about the perspectives that the participants address through our interactions, but their perspectives might have been different in a different situation. The other point is that a historical linkage exists between earlier experiences of situations playing a part in defining new situations and actions, but this is always open to change (Mead, 1934, 1938). This is important since people, according to Mead, interpret a situation based on the past, present and the future before acting, but they may not know the consequences of their act until afterwards, when people are also able to reflect on their actions (Mead, 1934).

Of particular interest is that, while perspectives are social, they have real consequences once acted on as real. If a student is acted against as a bully, this act has real consequences because people might act against this person based on this label. This summarises the socalled Thomas theorem known as the "definition of the situation" stating that: if men define situations as real they are real in their consequences (Thomas \& Thomas 1928, p.571-572). The material world therefore exists as an obdurate reality (Blumer, 1969), in line with what Clarke (2005) discusses as the materialist social constructionism that is inherent in symbolic interactionism (Clarke, 2005, 2015). The material world is always bound to the meanings and definitions that people attribute to it. In that way human definitions function as a lens towards - and on - the social world (Charon, 2009). Our definitions are also subjective, and multiple realties/worlds exist pinpointing the context-bound character of perspectives (Charmaz, 2014; Clarke, 2005). This captures the act of defining the situation as a preceding principle for human actions, but this act is never free (Farrell \& Swigert, 1972; Thomas \& Thomas, 1928) since humans are social interpretants who do not have access to truth, only to a set of assumptions about the world (Thayer-Bacon, 1996).

By adopting symbolic interactionism as a theoretical framework I further acknowledge that I have viewed my participants as active actors who have the ability to reflect on their social worlds but whose perspectives are socially constructed through interaction. This means that I have engaged with my participants, in symbolic interaction, and I have viewed my participants' perspectives as constructed through symbolic interaction. 


\section{The Social Self}

A very significant aspect of symbolic interactionism is that the people have a self, constructed in the social processes that the individual takes part in (Mead, 1934). The self is therefore inevitably social (Mead, 1934). The process of constructing a self reminds us that people act towards objects in the world according to the meaning they have for them (Blumer, 1969). Mead (1934, 1938) emphasised that humans can act towards themselves as objects. This process follows from taking part in symbolic interaction with others and themselves by taking the role of either particular others or generalised others (Mead, 1934). This means that particular or generalised others' reactions towards us and the individual's interactions with and interpretations of themselves together construct the social self. This does not mean that people uncritically adopt other people's perspectives of themselves; rather, humans are active in this process by interpreting and responding to social actions on their way to defining their selves in the world (Mead, 1934).

Mead (1934) describes the self as a process and a social structure, and separates the self into two parts, although they are interlinked. One part is the "I". The "I" is the part of ourselves that acts in the world by defining situations and by interpreting them. The second part of our self is the "me". The "me" part refers to the learned and the internalised attitudes and interpreted beliefs we know or think we know that others have about us (Mead, 1934; Sandstrom, Liverly, Martin, \& Fine, 2014). This means that the "I" acts in a situation but through the "me". However, the social self is constantly open for change as interaction is ongoing and people use the social self in different ways according to the situation (Charon, 2009). Furthermore, this suggests that we could rather refer to the self as selves. Different selves could be understood as roles, and roles are perspectives taken in the situation (Charon, 2009). Charon (2009) states: "Each situation calls forth a different role, which means a different perspective" (p.8). The self is defined in the situation and involves interpreting what role to use in the situation, once acted on the actor has given a presentation of the self (Goffman, 1990) and presented and used an identity in the situation (Charon, 2009). Identities are then our presentations and labels of ourselves, that we present for others. Hence, identities are negotiated as others are also involved in the process of defining and 
labelling of themselves and others (Charon, 2009). Mead (1934) refers to the social structure of the self and how the social self can remain stable if it is repeatedly confirmed (Mead, 1934). While acknowledging the social self as a structure, the interactional processes where the self is constructed may involve the construction of identities with different social values involving the construction of deviance. Constructions of deviant identities are of specific interest to understanding bullying processes (Burns, Maycock, Cross, \& Brown, 2008b; Thornberg, 2015a). Deviance processes evolve when an individual or a group is viewed as breaking a social rule and becomes socially "punished" by being defined and acted against as deviant or odd (Becker, 1963). Becker (1963) states that what stands as deviance varies in different contexts or groups from time to time, and different people are socially "punished" in different ways when challenging or breaking the same social rule, because this also depends on who it is that breaks the rule and whether someone reacts. In that sense, different social contexts have different interactional patterns that develop different constructions of deviance (Becker, 1963; Goffman, 1963).

Different people may also have different abilities for constructing social rules for others to follow, which highlights the importance of the different ongoing power relations based on such aspects as gender, ethnicity, class and age (Becker, 1963). Deviance processes may evolve into stigma (Goffman, 1963) or labelling (Becker, 1963), where people react negatively and degradingly towards that individual or group of people. This can affect the selfimage and identity of the person who is being acted against and labelled or stigmatised if the person starts defining him or herself based on others' interpretations due to being defined as a deviant object in the ongoing social interaction. Thus, the labelled person may not always end up subscribing to others' labelling practices because this has not become a way of acting towards oneself, because the individual either disagrees, or resists or has other images on which their identity is constructed. Different people who have been labelled or stigmatised may therefore react differently to others' identity labellings of them (Becker, 1963; Goffman, 1963). There may also exist several types of people or groups who are perceived as deviant in the same context; this could evolve in negotiating processes among 
different individuals or groups that share the categorisation of being perceived as deviant individuals or groups, where these individuals or groups themselves negotiate their social position against someone that they perceive as more deviant then themselves (Becker, 1963; Goffman, 1963).

\section{Negotiations and Social Order}

Within the symbolic interactionist perspective there has been a discussion regarding the tension between process and structure (Sundstrom et al., 2014). This discussion has occurred as people may have different opportunities to take part in social interaction as a result of social factors outside the situation. These social factors affect the processes on a micro level and may include factors such as gender, ethnicity, social class and age. This has been raised as a critique of symbolic interactionism, because the latter tends to miss or deny social factors outside the micro-sociological situation (Alvesson \& Sköldberg, 2009; Sundstrom et al., 2014). One way to address both process and structure has been conceptualised by Strauss, Schatzman, Ehrlich, Bucher, and Sabshin (1963) and Strauss (1978) in the concept of negotiated order. Negotiated order refers to social order where the social order is always negotiated but may, due to certain conditional patterns, affect who interacts with whom, how and under what conditions (Strauss et al., 1963; Strauss, 1978). Clarke (2005) discusses how Strauss by introducing the concept of negotiated order pays attention to negotiations as ongoing social processes but also the" micropolitics of power and the powers of discourses" (p. xxix).

\section{A Symbolic Interactionist Perspective on Bullying}

A symbolic interactionist perspective on bullying that focuses on social interaction, processes and meaning constructions is important in several ways. Firstly, bullying (the situation, the people involved and the actions that take place as parts and together) might be understood as various objects towards which the participants' act. Depending on the meaning objects in bullying situations have for the participants, the participants may define bullying situations differently and come to 
assume a range of various roles and perspectives based on these definitions, including the way they define their own and others' role(s) in various situations and act on these (e.g., Burns et al., 2008a, 2008b; Burns, Cross, \& Maycook, 2010). These definitions may be perceived as agreed-upon definitions of the situations in their environments, and lines of action (e.g., Burns et al., 2008a, 2008b; Goffman, 1990; Thornberg, 2015a) that can acknowledge how different identities are constructed in the students' understandings of bullying. For example, they may define victims as being responsible for the bullying by labelling them as deviant (e.g., Burns et al., 2008b; Thornberg, 2015a).

Secondly, in the symbolic interactionist perspective, identities and roles are viewed as social constructions. This means that the terms "bully" and "victim" and different bystander responses should be understood as social and processual and not static entities. These are constructed through social interaction, and depending on that interaction, people may be defined, labelled, or take on a bully or victim identity (Mead, 1934; Thornberg, Halldin, Bolmsjö, \& Petersson, 2013a). Hence, more stable identity patterns may be recognised, as the interactional patterns may be shared in a social group over a period of time (Mead, 1934; Thornberg et al., 2013a), which acknowledges that to learn about others' perspectives, we must learn about their generalised others (Mead, 1934, 1938).

Thirdly, by incorporating the negotiated order perspective, this opens up the possibility of including the way that different identitites and social orderings intersect with students' understandings of bullying. This perspective may also be useful for positioning this study, as different kinds of constraints may affect what and whose perspectives I am able to explore in this study.

\section{The Sociology of Childhood}

\section{Participants as Actors and Experts}

Taking a starting point in pragmatism and symbolic interactionism assumes that the participants are active and reflective. However, historically a distinction between children and adults (childhood and adulthood) has been assumed. I would add that these kinds of 
distinctions still largely reflect how institutions and society are structured. Children have been viewed as becoming objects with no agency (Greene \& Hogan, 2005; Prout, 2005) on their way to becoming adults and entering adulthood, a view that constructs adulthood as something stable and distinctively different from childhood (Lee, 2001). I have therefore incorporated the sociology of childhood in my study, wherein children are considered instead as active social agents constructing their social worlds and as experts in their social worlds (Corsaro, 2011; James \& Prout, 1997) but are also viewed as being shaped by their environments (Corsaro, 2011; Freeman \& Mathison, 2009). The sociology of childhood was formed as a reaction towards the dominant and essentialist perspectives on children and suggests a sociological approach towards social categories such as age (Corsaro, 2011; Mayall, 2013). Multiple realities and environments such as the historical and social are assumed (James \& James, 2004), and the concept of childhood is in itself understood as a social construction (Corsaro, 2011; James \& Prout, 1997).

A sociological approach towards social categories deconstructs the binary assumption of being and becoming, because all humans can be viewed as incomplete and dependent, and therefore different states of becoming should be highlighted. However, different positionings are still made today; we still refer to adults and children as social groups where the group of children is subordinated to adults (Alanen, 2009). The guiding principle for positionings between adults and children and between children seems to adhere to age order (Närvanen \& Näsman, 2007). Age order refers to how different actions and identities are used to position certain activities and behaviours where age is the guiding principle, and evokes ideas of normativity and deviance. Children may very well be an active pole in starting processes (e.g., Lee, 2001; Mayall, 2013) and constructing social worlds, but the age order perspective reminds us of how different age order positions can constrain their possibilities for doing so. Age order positions may, however, construct a specific knowledge of what it means to be a child that makes children experts in their social worlds (Alanen, 2009; Näsman, 1995) at the same time as it reveals that adulthood and childhood are produced in relation to each other. There is still a discrepancy made between actor and structure that to some 
extent further acknowledge a dualism between children and adults. At the same time, it seems impossible to neglect the power imbalance between child and adult (including child and researcher as well), as our social institutions are organised and constructed following an age order that may influence the construction of perspectives. While acknowledging children as actors who construct their shared peer cultures as well as affect the adult world, including the structural constraints embedded in society that affect children, Corsaro (2011) introduces the concept of interpretative repertoires to account for both of these matters.

In an attempt to account for both of these matters, I have incorporated researcher strategies that position the participants as actors and expert commentators of their social worlds (Prout \& James, 1997). I have also used a researcher position that aims to counteract tendencies that structurally position me as an older-adult-superior.

\section{A Reflexive Friendly Researcher}

Throughout this chapter on my theoretical and philosophical framework, I have outlined some of the influences that have affected the present study. This ending section will theorise more specifically on how these interlinked positions are approached in my researcher approach. This approach is built on some of the research strategies drawn from the sociology of childhood for conducting research with children, even though, generally, I think these strategies are suitable independent of the participants' age if you want to study perspectives. I have found the researcher strategy of the least-adult role (Mandell, 1991) and the friendly researcher strategy (Ravet, 2007) to be suitable. These strategies inform a researcher position that approaches the participants non-judgmentally, with an openness to their perspectives, viewing them as experts in their social worlds, and with an avoidance of authority, and with engagement in their activities (Mandell, 1991; Mayall, 2000; 2008; Thorne, 1993). Such a strategy may be useful to counteract tendencies in which participants are defined as lacking agency and having no valuable perspectives, and in which they may be unfamiliar with being listened to. At the same time, this strategy in part builds on an age order that assumes an adult-child dualism and that children are structurally positioned as powerless. Both Thorne (1993) 
and Mayall (2000) have problematised the least-adult approach, showing the difficulties in maintaining it where the participants may have a sceptical attitude towards these new roles, and not defining the researchers' attempts as genuine due to being used to distinctive adultchild roles (Freeman \& Mathison, 2009). However, these kinds of research strategies might contribute to attribute agency to children and making them active meaning-constructors (e.g., Fernqvist, 2010).

In this thesis I have collected data in the school and the participants have been asked to participate with "students" perspectives. This might influence how participants interpret and attribute assigned roles and the perspectives they address. In the school context, they might indeed be unfamiliar with having a conversation with an adult who is non-judgmental and interested in their social worlds rather than evaluating their school subject knowledge and behaviour in relation to school rules and teacher expectations. Researchers must consequently create an awareness of the possible cultural norms (Freeman \& Mathison, 2009), such as age order positions (Närvanen \& Näsman, 2007). This non-judgmental approach, however, is, according to Mandell (1991), in line with a symbolic interactionist perspective, where the researcher tries to examine the participants' perspectives. Another challenge lies in how to account for someone's perspectives without making conceptualised interpretations too soon (Charmaz, 2006, 2014; Lincoln et al., 2011) where my previous knowledge might function as preconceptions (Glaser, 1978, 1998) and the power to interpret the data is still ascribed to the researcher. The challenge lies in combining my interpretative approach, where the researcher is viewed as a co-constructor of meaning together with the participants, with my interest in learning about the participants' perspectives and taking the role of the other (Charon, 2009; Mead, 1934) during my interviews. Aware of these restrictions, I have used an open-ended interview strategy, probing for the participants' perspectives and, at several points during my contacts with the field, been acknowledging the participants as expert interpreters of their everyday activities, asking them to help me to understand their perspectives (Mayall, 2000, 2008). 


\section{Concluding Remarks}

To approach the participants' perspectives I used a symbolic interactionist perspective where the participants are viewed as actors who construct perspectives, which are at the forefront of the analysis (Blumer, 1969). However, researchers are positioned as humans who interpret and take part in social interaction, which further informs an interpretative constructivist paradigm as a way of enhancing my constructing act on the data material. I have still aimed to approach the data with imagination and an openness to learning from the participants (Charmaz, 2006, 2014; Lincoln et al, 2011); for example, by incorporating theories other than symbolic interactionism to account for the participants' perspectives if they fit (Thornberg, 2012). Interpretations must fit participants' perspectives. Opportunities for this may be found through a non-judgmental approach and exploring the participants statements by carefully approaching and elaborating the data, which is the logic of pragmatism building on abduction, seeking to explore participants' perspectives by not foreclosing the interpretations too early (Charmaz, 2006, 2014; Peirce, 1940) and by reflecting on my actions. Furthermore, this is inherent in acknowledging that all humans are actors; while historically children have not been assumed as such (Greene \& Hogan, 2005; Prout, 2005), this position informs the sociology of childhood, as it helps to position children as experts and active, but also highlighted the importance of a non-judgmental approach in seeking to explore the participants perspectives during my interviews. I have integrated these perspectives because they construct a theory and package fit, but also because they offer openness towards integrating different theoretical perspectives and openness in relation to the data and analysis procedures. Nevertheless, the outcomes of this thesis represent some perspectives on bullying, provisional and constructed (Charmaz, 2006, 2014; Lincoln et al, 2011; Peirce, 1940). 


\section{Methodological Framework and Methods}

In this chapter an introduction to my methodological framework of grounded theory is found, focused on the constructivist grounded theory approach I have chosen. I will then move on to present my research process, including recruitment of participants and semistructured interviews. Penultimate I will present my analysis procedures and lastly I report on my section with my ethical considerations.

\section{A Constructivist Grounded Theory Approach}

Students' perspectives have been approached with a grounded theory method, since this is suitable for studying processes and actions from the participants' perspectives (Glaser \& Strauss, 1967). Note, however, that grounded theory has been used only partially in paper II. This is a collaborative conceptual paper where our analysis has been only partly guided by grounded theory.

In wanting to broaden the perspectives on bullying by listening to the students' perspectives, grounded theory may be suitable, since in grounded theory the participants' perspectives are at the forefront rather than simply applying existing theories when analysing bullying (Charmaz, 2006, 2014). Grounded theory was first formulated by Glaser and Strauss in their Discovery of Grounded Theory (1967) and was developed as a reaction towards the sociological research field, which they at the time perceived as being occupied with verifying grand theories. Glaser and Strauss (1967) argued that sociological research appeared to be based on a verification doctrine. In contrast, they wanted to introduce methods for generating theory, which resulted in the grounded theory approach aimed at generating theories through comparative analysis. Significant in their approach is the backand-forth movement between data collection and analysis, with the use of constant comparisons where theoretical elaborations are aimed at developing conceptual categories or basic social processes for the specific context or phenomena under study (Charmaz, 2006, 2014; Glaser, 1978; Glaser \& Strauss, 1967). 
Today a range of different versions of grounded theory approaches exists (Bryant \& Charmaz, 2010; Morse, 2009; Thornberg $\&$ Charmaz, 2014), although they share some foundations. They all emphasise coding procedures, constant comparisons of data, grounding the analysis in empirical data and a constant movement back and forth between theory construction and data collection. In this constant movement, the constant comparison strategies - revealing new ideas to further explore as well as viewing the generated grounded theory as provisional while addressing the importance of being useable for the practice researched - are enhanced (Charmaz, 2006; Glaser, 1978; Glaser \& Strauss, 1967). Among the different versions of grounded theory, constructivist versions have emerged. In my thesis it is of importance to take the participants' perspectives as the starting point, and I wish to do so with the flexibility to analytically interpret and enhance the participants perspectives to make the most plausible conceptualisation (Charmaz, 2006, 2014; Lincoln et al., 2011). Therefore, the understanding of grounded theory as flexible guidelines inherent in constructivist version seem fruitful to me (Charmaz, 2006, 2014). The constructivist approach was developed by Charmaz (2006), who, along with Clarke (2005), and Bryant (2002) moved grounded theory closer to social constructionist epistemologies. In the third version of their Basics of Qualitative Research, Corbin and Strauss (2008) subscribe to this position as well. The constructivist grounded theory approach promotes reflexivity; the research has to reflect on how their preconceptions influence the study. Furthermore, the researcher studies how the participants construct meaning of a specific topic or action (Charmaz, 2014). Following a constructivist approach permits the use of my earlier knowledge by incorporating it as a possible theoretical lens, referred to as sensitising concepts (Blumer, 1969), for use in my analyses. Using sensitising concepts and earlier theories as a starting point is not something that one of the founders of grounded theory — Glaser (1998) — would accept; Glaser would see this as forcing the data. Glaser (1978, 1998), and Glaser and Strauss (1967) have adopted a more objectivistic understanding of the researcher as well as of data collection procedures. The researcher is assumed to be able to put earlier knowledge aside just as if the data were being viewed as emerging and "out there" ready to be discovered (Glaser, 1978; Glaser \& Strauss, 1967). The researcher should avoid reading 
literature and orientating himself in the phenomena under study until the end of the analysis process. In the constructivist version, grounded theories are viewed instead as being co-constructed by both the researcher and the participants, and further constructed by the researchers in which their earlier knowledge is viewed as important and as a lens through which to start your work (Charmaz, 2006, 2014). Charmaz's constructivist version $(2006,2014)$ builds on the theoretical underpinnings of symbolic interactionism and pragmatism. A constructivist grounded theory approach therefore fits with the ideas presented in my theoretical and philosophical framework. Symbolic interactionism and pragmatism are considered as the epistemological and ontological foundation of grounded theory (Clarke, 2005; Charmaz, 2006, 2014). These interlinked perspectives, stated as being the foundation for the grounded theory method, have never been fully explicated in either Glaser and Strauss (1967) or Strauss and Corbin (1998), as is being proclaimed and elaborated by Bryant (2009). However, in the third version of Corbin and Strauss's Basics of Qualitative Research (2008), these perspectives are undertaken. The relationship between interactionism, pragmatism and grounded theory methods are apparent. Bryant (2009) suggests that a lot of the critique against grounded theory, in terms of the objective researcher role and positivistic underpinnings, with these saying that the researcher should wait to read the literature, could be solved if these perspectives were further explicated.

Independent of which grounded approach one chooses, grounded theory is informed both by induction and abduction, with close interplay between them. The researcher constructs inductive categories and thereafter engages in abduction, where these categories are further explored and elaborated (Charmaz, 2014). The close link to abduction reveals an intimate link to pragmatism (Charmaz, 2006, 2014; Peirce, 1940; Thornberg \& Charmaz, 2014). Abduction is visible in the systematic guidelines for data collection and analysis, along with the curiosity towards conceptualising the participants' perspectives. Asking questions of the data, following theoretical leads and approaching the material with an imaginative view of understanding participants' perspectives, are accommodated (Charmaz, 2006, 2014). I have previously described how people may have an agreed-upon definition of why bullying occurs, an interpretation that they use when 
acting against bullying, and that this interpretation works because all the bullying incidents that they encounter can be understood within their interpretation. Let us now translate this into how this works from the researcher's perspective. I may have constructed an early idea that my participants define bullying as wrong, and it seems to be a plausible interpretation as I have found that statement among all of my participants. However, if bullying is wrong, then why do bystanders not intervene, and what do the participants include in their definition of bullying? Do they consider bullying to be wrong at all times? These are possible questions to further explore following abduction.

The role of symbolic interactionism in this thesis has made me focus on interaction, processes and how meaning is constructed among the participants. Even if symbolic interactionism and pragmatism could be incorporated as a way of conceptualising the data, these perspectives form epistemological ground in the constructivist grounded theory approach, which further acknowledges the possibility of incorporating other theoretical concepts as part of the analysis (Charmaz, 2006, 2014; Thornberg, 2012). I mention this since not all of the theoretical concepts used throughout my studies belong to symbolic interactionism. Thus, symbolic interactionism has contributed to my analyses in which the ongoing processes and changes within groups are acknowledged, and it addresses the participants' ways of defining these processes (Morse, 2009).

\section{Recruiting participants}

In grounded theory studies it is crucial gathering a range of perspectives on the research topic and selecting participants with "first hand experience of the topic" (Charmaz, 2014, p. 56). The recruitment of participants in all of the papers in this thesis is in line with open sampling procedures that give a heterogeneous sample. The open sampling strategy "seeks to maximize variations in experiences and descriptions by using participants from contrasting milieus and backgrounds" (Hallberg, 2006, p. 143), and in turn enhance the conditions of qualitative analysis. I tried to recruit schools from different geographical areas as well as socioeconomic backgrounds, but some of the schools I contacted, for various reasons, did not give 
me permission. The Swedish schools were located in several different neighbourhoods. Three of the schools were located in a middle-sized city with more than 130,000 inhabitants. Two schools were located in a smaller village with around 2,800 inhabitants, one school in a town with 30,000 inhabitants and two schools in a village with 7,000 inhabitants. In total, 133 students with an age range of 9 to 15 years have participated in this thesis. Eighty-seven of these students were Swedish students (17 boys and 70 girls) with an age range from 10 to 15 years (from the fourth to eighth grades), recruited from 12 school classes at eight different schools. Forty-six of the 133 students were US students aged 9 to 14 years and in the fourth to eighth grades, conducted by the US research team. These students came from two different schools described as "an urban district in the south-eastern United States" by the US research team. These two schools participated in a larger research project that included a district-wide bully prevention programme, consultations with the local university and interventions for individuals, groups, teachers and parents.

As noted in the table below, paper IV was conducted only with girls from the seventh and eighth grades, and took the form of pair and group interviews instead of individual semi-structured interviews. Development of aims and sampling procedures were made in the course of the research process, in which my collected data and my analyses pointed towards interesting processes to explore further, including indirect bullying, friendship groupings and gender. I also collected 10 new interviews to explore my codes and categories for paper III (e.g. 6 of these with old participants that I went back to interview again and 4 new participants for paper III). In paper III I also excluded five of the earlier interviews used in paper I and II as these did not focus on the topic in paper III. This means that some of my participants for paper III were interviewed two times (and that is way the total numbers of participants are eighty-seven instead of ninetythree in the table below). The same participants were included in paper I and paper II as paper II was a collaborative paper with a US research team. 
Table 1: Overview of participants, aims and methods

\begin{tabular}{|c|c|c|c|c|}
\hline Paper & Aim & Method & Participants & Analysis \\
\hline I & $\begin{array}{l}\text { Investigate bystander } \\
\text { actions in bullying } \\
\text { situations as well as } \\
\text { reasons behind these } \\
\text { actions as Swedish } \\
\text { students from fourth to } \\
\text { seventh grade } \\
\text { articulated them. }\end{array}$ & $\begin{array}{l}\text { Individual } \\
\text { semi-structured } \\
\text { interviews. }\end{array}$ & $\begin{array}{l}43 \text { interviews } \\
\text { with Swedish } \\
\text { students } \\
\text { Fourth to } \\
\text { seventh grade. }\end{array}$ & $\begin{array}{l}\text { Constructivist- } \\
\text { grounded } \\
\text { theory. }\end{array}$ \\
\hline II & $\begin{array}{l}\text { To investigate how } \\
\text { Swedish and US } \\
\text { students articulate and } \\
\text { discuss what factors } \\
\text { influence their own and } \\
\text { other students' } \\
\text { decisions to defend or } \\
\text { not defend victims } \\
\text { when witnessing } \\
\text { bullying. }\end{array}$ & $\begin{array}{l}\text { Individual } \\
\text { semi-structured } \\
\text { interviews. }\end{array}$ & $\begin{array}{l}89 \text { students: } \\
43 \text { interviews } \\
\text { with Swedish } \\
\text { students } \\
\text { (same as } \\
\text { paper I) } \\
\text { And } 46 \\
\text { interviews with } \\
\text { US students. } \\
\end{array}$ & $\begin{array}{l}\text { Constructivist- } \\
\text { grounded } \\
\text { theory and a } \\
\text { mixed } \\
\text { qualitative } \\
\text { collaborative } \\
\text { conceptual } \\
\text { analysis. }\end{array}$ \\
\hline III & $\begin{array}{l}\text { To investigate how } \\
\text { children themselves } \\
\text { discuss, reason on and } \\
\text { make sense of how and } \\
\text { why bullying emerges } \\
\text { to extend our } \\
\text { knowledge of what } \\
\text { social processes that } \\
\text { are made important } \\
\text { among the children. }\end{array}$ & $\begin{array}{l}\text { Individual } \\
\text { semi-structured } \\
\text { interviews. }\end{array}$ & $\begin{array}{l}48 \text { interviews } \\
\text { with students } \\
\text { from fourth to } \\
\text { seventh grade. } \\
38 \text { of the } 43 \\
\text { students from } \\
\text { papers I, II + } \\
10 \text { new } \\
\text { interviews. }\end{array}$ & $\begin{array}{l}\text { Constructivist- } \\
\text { grounded } \\
\text { theory. }\end{array}$ \\
\hline IV & $\begin{array}{l}\text { To take an explorative } \\
\text { approach towards } \\
\text { junior-high school girls' } \\
\text { subjective perspectives } \\
\text { of bullying by carefully } \\
\text { listen to how girls } \\
\text { themselves discuss and } \\
\text { reason on bullying. }\end{array}$ & $\begin{array}{l}\text { Semi- } \\
\text { structured pair } \\
\text { and group } \\
\text { interviews. }\end{array}$ & $\begin{array}{l}40 \text { new } \\
\text { interviews } \\
\text { with seventh- } \\
\text { and-eighth- } \\
\text { grade girls. }\end{array}$ & $\begin{array}{l}\text { Constructivist- } \\
\text { grounded } \\
\text { theory. }\end{array}$ \\
\hline
\end{tabular}


To recruit the Swedish participants, I contacted several principals who asked their teachers, and eventually several teachers allowed me to ask their students whether they wanted to participate. For one of the schools a teacher was asked first and the principal later on. Overall, students were easy to recruit, whereas the process of recruiting schools was sometimes a bit lengthy. When I had established contact with the teachers I went to visit the students. I visited the students' classrooms, where I described myself as a researcher writing a book about bullying from a student/child perspective. I described myself as someone interested in students' perspectives on bullying, and I revealed that I had only found a few studies that had actually focused on students' perspectives on bullying, which made this an interesting and important area to explore. I told them that they were experts on students' perspectives on bullying and that I wanted to learn from their perspectives, since their perspectives were crucial to the further understanding of this phenomenon.

All students were asked to participate, except in paper IV where I only asked the girls in the school classes to participate, and I declared that my interest was to listen to their perspectives on bullying and that I did not care if they had different opinions to, for example, those of adults or teachers. I exemplified what kinds of questions I would ask during the interviews to give the students an idea of what my questions might sound like, but I also said that what we would come to discuss would depend on what they wanted to talk about and what they came to think about when reflecting on bullying. Furthermore, I gave the students some general information-e.g. that it was voluntary to participate, how I would use the material to write a book where I would try to understand what seemed important to them according to their statements, that they would remain anonymous and that the names of the schools and their real names would not be used. After providing this information I handed out informed consent letters with information for both caregiver/s and students and including the same information I had given them verbally. The school counsellors chose to select and recruit the US participants and handed out consent letters to be signed by their caregivers. The interviews in Sweden (paper I and II) were conducted before the US interviews, but the US research team customised their sub-sample to this when recruiting participants (e.g. number of participants and per grade). There is a difference in how our 
two sub-samples have been recruited. Hence, the US participants were involved in a larger research project in which their school counsellors had an active role. The students were therefore familiar of talking about bullying with their counsellors and familiar with the researchers from the project.

In grounded theory studies it is suggested that you, as a researcher, "need to be current about the experience or situation that you will be studying" (Charmaz, 2014, p. 59). This could for example involve being familiar with common procedures, key terms used among participants or clothing norms (Charmaz, 2014). This familiarity could later be used by the researcher to position the participants as experts and the researcher as interested in the participants' worlds. The US research team already had established a familiarity with their schools as they collaborated on several levels in their larger research project. In Sweden, as part of my recruiting process for papers I, II and III, I therefore spend two to five days in every class, the idea being to make the students more familiar with me by giving them the opportunity to ask all sorts of questions during informal talks before I conducted any interviews. These visits ranged according to when the schools thought it would be possible to have me there as a visitor. In paper IV the recruitment process was similar but with one exception: I only spent two to five days in some of the classes before conducting the interviews. These interviews were collected later in my research process, so these visits were not always possible.

During these visits I participated in their classroom activities, went to lunch with the students and went out on breaks with them. In the classroom I seated myself in one of the school desks and tried to be a curious visitor, but also as someone participating in what was going on. For example, when the teacher gave a lecture, I listened too; when the class watched a movie, I watched it too; when the students worked in any of their books, I picked up a book of my own or a notebook. When I went to lunch I engaged in the same activities as the students: if they queued before entering the lunchroom, I queued too. I often approached one of their lunch tables and asked if I could sit there, and sometimes the students themselves invited me to sit at their table. During the breaks I went out with the students; I assumed a passive role and waited to be invited to participate in their activities. However, during breaks I was not always included in their activities; this made 
me feel like a visitor and a newcomer. Maybe I was positioned as such, or as an adult.

Overall, I experienced these visits as important for making the students familiar with me, especially before conducting the individual interviews. It also gave me the opportunity to present myself as interested in their social life in the schools, but also as a visitor and another kind of adult, not telling them what to do and when to go back to the classroom and not assuming I could sit at their table during lunch. Furthermore, I got a glimpse of the activities they engaged in, what clothing brands they used and what was going on in their classrooms at the moment. I sometimes used parts of these glimpses during our informal talks before the interviews started. For example, I asked what the name was of the game I had seen them playing during the break, or what they thought about the food we had eaten. Sometimes, whenever the students addressed activities like these during the interviews, I confirmed their statements. If the students started to talk about a certain activity, I might reply: "Was it the play you performed during the break?" to present myself again as someone who was interested in what was going on among the students.

Although the Swedish sub-sample and the US sub-sample contain students from different geographical as well as socioeconomic backgrounds, the participants were predominantly from white homes. In my material proportionally more girls have participated as well. This may be of importance when reading the findings, since other contexts, with other students, might have evoked other processes and perspectives. Hence, perspectives do not necessarily look the same in one particular group or class, which would be problematic to assume. Therefore I think this thesis still have been able to include many perspectives and processes of significance for other contexts. Additionally, the unit of analysis is the processes, not the individuals. This thesis does include a large number of participating contexts with its eight different schools and twelve different school classes, as well as students from the US context. Furthermore, theories are always open to revision when new puzzling data or other interpretations arrives that challenge or extend the theory (Charmaz, 2014; Glaser \& Strauss, 1967). 


\section{The Semi-structured Interviews}

Using interviews can be useful for exploring the subjective experiences and nuances of a phenomenon and is suitable for investigating students' interpretations of their social worlds; it also creates an opportunity to discuss potentially sensitive issues, such as bullying (Corsaro, 2011; Farquhar, 1999). Overall, interview research includes probing, careful listening and an open style in which it is possible to add new questions to the interview protocol. Open-ended questions combined with a probing strategy could therefore be of importance in trying to further facilitate the participants in explicating their perspectives. Out of the different options available, these circumstances initially made me choose to work with in-depth individual semi-structured interviews (Kvale \& Brinkmann, 2009), or what Charmaz (2014) defines as "intensive interviewing". The US research team used semi-structured interviews as well, which were conducted by two graduate research assistants from the university (Laura Wood and Jennifer Smith). Both research assistants were white, female students from the Counselling and Psychological Services Department.

Intensive interviewing can be described as "a gently guided, onesided conversation that explores a person's substantial experience with the research topic" (Charmaz, 2014, p. 56) and further addresses flexibility as well as being open-ended (Charmaz, 2014). However, in paper IV I decided to conduct group interviews instead so as to further explore bullying with girls. In childhood research, group interviews have been articulated as helpful in positioning children as experts and in counteracting power imbalances between adults and children (e.g., Corsaro, 2011). This was one of the reasons for choosing to work with group interviews. The other reason was that my ongoing data collection and my interpretations was pointing towards interesting processes in the girls' statements, and this was something that I was curious to further explore, and group interviews appeared to be particularly suitable, as they might capture different interactional processes in a familiar group context (Kitzinger, 1995, Morgan, 2012). Working with grounded theory permits different kinds of empirical data sources, both qualitative and quantitative data, as well as combinations of sources (Charmaz, 2006, 2014; Glaser, 1978; Glaser 
\& Strauss, 1967; Strauss \& Corbin, 1998); this also opens up the possibility of changing methods during the research process. For the group interviews I let the participants select whom they wanted to be interviewed together with, a strategy used elsewhere as well (e.g., Bliding, 2004). By letting the participants choose whom they wanted to be interviewed with, I intended to have them construct a familiar group context for the interviews (Kitzinger \& Barbour, 1999; Kitzinger, 1995, Morgan, 2012). Familiar contexts can promote comfortable feelings among the participants and therefore affect the interaction in the group (Morgan, 2012). However, the participants sometimes wanted to be interviewed in pairs. I therefore ended up collecting both pair and group interviews.

All interviews, including the US interviews, set out to explore the perspectives of the students. The interview protocols covered openended questions on general themes and were brought to all interviews. An interview should aim to encourage participants to share their perspectives, and the researcher can act in several ways to encourage this (Kvale \& Brinkmann, 2009). The interview protocols were used in a flexible and sensitive manner in order to counteract power asymmetries (adult-child as well as interviewer-interviewee) and to co-construct a dialogue or a conversation-like interview. This was done to engage in relationship-building strategies and to reflect the interpersonal relationships (Lillrank, 2012), where the participants were positioned as experts and the researchers as interesting in their perspectives. It was important to strove to create a friendly atmosphere, having the students decide where in the room to sit as well as informing them about my interest in listening to their perspectives and therefore not valuing their answers as wrong or right and emphasising from the outset that they as students know much more about how to be and think as students. The pace of the participants was crucial; this sometimes meant that they could continue to talk while the researcher kept a record of probing questions and sometimes talk about something that was not of interest for the study.

Both the US team and I used probing questions. These commonly reflected some word or action mentioned by the participant that was followed up by probing to clarify their meaning constructions. For example, during my interviews in paper IV, the participants often declared that girls typically bully in a certain way, as if this was 
common knowledge. I then followed it up by asking "How come girls engage in this kind of bullying"?, which revealed a gendered understanding of bullying and bullying practices. In line with theoretical sampling (Charmaz, 2014), the interview protocols were updated once more elaborated codes (categories) or possible associations between categories emerged in the analysis as theoretical leads, which needed to be further examined. Moreover, new and related themes that emerged in the interviews guided choices of what to explore further in subsequent interviews. This can be exemplified by the changes made during my first data collection. The participants were asked to describe how they reacted to bullying, but along with their reports on this they were also discussing why a specific bullying incident had happened. In the later interviews I therefore added a question to my interview protocol on why they thought a certain incident had taken place if that kind of reasoning had not already occurred during the interview. The very same thing occurred when the US team collected their interviews. They also recognised that the students were discussing why bullying happens and added this question to their future interviews. New theoretical ideas on what the participants discussed during the interviews also functioned as themes in my later papers, to be further explore in new interviews. As such, the different papers in this study build on each other. I have collected interviews several times and I re-interviewed some of my participants while working on paper III.

Even though our comparision comprises two data sets collected from two research teams (in paper II), the teams used the same interview protocol throughout the data collection. We had discussions on what questions to include and how, and both of our teams extended and clarified our questions when needed during the interviews and also as part of our ongoing analysis of what was being said among the participants, and where we added new themes and questions to our interview protocol. It is, however, important to remember that I constructed the background research questions, the interview protocol (together with the Swedish-US team in paper I \& II) and interpreted the participants' statements.

All interviews started with informing the students about the study once again, asked for consent to start the interview and informed that they did not have to answer any questions if they did not want to 
or could not. Overall, the interviews started with having the participants reasoning more broadly and generally, and later on the questions were more specific, having them describe or reason about experiences they had (Kvale \& Brinkmann, 2009). For example in our collaborative paper (paper II) the students were asked how they viewed bullying; how they thought others would react and later on how they themselves would react. Sometimes the interview protocol was checked so that there was not anything that was forgotten to ask, and in some of the interviews the flow in the interviews made it easy not to use the interview protocol. All the interviews were performed by one researcher at the students' own schools in rooms that we were assigned by the principal or the teacher. All interviews ended with asking whether the participant(s) had something further to tell or wanted to ask about.

I found that most of my interviews went well, which means that I sensed a form of connection with my participants and tried to encourage the participants by probing and using the participants' own words when probing, where I performed the role of active listener, and I also nodded my head on several occasions to demonstrate that I was interested in hearing what they had to say. There were some differences between the different types of interviews. During the pair and group interviews my role as an interviewer was a bit different, as the dialogue among the participants was more prominent, with turntaking discussions and me being more passive and throwing in probing questions whenever suitable. During the pair and group interviews I found it a bit trickier to have them discuss their own personal experiences, while this topic was more easily discussed during the individual interviews. This might happen in pair and group interviews (Corsaro, 2011), where different interpretations of the interview context become important in respect of what processes and social selves are enacted and how (Barbour, 2014; Farquhar, 1999). I found this interesting as these two types of interviews, even if they support different papers, enabled me to approach bullying from the students' perspectives from different angles, revealing various perspectives. For example, during my individual interviews the girls more often spoke about indirect bullying, but they did not gender these acts as much as they did during the pair and group interviews.

My shortest interviews were 20 minutes and the longest two 
hours. The pair and group interviews commonly lasted longer as compared to the individual interviews - for one hour or more. The US teams interviews lasted approximately 20 to 60 minutes. The interviews with the fourth grade students were generally shorter compared to the other grades (same in the US interviews), and a couple of interviews did not turn out as expected, which meant that the participants replied "I don't know" to a lot of the questions. During those interviews less probing were used to end them as soon as possible. All interviews were recorded and transcribed, my interviews have been transcribed in Swedish and the US interviews in English. It is worth mentioning that I have done the transcription of all the Swedish interviews myself.

The issue of transcription is not discussed or problematised that often, even though transcribing in itself can be understood as an interpretative practice, as the beginning of the analysis, and evokes ethical concerns (Kvale \& Brinkmann, 2009; Lapadat \& Lindsey, 1999; Mischler, 1991; Tilley, 2003). Researchers make many choices as to what to transcribe and how to do it, which affects the text that we later analyse and quote. Completeness is not possible; rather, the researcher should reflect on how the transcripts need to look in order to be useful in the particular study (Hammersley, 2010; Kvale \& Brinkmann, 2009). Lapadat and Lindsey (1999) add that reflexivity is needed in the act of transcription. In my group interviews it was sometimes difficult to hear who was speaking, even though I repeatedly listened to the recordings to try to figure it out. I tried to listen to when the processes changed and the shifts of speakers but sometimes I could not be sure that "Allie" was "Allie". I always tried to hear and name the different participants, but it was not always possible. It was not always easy to know where and when I should type a comma or a dot, and how would a comma or dot affect how the participant in our conversation was represented (Mischler, 1991)? Most often a new section would start whenever I asked a new question. This means that I cannot guarantee that "Allie" is not "Paula" on occasions. This is of course problematic because it becomes problematic to follow a specific individual's argument and how it changes. However, my transcriptions have still captured the social processes and various negotiations made during the interviews. Hence, it was not always easy to hear what was being said during the 
individual interviews either. On these occasions I (and the US team) marked in the transcript that we could not hear what was being said [Inaudible].

\section{Table 2: Example of transcription}

\begin{tabular}{|l|l|}
\hline Girl, grade 6, interview 21 & $\begin{array}{l}\text { Participant: you are scared sort of } \\
\text { that those who bully sort of will do } \\
\text { something worse }\end{array}$ \\
& $\begin{array}{l}\text { Interviewer: ok. What do you } \\
\text { believe, how come people do these } \\
\text { things when the teachers are not } \\
\text { present? }\end{array}$ \\
\hline
\end{tabular}

Otherwise, the interviews were transcribed word by word as in the example above, using the participants' wording. To perform my grounded theory coding I retained space for my word by word, line by line coding to the left in the document. I named every interview in the left corner on top of the transcript. Sometimes I have not transcribed parts of the interview that are not connected at all to the study, and I have not always transcribed the ending part of the interview when I ask if the participants have something to ask me. The US research team transcribed everything verbatim. Noted in the transcripts were such things as laugh, repetitions of words, hesitations, when someone entered the room and pauses or interruptions took place. Readability further evokes concerns of how to represent the participants. For example, if the researchers recurrently position the participants as hesitating and repeating their own words, this may portray them as "childish" and as "less knowledgeable" (Fernqvist, 2010), and it may also make the excerpts less readable. Quotes have therefore sometimes been made more readable, but in those cases clarifications are highlighted.

The interviews and transcriptions are viewed as constructed by the researcher and the participants through our social interactions during the interviews and the researchers interpretations and 
transcriptions of the interviews. Questions asked, ideas during the analysis and theoretical sampling are constructed by the researcher(s) and influenced by earlier experiences and interpretations. For example, in paper II, we were three different researchers who conducted the interviews, we do not believe that our interviews took the same direction and that we probed for the same things.

\section{Researcher Positioning}

Interviews take place in a social context; they are performative and evoke roles and identities to play during the interview (Charon, 2009; Denzin, 2001; Mead, 1934). Razon and Ross (2012) discuss how identities are negotiated throughout the data collection process. I would add that these identity negotiations were already taking place from the moment I entered the schools and tried to recruit participants, While I have highlighted that I (and the US research team) have viewed the students as experts and how this may have framed their role during the interviews, it is worth recognising that some of the information that the students discussed had no clear link to the school context. By interpreting how the participants were active meaningconstructors during the interviews by incorporating other contexts into our interviews, this could exemplify that the participants had the position to frame the processes. The research strategies and approaches from the sociology of childhood may have influenced this and indicate that the students had a position to frame the interview process (Fernqvist, 2010).

There were also moments during the interviews, for example when I asked a boy if he could tell me about a bullying event that he had heard or seen, and he replied: or experienced. This was a special moment during the data collection; not only was his reply really brave, but it also indicated that the student was actively engaging in the interview and had positioned himself as knowledgeable about what interviews on bullying in school should contain. His response affected the later interviews. In later interviews a question was incorporated that would pave the way for this kind of reply by instead asking if they had heard, seen or experienced any bullying situations. This addressed how the first interview question was focused on the bystanders' 
perspective and it therefore seemed important to add experiences so that students would be able to address their own bullying experiences as well.

If we consider possible roles and identities during the recruiting process, it is noticeable that more girls chose to participate in my studies. One explanation is that there were predominately girls in some of the school classes I visited, but in some classes the number of boys and girls were equal. However, the fact that fewer boys chose to participate did puzzle me, since I perceived that I had a good connection with them while visiting the participating schools. In fact, it felt easier to communicate with the boys, since they often initiated communication with me, but fewer boys handed in their consent letters. Independent of my own experience where I sensed a connection especially with boys in the schools I visited, maybe I did not manage to build as trustful relationships with as many boys as girls, since they to a lesser degree chose to participate. If and why this happened is difficult to know; could it be that they regarded me as someone they could not trust? Was I regarded as someone not worth talking to, or did my research agenda seem uninteresting or boring? Could it be a gender issue? Did they perceive that they had nothing to contribute on the topic? Was it a peer norm in the class? Others have identified a similar issue when trying to recruit men for studies on friendship (Butera, 2006) and paid domestic labour (Kristensen \& Ravn, 2015), and have suggested that gendered identities may be at play, when men may perceive the research agenda as threatening where there is a female researcher but have also positioned the research topic as feminine.

In terms of gender, several boys commented on the fact that only girls participated during my last data collection (paper IV). At one point, when I was alone with all of the girls in one of the school classes for this study, the boys were outside yelling and banging on the doors, some of them even shouting out that they felt discriminated against. Later on during my group interview with this class, the girls, while speaking of their social worlds, discussed several incidents where the boys in the class had constantly kept harassing them and did not listen to any protest from the girls. While being in the ongoing situation in the classroom and having the boys outside, gender positions were negotiated. Maybe I had contributed to reinforce this negotiation by interviewing girls only. I had tried to explain to the boys that their 
teacher was going to start the lesson ten minutes later because I was talking to the girls, but they continued to bang on the door. They did not become silent until a teacher in the classroom next to theirs, a male teacher, told them to stop. In this situation I was there in their school and may have been interpreted as a stranger, a visitor, but I may also have been viewed as a female.

While trying to take a role as a least-adult, utilising the leastadult non-judgmental approach, during my recruitment processes and contacts with the students, (Mandell, 1991), I sometimes positioned myself as part of the participants' norm systems by wearing certain clothes and symbols that seemed important in their contexts. I was also marked as female and white and as someone who could be used as an object to construct ideas around during the interviews. I was not always included in their activities, and students who did not participate sometimes made contact with me while others did not. On other occasions, younger students interacted with me on the playground although they were not participating in the study. The way I perceived it, they positioned me as a helper, which may indicate that the younger students had ascribed to me an adult or teacher role when had me help them to put on their gloves. Furthermore, my presence sometimes made the students turn to me and ask whether certain actions could be viewed as bullying; I ended up responding with "I don't know, what do you think?"

Lastly, as I delved deeper into the data by listening and conceptualising the students' perspectives, my definition of bullying and my definition of my own experiences were affected. At first I sometimes had issues with the students' perspectives on bullying as I sometimes thought that what they were describing was not bullying. I therefore realised that I had been occupied with interpreting their perspectives on bullying from an adult-research perspective. However, from their perspectives I later came to analyse my own experiences and realised that if their perspectives could be interpreted as bullying, I had taken part in bullying incidents. In the beginning, when the students asked me if I had been bullied, I answered by saying no to these questions but that I had heard about bullying taking place. Later in the research process I was still replying that I had not been bullied, but that I had had experiences of being teased for a while and that I had seen bullying taking place, but without providing them with detailed 
descriptions. By changing my reply, I clearly had been emotionally affected by the students' perspectives, as they made me redefine my own experiences and view these in a different way. The question of whether these experiences of my own count as bullying or not is therefore a matter of how I do define and have defined a situation. However, this positions me as emotionally affected, and even if the participants had not been aware of my shift in perspective, their own perspectives clearly influenced how I perceived bullying. Being emotionally affected and affected by the participants' perspectives might also be an example of how I took the role of the other (Charon, 2009; Mead, 1934). Taking the role of the other might here refer to how my interactions with the participants influenced my interactions and interpretations I had with myself and my experiences.

\section{Analysis}

It can be difficult to grasp the analysis processes in a qualitative study since they require a continuous back-and-forth movement, not only between the different levels of coding procedures but also between data collection and data analysis. Three of the four papers in this thesis rely on a grounded theory approach. In paper II, the Swedish material was analysed with grounded theory and our conceptual comparison coding was also inspired by grounded theory. My coding was influenced by Charmaz $(2006,2014)$ and Glaser's $(1978,1998)$ coding procedures. The following steps were undertaken in my research process: initial, focused and theoretical coding, and further explorations by using constant comparisons, memos and theoretical sampling (Charmaz, 2006, 2014; Glaser, 1978, 1998). I approached my analysis by coding the interviews using gerunds since I coded for actions and processes. Throughout my initial coding I went through the interviews line-by-line and word-by-word.

While coding I wrote analytical reflections about my codes and elaborated ideas on what the participants were saying. I highlighted words or wrote myself questions to be followed up in new interviews or while reviewing the coded interviews. These analytical reflections were kept in a separate document and are referred to as memos (Charmaz, 2006, 2014; Glaser, 1978). These memos have been very 
important for the construction of my findings. I have elaborated ideas, constructed illustrations of possible links between my codes, and written long free-form reflections. From the beginning, my memos were fragmented and mostly contained different reflections on various codes. Eventually they became more text-driven and analytical as my coding and data collection continued. My memos were also the link between different interviews and thereon functioned as the binding link for comparing my codes and categories. I reread my memos occasionally while also revealing new links between codes. I also corrected some of my reflections and code names as I developed conceptualisation.

It can be unclear when changes occur between the different coding procedures since they are not considered linear (Charmaz, 2006, 2014). Therefore I cannot pinpoint exactly when I moved to focused coding. However, after going through my material several times and writing endless memos, trying to arrange my codes and comparing them, I started to see patterns in my material that I identified as focused codes, codes that kept returning. When I entered focused coding I analysed the preceding interviews with a focus on these codes, meaning that I no longer analysed every line or word but rather allowed the focused codes to guide my further data collection and analysis. Therefore at this point I narrowed my focus since I had identified what seemed to be a set of plausible theoretical concepts (Charmaz, 2014). Some of the codes that frequently occurred during the initial coding of my first paper were 'friendshelping', 'being scared', and 'it depends'. I then went through my interviews and memos, keeping these codes in mind, and asking analytical questions such as when, why, and to whom, in order to further construct the actions in my material and put pieces together by focusing on these codes. This elaboration helped to identify what to further look for in my already collected and coded interviews where I went through them again, but also made me aware of aspects to further explore. This iterative process could be understood as theoretical sampling (Charmaz, 2006, 2014), which aims at broadening and refining the codes/categories (Leigh-Star, 2010) and letting the researcher know what analytical leads to further explore in the upcoming data collection. In the table I illustrate my different levels of coding of one of the categories from paper I. 
Table 3: Example of coding paper I

\begin{tabular}{|c|c|c|c|}
\hline Initial coding & Data & Focused coding & $\begin{array}{l}\text { Theoretical } \\
\text { coding }\end{array}$ \\
\hline $\begin{array}{l}\text { Knowing-depending, } \\
\text { daring-affecting, being } \\
\text { scared, friendship } \\
\text { helping }\end{array}$ & $\begin{array}{l}\text { It depends, If it's } \\
\text { is someone I } \\
\text { don't know at } \\
\text { all, I would not } \\
\text { dare to approach, } \\
\text { but if it is my } \\
\text { best friend. }\end{array}$ & $\begin{array}{l}\text { Friendship } \\
\text { defining } \\
\text { Intervening } \\
\text { responsible } \\
\text { Situation } \\
\text { depending }\end{array}$ & $\begin{array}{l}\text { Defining } \\
\text { horizontal } \\
\text { relations }\end{array}$ \\
\hline $\begin{array}{l}\text { Hanging out in groups, } \\
\text { leader-bullying, fear } \\
\text { creating, inhibited by } \\
\text { fear, self-protecting }\end{array}$ & $\begin{array}{l}\text { Some people } \\
\text { hang out in } \\
\text { groups, and he } \\
\text { (eg.,the bully) is } \\
\text { the leader and he } \\
\text { starts to bully, } \\
\text { then no one else } \\
\text { dare to do } \\
\text { anything else, } \\
\text { they might want } \\
\text { to, but he might } \\
\text { bully them then. }\end{array}$ & $\begin{array}{l}\text { Social } \\
\text { hierarchical } \\
\text { Non-intervening } \\
\text { Self-protecting }\end{array}$ & $\begin{array}{l}\text { Defining } \\
\text { vertical } \\
\text { relations }\end{array}$ \\
\hline
\end{tabular}

In the elaboration of codes and categories as the ones in the table, ideas were incorporated from outside the material as a way to conceptualise my codes/categories and create an analytical conceptualisation. This is when I moved to theoretical coding. I realised that the students' wording of 'it depends' seemed to indicate an important process in their understandings of their bystander reactions. I tried to reflect upon this in my memos with further illustrations. After a while, when comparing and sorting my memos, I remember writing and repeating 'it depends' to myself, which was similar to what the students repeated in the interviews. I reviewed my material again with this focus, and 
asked analytical questions: When does it depend on, why does it depend, and what is it that depends? This brought me to the hypothetical theoretical conclusion that their bystander reactions depended on the situation, which led to an incorporating of 'the definition of a situation' concept, formulated by Thomas and Thomas (1928). I adopted 'the definition of a situation' as a theoretical code (Glaser, 1998) and sensitizing concept (Blumer, 1969). With this in mind I again went through my coded interviews and memos to elaborate on whether this concept could contribute to the construction of an analytical story for my data. This elaboration of the concept appeared to make, what Glaser (1978) refers to as, an emergent fit. However, according to Glaser an emergent fit states that the concept earns its place and relevance in the analysis and theory construction (Glaser, 1978). Wuest (2000) found the concept of emergent fit confusing and elaborated on the concept to understand its logic. Wuest (2000) reveals that theoretical concepts that are incorporated to make an emergent fit are worked upon through the constant comparison method, and when conducting new data the researcher compares the categories with concepts from the incorporated theory. For me, this meant that I elaborated on this concept by comparing how my categories and new interviews of the bystander reactions could be understood through the concept of 'definition of the situation'. This process could also be referred to as theoretical sampling, which aims to broaden and refine the codes/categories (Leigh-Star, 2010), and let the researcher know what analytical leads should be further explored in the upcoming data collection (Charmaz, 2006, 2014; Glaser \& Strauss, 1967).

The theoretical concept of 'the definition of a situation' turned out to be a fruitful concept for constructing an analytical story of my data and came to function as a core concept to which all my constructed categories in my first article were linked. Students' reactions and ways of reasoning on why they act and reason the way they do as bystander to bullying depend on five different 'definition of the situation' processes that the first paper concentrates on (emotions; relations; seriousness; victim's contribution; social roles responsibility). This is also an example of theoretical coding that aims to combine the categories constructed through focused coding in order to create an analytical story of the categories. This is done by 
comparing categories with categories both inside the data and by integrating theoretical categories/concepts (Charmaz, 2006, 2014).

Theoretical sampling can either be used to saturate a specific category or relations between categories (Charmaz, 2006, 2014). To engage in theoretical sampling it is pivotal to already have collected data where focused codes or categories have been constructed. In my research papers the processes of theoretical sampling were aimed at this, but depending on the on-going analysis and research process, my theoretical sampling looked different. This means that I sometimes elaborated on a specific category, and sometimes, as in the example above from my first paper, I elaborated on a specific theoretical concept from the literature (Thornberg, 2012; Wuest, 2000). On the issue of theoretical sampling, it is worth noting that I sometimes performed more than one interview a day due to social constraints in the schools. It is recommended for the purpose of theoretical sampling to code and create new questions in-between the interviews (Charmaz, 2006). This was done as often as possible, but it is also recommended that one return to the research participants to further explore theoretical ideas. I managed to return to some of my participants during the collection of interviews for paper III, otherwise I only had the opportunity to meet the participants once. Charmaz (2014) recommends that if the researcher only has the opportunity to meet the participants once to instead incorporate more interview questions and a lot of probing questions. This is what I have done and I have also been exploring categories and ideas with new participants.

Overall, I have tried to enhance the grounded theory approach throughout the whole data and analysis processes, and I have coded and written memos in-between my interviews. I stopped collecting interviews, partly because I could no longer construct any new ideas, but also because I had to due to time constraints. I did manage a few rounds of theoretical sampling where the categories constructed through my coding were further elaborated and refined through my data collection, and through the incorporation and elaboration of concepts, such as 'the definition of the situation'. There have been a lot of elaborations with how and what theoretical concepts to use to construct hypothetical relationships and understandings of my findings. Some of these theoretical concepts were rejected after I determined whether they fit with my findings or not. Theoretical 
sampling also illustrates why grounded theory is influenced by abduction through these movements of further exploration, by constant comparisons and the asking of analytical questions (Charmaz, 2014).

Theoretical sampling was also a part of how I reanalysed my interviews for paper III and paper IV in order to further explore my constructed categories as part of a new data collection processes.

The process with the third paper started during the data collection for paper I (and II) where early on in my interviews one important theme, or concern, occurred. The students were talking about the reasons why bullying occurs in addition to describing bullying incidents. I therefore added a question about this in my protocol, and I also made sure to always ask why a bullying incident took place to see how the students would respond. Thus, I began to explore and code students' perspectives on why bullying occurs as this emerged, and I considered it as a suitable focus for my third paper. This also made me reanalyse the already collected interviews with focus on students' reasoning on why bullying occurs to see if this aspect was mentioned there as well. In this process a couple of the already collected interviews were excluded since these did not address this question. While analysing my data, I soon discovered that the victims were described as 'responsible' and 'odd', but the participants also contextualised this 'oddness' in different situational contexts. I reanalysed my material with this focus, paying attention to the specific incidents mentioned, and could see a pattern of three different conditions. This situational context along with the different ways they defined the 'oddness' of the victim was added to my interview protocol as important categories to further explore. Thereafter, I conducted new interviews following theoretical sampling procedures (e.g., Charmaz, 2014). Some of these interviews were with students I had already interviewed and some of these were with new participants. This is also an illustration of how the participants' perspectives were important for the construction of the study focus. A similar process was evoked when I found a focus for my fourth paper.

When working on paper III, I started to sense there was something happening in my data because gender and different bullying types was becoming important. This included distinctions between the kind of bullying that took place and whether it was gendered or not. This also portrayed girls' bullying as related to the peer group, and 
related to fights and unforeseen critical incidents. Mostly this addressed acts of indirect bullying. I reanalysed my material, paying specific attention to these aspects, and found a gendered pattern where girls spoke about these issues. This theme was developed as the focus of paper IV. I also changed my method from individual to group interviews to study these reflected processes in the setting where they were said to take place, and I only conducted interviews for my fourth paper with junior high girls.

In paper II, two teams initially performed the conceptual analysis separately. However, we soon started to share our initial analyses to pinpoint occurring themes and further the data collection process. Both teams constructed concepts of our different data sets, but performed different levels of analysis that aimed at concept development. The US team (Laura Wood, Jennifer Smith, Kris Varjas and Joel Meyers) coded their data with MAXQDA-11, and their data were coded into primary, secondary, and tertiary themes. Before performing the MAXQDA analysis, the US team used an inductive-deductive approach (Nastasi, 2009) where deductive theoretical coding was used for the primary codes, whereas inductive coding was used for the subsequent codes and included themes used among the participants. The US team further coded for interrater reliability (IRR) until $90 \%$ was achieved. Individual coding was performed on the remaining interviews, however the US team discussed all discrepancies until reaching $100 \%$ agreement. Even though we used different methods we shared similar principles for our analysis. Both of our analysis approached the interviews from different levels with individual coding as well as concept development. I used initial, focused and theoretical coding from a grounded theory approach (Charmaz, 2014; Glaser \& Strauss, 1967). I discussed my individual coding in detail with my supervisor Robert Thornberg. The teams entered the comparison analyses with a construction of one model each, constructed on concepts we had found in our respective data sets and with influences from our shared discussions and analyses. 
Table 4: Overview of concepts paper II

\begin{tabular}{|c|c|}
\hline Swedish concepts (Paper 1) & US concepts \\
\hline $\begin{array}{ll}\text { 1. } & \text { Definition of seriousness } \\
\text { 2. } & \text { Social roles and responsibilities } \\
\text { 3. } & \text { Defining victims contribution } \\
\text { 4. } & \text { Defining relations } \\
\text { 5. } & \text { Distressing emotions }\end{array}$ & $\begin{array}{l}\text { 1. Aspect of bullying incident } \\
\text { 2. Expectations of others' response } \\
\text { 3. Relationships and social status } \\
\text { 4. Perception of environment/sense of } \\
\text { safety } \\
\text { 5. Personal feelings and reactions }\end{array}$ \\
\hline
\end{tabular}

We then started to compare our concepts to identify differences and similarities by asking how students articulate and discuss what factors influence their own and other students' decisions to defend or not defend victims when witnessing bullying. When comparing our concepts, we at large developed shared concepts because we found large overlaps in our findings. Our team analysis was performed through constant comparisons of codes and concepts (Glaser \& Strauss, 1967) where we aimed to produce a shared and agreed interpretation of our data through "coordination through mutual adjustment" (Hall, Long, Bermbach, Jordan, \& Patterson, 2005). In this way we engaged in processes of "joint focus and dialogue among two or more researchers" (Cornish, Gillespie and Zittoun, 2014, p. 79). In this process of conceptual comparisons, we compared our individual codes and concepts and had open and critical discussions when constructing the shared concepts and theoretical understandings. This meant we moved back-and-forth between our individual data sets in order to analyse our interviews repeatedly to refine our concepts. Our analysis developed five broad factors that students articulated as important when making decisions of whether to defend a victim or not (e.g., (a) informed awareness, (b) bystander expectations, (c) personal feelings, (d) situational seriousness, and (e) sense of responsibility. 


\section{Ethical considerations}

This study followed the ethical principles constructed by the Swedish Research Council (Vetenskapsrådet, 2002) considering informed consent, confidentiality procedures in place for research use only. Informed consent was obtained from both caregivers and students for all students who participated. To address confidentiality, the names of participants, other people mentioned during the interviews, schools, and geographical locations are not revealed in the reporting. The participants were also informed that the interviews would be treated carefully and not shown to anyone nor would anyone be told what had been said during the interviews. Additionally, students were informed that no information on schools, names, or places would be revealed in the study. Although I had already been given informed consent, I further reminded the participants of this before conducting the interviews and let them again decide whether or not to participate. I also informed them that the interview was voluntary and they were not obliged to answer my questions if they did not want to.

Approval from the Regional Ethical Review Board was obtained prior to all data collection (dnr 2011/175-31) because the focus of my $\mathrm{PhD}$ project could be considered as ethically sensitive and since my data concerns underage participants. Prior to the data collection made by the US team, students and their caregivers were informed about the research project and consent letters was obtained. The project was also approved by their Ethical Review Board. I revised my approval when changing my data collection method from individual to pair and group interviews (dnr 2014/93-32.). To counteract the ethical concerns where someone might not be selected, I informed the students when handing out the consent letters that the option of doing an individual interview was available. Several participants wrote the specific names of whom they wanted to be interviewed with, and some wrote that they could be interviewed with any of the girls in the class. Overall, this strategy was very helpful, since the girls helped me to construct the constellations of these pair and group interviews. However, in one class one girl had chosen two other girls, but these two girls did not choose her back. This was something that I had feared might happen. I was a bit concerned with how this situation would be resolved. During my first 
interview in this class I therefore asked two other girls how they had come to choose each other, and what their thoughts were in general on these choices. They said that they thought all the girls could be interviewed with anyone, and they themselves had only written down some of the girls that they had come to think of. My strategy was therefore to further explore the possibilities for including this girl in the group she herself had wanted to be included in. The next time I returned to this class, the remaining girls to be interviewed started a conversation on who had or had not been interviewed already, which ended in their forming a new group that included all of the remaining girls, including the one who had not previously been chosen. Difficulties such as these could be particularly crucial depending on my intended research focus. In this example, the girls resolved my concern, but if they had not done so, my role as a researcher might have been forced to change. This could have involved actions such as rearranging the group constellations myself or involving the teacher to figure out what to do.

Ethical considerations were something I had to think through prior to my data collection because there was a chance I would receive sensitive information about bullying incidents and other sensitive topics associated with bullying or other situations. As stated earlier, I adopted a least adult role where I was not supposed to actively act as an adult or intervene when I found situations inappropriate. This included criticising, disciplining or correcting students based on their reported attitudes, perceptions, arguments or behaviours, or immediately tell a teacher about any current situations. Instead I maintained that I was there to listen and learn from them. However, knowing that a bullying situation might continue and being aware of the possible health effects caused me to have an ethical dilemma in terms of being an uncaring individual who I had read about in the literature. Furthermore, this made me carefully consider how to respond if this kind of situation would occur. My aim has been to regularly reflect on ethical considerations, and while doing so I have found that the ethical principle of informed consent was not enough. I incorporated a principle which Marzano (2012) calls "ethics of care as a guiding principle rather than informed consent" (p. 452), and by doing so I stayed open to what happened during the data collection and tried to stay prepared for different scenarios. 
Because the interviews encouraged in-depth considerations about bullying and included probing questions, this raised ethical considerations concerning sensitive information and eventual emotional distress for the participants when recounting their experiences. I had to decide when to stop questioning them and how to handle emotional distress. As Johnson and Rowlands (2012) state, I had to be prepared for the worst-case scenario and form an ethically sensitive plan for when to stop questioning, and instead adopt a commitment to the wellbeing of the participants (e.g., the psychological, emotional, physical, and social well-being). In one case during the interviews I handed out a telephone helpline card from BRIS (Barnens rätt i samhället, a telephone helpline for children). Sometimes I offered information but without handing out any specific helpline card. Instead I suggested a certain helpline organisation or project after the interview by asking, in a curious way, if the student knew if a certain organisation or project visited their school. I did not observe any situations in which I felt I had to intervene, nor did I have to stop any of my interviews because of participants' emotional reactions.

I did not ask for a specific experience when recruiting participants. Rather I was interested in learning about the students' perspectives on bullying, which then might include experiences of being bullied. However, during the interviews I never knew beforehand what kind of experiences the participants would discuss. This meant that I had to be open to all kind of stories, experiences and scenarios with a curious, non-judgemental and emphatic approach that meant I occasionally had to normalise these experiences, including my reaction when hearing them. This issue addresses the problematic aspect of building alliances with the participants rather than questioning them (Razon \& Ross, 2012) and acknowledging the distinction between a close and emphatic approach to your participants rather than adopting a distant and critical approach. This normalising approach was not always easy to maintain, especially when meeting students who told me about their experiences of bullying. In these moments I often validated their experiences. For example, if the participants told me that they had switched schools due to being bullied and were upset with the school for not having done enough I was empathic and agreed that the school should have helped them 
more. This process has been referred to as a "validation of the children's experiences" and was used by Eriksson and Näsman (2012) during their interviews with children who had been exposed to violence. They chose to adopt this strategy since they did not want to be positioned as neutral adults who accepted violent behaviours while acknowledging children's right to participate with care for their wellbeing.

I have also had emotional reactions to some of the interviews because I felt the participants were brave to share their experiences. Some of them also seemed to have a need to tell their perspective to someone who listened to them. This was obvious when some of them described past bullying events that ended with one of their bullied classmates or a bully leaving their school. The participants often said that they had not discussed this in school, and they were left feeling frustrated and concerned about what had really happened and how they would react to a similar situation in the future. During my data collection on junior high school girls' perspectives of bullying, it was more difficult to maintain a neutral position. In one of my interviews I was upset with their description of racial and sexual harassment and I pointed out that it was not ok to have these things happening to them. Several girls had described how their social worlds had appearancerelated demands and encouraged low self-esteem and they described how they tried to handle this. Afterwards at home I had to call one of my friends and point out that nothing has changed because their experiences reflected my own experiences of being a girl in junior high.

It would be fair to say that the participants' perspectives affected me, and I remember certain moments more clearly than others. This may be because these incidents or scenes affected me, or highlighted a critical moment from an ethical point of view or again pointed toward taking the role of the other (Mead, 1934). 


\section{Summary of Papers}

All studies have focused students' perspectives on bullying with qualitative interviews. Three out of the four papers have been conducted with a grounded theory approach, whereas the second paper was initially collected with a grounded theory approach while our conceptual, collaborative analysis was only partly inspired by grounded theory. Paper I, II and III have used individual interviews while the fourth paper used pair and group interviews.

\section{Paper I: Bystanders to Bullying: Fourth- to Seventh-Grade Students' Perspectives on Their Reactions, Camilla Forsberg, Robert Thornberg, Marcus Samuelsson (2014). Research papers in Education, Vol. 29, No. 5, 557-576.}

This study aimed at investigating bystander actions in bullying situations and reasons behind these reactions, as they were articulated among fourth to seventh grade students. Forty-three semi-structured individual interviews were conducted with students and analysed with a grounded theory approach (e.g., Glaser, 1978, 1998; Glaser \& Strauss, 1967). We adopted the constructivist version (Charmaz, 2006, 2014) due to our interest in what meanings students gave to bullying bystander situations and different bystander actions. Five different schools participated. The data and analysis were viewed as constructed through the work of the interviewer and the research team as well as through the interactions with the participants (Charmaz, 2006). Our analysis was performed in three phases: (1) initial, (2) focused, and (3) theoretical (Charmaz, 2006, 2014). The first author, who collected the data, spent two to five days in every class in order to make the students more familiar with the researcher. During her data collection, and interactions and conversations with students, including the interview situations, she avoided the position of authority in accordance with the 'least-adult role' (Mayall, 2008) and the 'friendly researcher' position (Ravet, 2007). She used a non-judgmental approach and treated the students as competent commentators of their social life. She explained to them that she did not work at the school as a teacher but instead was 
there as a visitor or guest in order to learn from the students about their experiences of and thoughts about bullying (Thorne, 1993). The analysis of the students' perspectives of being a bystander in bullying were complex and revealed five different definition-of-situation processes: (a) relations (friends and social hierarchy), (b) defining seriousness, (c) victim's contribution to the situation, (d) social roles and intervention responsibilities, and (e) distressing emotions. We found conflicted motives in students' reasoning about their bystander acts, which could evoke moral distress among the students. The contribution of our analysis is unique in that it introduces the concept of moral distress as a process that has to be considered in order to better understand bystander reactions and actions among children. The findings also indicated that bystander responses could be associated with moral disengagement, such as not perceiving a moral obligation to intervene if the victim is defined as a non-friend (it's none of my business'), protecting the friendship with the bully, and blaming the victim.

\section{Paper II: Students' views on factors affecting their bystander acts in bullying situations: A collaborative cross-conceptual qualitative analysis (submitted), Camilla Forsberg, Laura Wood, Jennifer Smith, Kristen Varjas, Joel Myers, Tomas Jungert, and Robert Thornberg}

The aim was to focus on how Swedish and US students articulate and discuss what factors influence their own and other students' decisions to defend or not defend victims when witnessing bullying. This study is a unique qualitative collaborative study where two research teams collected interviews from two cultural contexts. Eighty-nine students (43 Swedish students and 46 US students; 50 girls and 39 boys) with an age-range from 9 to 14 years old participated. The research teams collected the interviews individually (e.g., the first author collected all the Swedish interviews whereas the second and third authors collected all the US interviews). Interviews lasted approximately 30 to 60 minutes. The Swedish data set was collected from five different schools in different boroughs and cities. The US data have been collected from two different schools from one city in the Southeastern US. The same interview protocol was used throughout the data collection with 
adjustments made according to what the students focused on during the interviews. The students were asked to describe bullying situations and their and other children's reactions. They discussed how, why and when they reacted the way they did as bystanders. The results revealed five broad considerations and few differences among the students when they reasoned about how to react as a bystander in bullying situations: (a) informed awareness, (b) bystander expectations, (c) personal feelings, (d) situational seriousness, and (e) sense of responsibility. These considerations highlighted that each layer of bystander considerations could make the students more or less likely to defend as well as to defend in a certain way. According to these five broad considerations, students seemed to adjust their bystander acts, which suggest that students' bystander acts are situational. This study contributes, not only to the research on students' perspectives on bystander actions and with addressing how different factors are associated with different bystander reactions, but is also unique because it introduces a qualitative collaboration between two research contexts.

\section{Paper III: The social ordering of belonging: students' perspectives on bullying, (submitted). Camilla Forsberg and Robert Thornberg}

In this study, the aim was to listen to how students themselves discuss, reason, and made sense of how and why bullying processes emerges. To examine this, we adopted a symbolic interactionist perspective as a starting point. Forty-eight interviews with Swedish students (14 boys and 34 girls) from fourth to seventh grade, and with an age range from 10 to 13 years, participated in the current study. Semi-structured interviews were conducted and lasted approximately 30 to 60 minutes. The participants were asked to describe bullying incidents they knew of, what happened during these incidents, and why they happened as well as more general questions about why bullying occurs. Prior to the interviews, the first author who conducted all the interviews, spent 2-5 days in every class with the intention of making the students more familiar with her, in which she adopted a non-judgmental approach based on viewing and treating students as experts of their social worlds and with an openness towards and interest in learning about their 
experiences and understandings of bullying. In accordance with the least-adult role (Mandell, 1991; Mayall, 2000; Thorne, 1993) she avoided the position of authority. The data analysis in this study was guided by a grounded theory approach (Glaser, 1978, 1998; Glaser \& Strauss, 1967) based on a constructivist position (Charmaz, 2014) where (a) participants' perspectives were at the forefront of the analysis, (b) methods for analysis were used in a flexible manner, and (c) data were viewed as co-constructed by the researcher and the participants. This approach was suitable due to the interest in school bullying as a social process and the meanings the participants associated with bullying incidents.

Our findings suggest that social ordering of belonging appeared to occupy students in their interactions and as such seemed to be a core process of students' social life in general, but was also a way for students to understand what produces bullying. Social ordering of belonging refers to a complex process in which students positioned themselves and others in terms of social inclusion/exclusion and social dominance/subordination and addressed three subcategories that could produce bullying: (a) social hierarchical ordering, (b) peer ordering, and (c) new-member ordering. Our findings contributes with the process of social ordering of belonging that seemed to acknowledge that students strived for belonging and might be interpreted as negotiated belonging processes (Kraus, 2006). This identifies how membership and identities were constructed and negotiated, and as such were unstable and ongoing due to possible reordering's evolving from interpretations of conflicts, behaviours or changes as uncool, deviant or norm violating, in upcoming situations. The study contributed with adding that according to the students narratives, ongoing processes seemed to evolve in questions on 'who belongs and why' that reinforced definitions of membership based on social hierarchies, activities, and being new or old in the group.

\section{Paper IV: Negotiating bullying identities: junior high school girls' perspectives (submitted), Camilla Forsberg}

The aim with the present study was to take an explorative approach towards junior-high school girls' subjective perspectives of bullying by carefully listen to how girls themselves discuss and reason on bullying. 
This study consists of 10 semi-structured pair and group interviews with 40 seventh- and eighth grade girls. As part of the informed consent letter, the participants were asked to select the constellation for the interviews. This was done to put them in familiar settings while discussing possible sensitive issue. Furthermore, the participants were considered experts of their social worlds, therefore a non-judgmental and open approach for learning from their perspectives guided the research process (Mandell, 1991; Mayall, 2000; 2008, Thorne, 1993). The girls in this study came from three different schools divided between three neighbourhoods. The interview was open to what the participants wanted to discuss and probing questions were used to further elaborate on their perspectives. The constructivist grounded theory approach guided both the data analysis as well as data collection methods (Charmaz, 2006, 2014), and data analysis were performed in three phases (initial, focused and theoretical coding) (Charmaz, 2006, 2014).

The findings revealed that bullying could be understood as a social identity process where three different identities were constructed: (a) the gendered identity, (b) the victim identity, and (c) the socially valuable identity. Throughout the participants' discussions, these identities were negotiated and evoked positioning of both themselves and others. A crucial aspect in these negotiating processes were the concept of self-confidence that functioned as an indicator of who was and who was not self-confident. Bullying therefore appeared to be an identity project, where self-confidence was negotiated and changeable and as such the identities in bullying. Self-confidence was socially valued but constrained by a gender- and a normative peer structure where pressure to fit in made it difficult to have both self-confidence and have a socially valuable identity. These negotiations were theoretically approached by incorporating the perspective negotiated order (Strauss, 1978). Negotiated order stresses how social order is negotiated and ongoing, as well as how actors, while negotiating, are constrained by social structures. As such this perspective was crucial when addressing the ongoing processes and social constraints of a gendered structure and a normative peer structure that affected their self-confidence and made fitting in central but difficult to combine with self-confidence. 


\section{General Discussion}

In this chapter I will discuss my main research findings. Thereafter I will reflect on the strengths and limitations of this study and discuss some possible pedagogical implications of my study.

\section{Main Research Findings}

In this thesis I set out to explore students' perspectives on bullying, more precisely fourth- to eighth grade students' perspectives on bullying. Several points were made as to why this would be an interesting focus, but one of the most critical starting points was an identified need to address students' perspectives, as these had not been a large part of the bullying discourse nor in research. In that sense I wanted to contribute to the small but growing body of qualitative research on students' perspectives on bullying. While taking my starting point in a philosophical and theoretical framework that addressed perspectives and knowledge as constructed through social interaction, it was clear that both the researcher's role and the role of the participants together were considered to be involved in the act of construction. As such, the outcome and the findings of my studies are provisional and could have been portrayed differently if data had been collected in a different context, with a different researcher, or with other participants.

Nevertheless, the four studies in this thesis build on each other as the students themselves discussed aspects which were then further examined in the upcoming studies. In the first two studies I set out to study students' perspectives on being bystanders to bullying. During the research process students discussed why bullying took place, and this became the focus of my third paper. As part of the description of different bullying incidents and types of bullying, gendered normative issues seemed to be articulated by the girls. This eventually made me focus on girls' perspectives on bullying, which was the focus of paper IV. In these four studies several social processes and an array of factors were identified when the participating students discussed bullying. The interpretation and conceptualisation of the students 
perspectives shared insights that have increased our understanding of students' perspectives on bystander responses and bullying. Altogether three processes were identified in the different studies: (a) the definition of the situation as a guiding principle for students bystander responses; (b) the social order of belonging as an explanation to and discussion of different contextual situations in which bullying could be produced, and (c) bullying as negotiated identities, an example of how bullying could be understood as a social identity process. In this final chapter of my thesis I want to focus on the overall reflections of the contribution of these findings by comparing them with previous research.

\section{Bystanders Situational Reactions}

These papers on students' perspectives on bystander reactions (paper I and II) contribute with adding students' perspectives on bullying and the process of defining bystander roles in these situations. Our findings confirmed previous research findings that students assume a range of participant roles (e.g., Salmivalli, 1999) by interpreting the bullying situation (Bellmore et al., 2012; Rigby \& Johnson, 2005; Thornberg, 2010; Thornberg et al., 2012). The present studies further identified similar factors found in previous studies, such as where emotional reactions based on the belief that bullying is wrong strengthened students' need to intervene (Bellmore et al., 2012; Rigby \& Johnson, 2005; Brinkmann \& Manning, 2015; Thornberg, et al., 2012). However different barriers made this response difficult (Brinkmann \& Manning, 2015). Instead the students' positions in the social hierarchy (e.g. age and popularity) become crucial (Bellmore et al., 2012; Rigby \& Johnson, 2005). Another similar factor acknowledged students' ability to determine what counts as bullying and how to respond to it (Rigby \& Johnson, 2005; Thornberg, et al., 2012). Students based their decision on whether a situation is harmful or not by interpreting different acts as more or less harmful (Bellmore et al., 2012; Thornberg, 2010; Thornberg, et al., 2012). Students are also seeking clues about whether it is harmful by focusing on the victims' reactions (Patterson et al., 2015) or determining the situation through knowing the people involved (Thornberg, 2010). 
As found in both of the bystander papers in the present study (I and II), and in a previous study, being friends with the victim turned out to be an essential factor for intervening (Thornberg et al., 2012). However, friendship could also evoke dilemmas where loyalties to maintain friendships, even if the friend was bullying, could instead evoke nonintervening or co-bullying (Thornberg et al., 2012).

Two processes were crucial among the participants (paper I and II) these were referred to as self-efficacy and moral disengagement processes. Both of these processes confirm previous research (Bellmore et al., 2012; Thornberg et al., 2012). Self-efficacy refers to the students' beliefs in being able to handle a situation in a way that will resolve it (Bandura, 1997), and it was evident that students did not always view themselves as able to do something either because of bystander fear interconnected with social hierarchies or not knowing how to respond. Moral disengagement (Bandura, 1999, 2002) was involved when different bullying situations or types of bullying were not viewed seriously or when victims were held responsible by being subscribed as deviant or odd. In these cases students sometimes said that they would co-bully or not intervene. Self-efficacy has been found as affecting students' bystander reactions (e.g., Pöyhönen et al., 2012; Thornberg \& Jungert 2013). A notable contribution from the findings in the present study (paper II) revealed that students had a generally higher perceived self-efficacy for intervening indirectly (telling the teacher or giving the victim social support) than for defending directly (e.g., telling the bullies to stop). This is an interesting contribution as self-efficacy seems to vary with different types of bystander reactions, and might be of interest to explore in future research.

By focusing on the students constructions of factors as a process, they described how they defined the different situations they encountered when constructing a suitable bystander role. According to how the students constructed meaning around these factors they seemed to contribute to a construction of situational bystander roles. The factors among both the Swedish and US students recalled a similar pattern, where the complex interplay of factors was interpreted. Nevertheless, sometimes these factors collided and revealed a bystander dilemma (Paper I). Therefore while some students felt they were capable of intervening or being involved in moral disengagement processes, other students recalled processes of moral distress. 
Processes of moral distress evoked by their bystander dilemma were identified as a third process among students and is conceptualised as painful feelings or psychological distress when a person is conscious of the morally appropriate action but cannot perform that action because of identified barriers (Jameton 1984; McCarthy \& Deady 2008). This third bystander process is a contribution from the present study (paper I) that has not been explored elsewhere.

Another issue identified in the present study, which has not been discussed previously, is earlier experiences of being a bystander or being a victim of bullying (paper II). Positive experiences of intervening, such as there being no negative consequences to standing up to the bully or going to the teacher to solve the situation, were associated with students saying that they would respond as bystanders in a similar way in the future. However, if their bystander response did not solve the situation, by making things worse or if the teacher/adult that they asked for help did not solve the situation or help the student, students were more likely to say that they would not respond that way again and that they actually did not know how to respond in the future (paper II). This response was especially directed at the school and the adults when they were viewed as not having helped the situation. Additionally, while Pattersson et al. (2015) found that students generally thought that those with earlier experiences of being bullied might choose to defend, those in the present study who said they had been bullied said that their earlier experiences made them want to do something about bullying in the future.

Overall, these two studies (paper I and II) add that interactional processes are ongoing and the different bystander reactions seemed to be constructed with reference to group processes among the students. Only a few differences were noted among the students in paper II (e.g, In the Swedish data victim contribution was more often mentioned; US students reported more differentiated between different types of bullying, and considered whether they could stand up themselves (direct defending) before going to the teacher (indirect defending) or not, whereas Swedish students said they could use direct as well as indirect actions when defining a situation as bullying). These similarities might be an effect of our interpretations, but as noted in previous research, these processes and factors might be of importance when students become bystanders to bullying. 


\section{The Social Ordering of Belonging Producing Bullying}

In this paper (paper III) students' explanations of bullying were understood as a complex core process referred to as the social order of belonging, a process that announced how students described their social interactions in school and how students positioned themselves and others in two dimensions: social inclusion/exclusion and social dominance/subordination throughout our interactions. This process was further interlinked with the students' explanations to bullying in which they discussed three different conditions that could produce bullying: (a) social hierarchical ordering, (b) peer ordering, and (c) new member ordering.

Previous research on students' explanations of bullying have pinpointed that it can either be understood as produced by peer pressure because of social hierarchies (Burns et al., 2008a; Erling \& Hwang, 2004; Thornberg, 2010) or by organising social relationships where inclusion and exclusions might occur (Bliding, 2004; Cadigan, 2002; Eder et al., 1995). Oftentimes bullying has been described as occurring either because of the victim (for a review, see Thornberg, 2011b) or the bully (Frisén et al., 2008; Thornberg, 2010; Thornberg \& Knutsen, 2011a, Varjas et al., 2008). Moreover, previous research has understood these aspects as social processes among the students where the positioning of the victim and the bully might be part of interactional processes among students (Thornberg, 2011b; Thornberg, 2015), with special attention to how the victim is defined as odd and deviant as being interpreted as a collective action aiming at constructing the 'normal us' (Thornberg, 2015a). Part of the core process of social ordering of belonging was the ongoing construction of deviance in these three different conditions where bullying were said to occur, and this functioned as an explanation as to why bullying occurred. While the findings in this study confirm previous research where students incorporate the victims, the bullies and the group processes as reasons for the emergence of bullying, this study adds to how deviance is constructed in three different contexts and how their social organising, deviance constructions, and construction of moral orders based on normative agendas (Ellwood, \& Davies, 2010) were a part of their understanding of how bullying emerges. Hence, this study also revealed that students' ways of defining and describing bullying incidents included aspects such as bullying based on sexuality or 
ethnicity, and this was incorporated into the students' definitions of bullying'. According to Swedish law (SFS: 2010:800), these types of acts might be referred to as discrimination rather than bullying. It is therefore important to address that the students in this study did not make the same kind of distinctions; rather they addressed these acts as bullying. This core process of social order of belonging also addresses the importance of fitting in with peer norms, which sometimes evokes a fear of exclusion.

\section{Bullying as Negotiated Identities}

In paper IV, the girls discussed a complex system of negotiating identities as important for understanding bullying. This included three identities: the (a) gendered identity, (b) the victim identity and (c) the socially valuable identity. These identities were discussed in terms of bullying and negotiated in terms of the concept of self-confidence that was interlinked with the position of a socially valuable identity. Throughout their perspectives, a negotiation based on self-confidence, a concept that functioned as an explanation as to why girls used indirect bullying, was revealed. In this study the social expectations, in terms of gendered appearance-related demands and agency norms, were described as causing lower self-confidence among girls. By incorporating the concept "generalised other" (Mead, 1934), others were positioned as crucial for increasing and/or decreasing their selfconfidence and identities, which highlighted normative peer structures and a gender structure. A socially valuable identity was crucial since it was interlinked with fitting in rather than being excluded and positioned in the undesirable victim position. However, these identities revealed complex negotiating pattern' because what in one sense could position someone as socially valuable, could in another sense cause low self-confidence and evoke a position of low self-confidence or social value. For example, by not fitting in to gendered appearance norms or agency norms, one could be positioned as self-confident and socially valuable, but this person took a risk by not fitting in which in turn could evoke a victim position that was associated with low social value and less self-confidence. Fear of exclusion and striving to fit in to peer norms, including gender norms, was therefore crucial yet problematic. 
This study (paper IV) revealed a complex interplay between these three identities and how they were understood and acted against. Furthermore, these negotiations contributed with how bullying could be understood as an identity process and, according to the girls in the study, be interlinked with a gendered social order. The negotiations of identities highlighted the importance of gender and (hetero)sexuality. This confirmed findings where identities of gender and sexuality have been revealed as important for understanding bullying (e.g., Currie et al., 2007; Jennifer, 2013; Ringrose, 2008, Ringrose \& Renold, 2009). In this study this reflected the statements made in previous research where gender norms (Rivers \& Duncan, 2013), popularity (Duncan, 2004; Duncan \& Owens, 2011) and appearance are considered crucial among girls and constructed in their bullying episodes (Besag, 2006; Owens et al., 2000). In this study the girls constructed bullying as a gendered phenomenon where girls used indirect bullying and boys physical bullying. Even though their discussions were conceptualised with the concept of negotiated order (Strauss et al., 1963; Strauss, 1978), which contributes with focusing on what orders are being negotiated, the negotiation itself reveals that these negotiated identities and their interlinked conceptions among the participants were ongoing rather than static. This study further contributes with the girls' subjective experience of making a connection between indirect bullying and gender, but they constructed bullying as an identity process where self-confidence was considered crucial throughout their negotiations and discussions.

\section{Bullying as a Social Process}

In the present thesis it has been highlighted how bullying and related themes could be interpreted as giving insights to what objects are considered important to the students when discussing their perspectives on bullying. According to symbolic interactionism, people act against objects according to the meaning it has for them (Blumer, 1969). An object could be other people, things, or situations that are interpreted and acted against based on people's interpretations. Altogether, in the participants constructions of deviance, the social order of belonging and the negotiations of identities, the social life with their peers and peer norms seemed to influence them. Their social 
lives with their peers influenced how students viewed bullying, bystander roles, the emergence of bullying and their own social selves, and these objects appeared to construct a shared perspective among the participants, acknowledging these objects as important in their constructions of their social worlds. In the present study, interactional patterns where they referred to their peer groups, peer norms and the construction of deviance appeared to be essential objects of their social life (e.g., Blumer, 1969; Charon, 2009). The constructions of identites and social norms affected their perspectives on bystander reactions, views on what causes bullying and evoked the construction of deviance. However, these different objects were negotiated, interpreted and ongoing. Bullying and interlinking activities could therefore be interpreted as a social process..

The interpretation of different bullying incidents and how these were part of their definition of bystander reactions indicated the importance of navigating in their social worlds. One of the interpreted outcomes is that depending on what kind of social moral and/or definitions of the situations that are viewed as critical in that particular moment will then influence what perspectives are taken. Different kinds of morals therefore appear to exist in parallel and these are constructed in the social interactional processes among students (Dewey; 1925). One does not always know the outcome of one's actions until afterwards when one reflects on the outcome (e.g., Dewey, 1925). Several outcomes were identified among the students when they considered their different bystander reactions: moral agency, moral distress and moral disengagement (paper I and II). This reveals that several morals exist, but that the social circumstances had a huge influence on how students defined how they would respond and why. However, when students mentioned how earlier experiences of being a bystander influenced their present beliefs and responses, some said that going to the teacher was no longer an option. This again points to how bystander reactions, and the associated morality, could change according to experiences (paper II). As found in a previous Swedish study (Frisén et al., 2008), the most common response among students on whether they had received help from adults when they were bullied was 'no'. The social constrains in the context, where it seemed dangerous for students to intervene, addresses that the morality of the peer group(s) evokes a different line of social morality. Peer 
moral(s) were indeed significant as they subscribed identities and evoked a social exclusion anxiety (Søndergaard, 2012), where partaking in the social ordering of belonging (paper III) or normative peer and gender structures to fit in (paper IV), became patterned regularities where the fear of not fitting in was strong. In a patterned regularity of striving to fit in, everyone desires to fit in, as fitting in recognises that you are included rather than excluded. In these kinds of processes, someone needs to be labelled with the least desirable position, the victim, to make others fit in (e.g., Thornberg, 2015a).

\section{For The Future}

The present study offers an interpreted picture of how students' perspectives on bullying could be understood as different kind of processes, where different responses are possible in different situations due to different opportunities and constraints (Närvanen \& Näsman 2007). These perspectives have been made visible by theorising these processes through symbolic interactionism and pragmatism, but there are still a few things that have not been fully explored in this study.

For example, how are the students' definitions of bullying, knowledge of bullying and bystander reactions influenced by how their schools engage with students and respond to bullying? Research on bullying oftentimes tends to focus of the individual bully's behaviours or the actions of the bystanders (Horton, 2011). In this way less attention is put on the schools and their activities. Horton (2011) stated: "The school often tends to disappear into the background, and becomes little more than the setting within which school bullying occurs" (pp. 114-115). The students often said that teachers responded more to physical bullying acts, as students themselves did. This would be of interest to explore, what are the issues taking place; what responses are occurring at different levels, including the teachers, students, parents and head teachers? For example Ahlström (2009) found that the role of the head teacher affected how teachers viewed bullying and in turn how students felt how their school worked against bullying. If the head teacher stated that bullying was not a major issue at the school, the teachers reacted to bullying based on this definition and students felt that their schools did not do enough against bullying. Studies have also revealed that teachers define physical bullying as 
more serious than non-physical and this affects their intervention responses (Mishna, Scarcello, Pepler \& Wiener, 2005; Yoon \& Kerber, 2003) and victim blaming (Mishna, Scarcello, Pepler \& Wiener, 2005). Furthermore, teachers experience different kind of barriers, such as not knowing how to respond because of lack of knowledge, institutional norms and barriers with how issues such as bullying are handled. Additionally their workload and colleagues opposing actions affect whether there is a joint approach to bullying (Meyer, 2008). These processes are similar to those found among students in this study.

In all of the studies, the definition of bullying was acknowledged in one way or another and seemed to be a crucial issue for the participants' perspectives on bullying, their negotiated identities and how to act when witnessing bullying. Previous research has revealed that students and adults might have different views on what counts as bullying (Cheng et al., 2011; Compton, Campbell, \& Mergler, 2014). The teachers/adults perspectives' were not explored in my study, but I do know that the students sometimes referred to not knowing what counted as bullying and did not make distinctions between discrimination and bullying as the Swedish school legislation do (but several international bullying researchers in contrast do not but instead identify bullying based on discrimination (e.g., Cowie \& Jennifer, 2008; Davies, 2011; Duncan, 1999; Ellwood \& Davies, 2010; Rigby, 2008). In this study students' ways of making distinctions between different bullying acts were interpreted as a possible example of moral disengagement or an example of the construction of bullying in their peer groups. However, one cannot totally dismiss that among researchers and adults, the perspectives on bullying are shifting and the ways that teachers respond are shifting as well. Of course, how the students come to define and make sense of bullying is interpreted in their peer groups (Corsaro, 2011), but not without linking the definitions and actions made among adults. Hence, in this study the students' perspectives are at the forefront and viewed as important to study in their own right. Future research might focus on how different mechanisms and different interactional patterns influence how bullying is understood and handled. These studies might focus on what processes are important for bullying and/or other interlinked issues to occur, what similarities and differences can be found. These studies should also include micro-interactional analysis as presented in this 
study, but as bullying could be understood as a complex phenomenon where researchers need to use different methods and approaches to understand it (Thornberg, 2015b).

I have discussed the issue of gender, as this was part of the way the junior high school girls' discussed bullying. I have not however discussed whether boys would have had a different perspective compared to the girls. It has been claimed that the social context affects the perspectives, which means that the processes addressed among the junior high school girls in my study could have been different in another setting. It has also been found that girls more often include issues of indirect bullying as part of their definitions (Frisén et al., 2008), which was also found in my individual interviews previous to collecting pair and group interviews. Further, Frisén et al. (2008) found that girls to a larger extent included the victims' experiences as part of their definition of bullying. This is interesting in the discussion of developing the definition of bullying, where it has been suggested to consider the victims experiences of the action (Volk, Dane \& Marini, 2014). As Frisén et al. (2008) noted, the definition that has been largely used among researchers is better suited to the definition provided by the boys and suggests that boys' views on bullying might have been given more attention in previous research. There is also the issue of boys not choosing to participate and whether this was a gendered issue or not has been previously discussed. However, future research might involve collecting group interviews with boys as well. If found suitable, mixed groups might also be used. Hence, ethical issues might be raised as we should not forget that sexual bullying might be ongoing among boys and girls (Duncan, 1999) and gendered relations might affect the interview (Pini, 2005). The issue of gender might also be further explored when it comes to bystander responses, as bystander responses might be gendered (e.g., Thornberg \& Jungert, 2013).

Besides the fact that other social identities were sometimes made visible when the students discussed bullying, involving issues of sexuality, ethnicity, and so forth, these aspects are necessary to consider in future research. Future research might focus on how students uses different identities as part of their explanations to bullying, but also how these aspects might be involved in 
schools/teachers way to approach bullying and interlinking issues, and the emergence of bullying.

\section{Strengths and Limitations}

The grounded theory approach provided me with tools for gathering and analysing data, but several points could still be made about this approach. Firstly, it is a time-consuming approach. It takes time to code, write memos and perform theoretical sampling to further explore the theoretical ideas constructed. I must admit, along with Charmaz (2014), that although the focus does eventually narrow, there is still the question of what would have happened if I had collected several more interviews, and this thought-process addresses the issue of time as well as how to perform grounded theory as a novice. Secondly, I sometimes found it a bit tricky to chose theoretical concepts. I remember my initial perception of data as fragmented and myself being worried that I would never create any categories, which according to Glaser (1978) is a normal phase for novice researchers. Thirdly, I also experienced anxiety around having too many codes. I do believe I could have both ended, directed and elaborated my data collection earlier in order to focus on the question of how students reason on and react as bystanders. However, one should not enter focused coding too soon because then the analysis will foreclose the interpretations and the risk of forcing external concepts on the data is overwhelming. Instead of foreclosing my interpretations and directing my data collection and analyses, I felt I was drowning in codes. I think this happened because I was a novice and because I coded everything. I was caught up in the analysis and data collection phases. It is only now upon reflection that I can actually see parts of what I have done.

Fourthly, there is also a contextual unawareness (Charmaz, 2006) in the constructivist grounded theory approach, where constraints in the context that are being researched are not accounted for. It was sometimes difficult to perform one interview at the time, and thereon I was not able to transcribe, analyse and update the interview protocol between every interview. Another concern involves the participants, where it is recommended to do follow-up interviews. This is not always easy because of social constrains in the context under study, in 
my case the context of school. Students might transfer from schools and sometimes they do not want to be interviewed a second time. The same could be said about the fact that ethical review boards require questions that have to be addressed before the data collection begins. The grounded theory approach stays open to the contexts under study. Although this study had a research question, there is also an openness about what happens in the data. Being constrained by organisational demands might affect this openness. This openness in research is also worth discussing. I do not believe that researchers are free to choose a context and then study what happens overall but without any specific focus in mind; this is not how our research community works.

Fifth, the level of microanalysis inherent in grounded theory has sometimes bothered me, and I have struggled with how not to overlook the political and ideological perspectives that might affect my participants' perspectives. This is a critique that has been raised against micro theories such as symbolic interactionism (Alvesson \& Sköldberg, 2009; Sandstrom et al., 2014). For me this articulated how to not overlook these issues by not forcing a pet code on the constructed theories (Glaser, 1978). I had to return to the symbolic interactionism literature and remind myself of the use of sensitising concepts (Blumer, 1969) that acknowledge how theoretical concepts could be used as possible theoretical lenses to include in the analysis. Even so these structural issues were not closely examined in my study.

Sixth, despite the theoretical and methodological package fit between the choices made in this thesis, there are still some critical concerns to contemplate. One prevalent concern is raised by Glaser (1998) who strongly rejects the idea of defining grounded theory as belonging to a certain epistemology or theoretical underpinning, such as symbolic interactionism and pragmatism. Glaser (1998) views this as forcing, and as such taking away the whole idea of grounded theory - staying open towards theoretical perspectives since they must earn their way into the grounded theory (Glaser, 1978). I did find my theoretical and methodological considerations to fit this research, and symbolic interactionism and some of its concepts were very helpful in my analysis. Glaser's critique might be understood in the light of a discussion of pure induction versus an interplay between induction (in which the researcher never can be tabula rasa) and abduction (e.g., Thornberg, 2012; Thornberg \& Charmaz, 2014). Glaser (1998) rejects 
that pragmatism influenced grounded theory, however he does not reject that there are signs of deduction in grounded theory. The fact that codes gets more narrowed, as part of theoretical sampling, readdresses the question of abduction since, as Dey (1999) states, this still means there is a complex relationship between complexity and reduction in grounded theory analysis. Dey (1999) has criticised this by identifying this conflict as inherent in the coding procedures. The reduction of complexity in grounded theory identifies a homogeneous tendency that I have struggled with. It has been difficult to decide what to include when entering into focused coding and later in theoretical sampling. This was a struggle, because according to the logic of abduction this imaginative exploration of codes is supposed to be continued. In the grounded theory approach it's suggested that the researcher should stay open to and collect data until no further ideas could be constructed, and to accept multiple realities and perspectives. On the other hand during the coding procedures the researcher has to decide which constructed codes/categories to further elaborate on (e.g., Charmaz, 2006, 2014). This often includes the most frequent codes/categories (e.g., Charmaz, 2006, 2014) or those related to the core category (e.g., Glaser, 1978). Even if it is possible to enhance or reveal the dynamics of one category through theoretical sampling and then with theoretical coding, some codes are lost along the way since they were not considered as important.

Seventhly, inherent in my theoretical and methodological framework is that I wanted to study students' perspectives on bullying, but I also viewed the researcher as a constructor. The struggle between complexity and reduction in the grounded theory approach for me represents how I became part of the construction when I made choices on what aspects to further explore and how this was acknowledged and how it influenced what had been addressed among the participants. In other words, what I interpreted was part of the construction of the perspectives of the students, but my interpretations and further data collection was always informed by what seemed to be the most crucial aspects in the students' perspectives on bullying. For example, this is apparent in how my research aims became more specific throughout the research process, which reveals how I interpreted their perspectives. 
Throughout this study I have tried to address my role as a researcher and the different dynamics at play when constructing my findings. This reflects my decisions, reflections and interpretations made during the research process and involved positioning myself, my experiences and my knowledge in order to reflect on how this coconstructed role influenced me. Furthermore, I therefore chose to work within a theoretical and methodological framework that enhanced this co-constructing role of the researcher while at the same time providing analytical and methodological tools for how this role of the researcher can be used in an analytical and reflexive way.

In qualitative research, to which this study belongs, the role of the researcher is one of the repeatedly criticised aspects. Qualitative research is based on subjective interpretations, which is said to make the findings of a qualitative research only important for the specific researched context and this makes it difficult for the findings to transfer to other contexts. Because of the situational character of interview statements that might have been different in another interview setting, interview research have received this kind of criticism (Maxwell \& Chmiel, 2014). Interviews do not capture actual actions but meaning constructions; we thereby collect social constructions (Arfwedson \& Ödman, 1998). Hence, in trying to describe the qualities of qualitative research these critical aspects have been incorporated and have evolved into different ways to account for, or reflect on, the role of the researcher and the multiple interpretations available to which the quality of qualitative research might be judged. These aspects could be referred to as a debate or ongoing discussions since there are multiple ways to conceptualise what defines quality in qualitative research and how to account for these matters (e.g., Corbin \& Strauss, 2008; Denzin \& Lincoln, 2011; Hammersley, 2007).

Firstly, one of the strengths with qualitative research is its focus on meaning constructions that emphasise nuances and ongoing social processes of changeable understandings among people (Patton, Hung, Patel, \& Kral, 2015). Secondly, qualitative research also assume that knowledge is context-bound, socially constructed and enhances the importance of researching people's subjective experiences (Charmaz, 2006, 2014; Patton, et al., 2015). The aspects mentioned above were inherent in the theoretical and methodological framework chosen for this thesis and guided my starting points, how I approached the data 
and my data collection procedures. By reflecting on my decisions and how these starting points were inherent in my thesis, I reflected on how my knowledge constructions and interpretations were made and some of the obstacles I experienced. Hence these starting points, which are common among qualitative researchers, also highlight the criteria for judging the quality of my research

In my starting points, and more precisely in the criteria for judging the quality of grounded theories, it is important to turn to the knowledge construction process to judge the quality. This involves carefully revealing how decisions were made throughout the research process, interpretations of the data, and the role of the researcher and how the findings could be used (Charmaz, 2006, 2014; Corbin \& Strauss, 2008; Glaser \& Strauss, 1967). I have revealed my research process and therefore have already touched upon these matters in the previous chapters when I discussed my recruiting processes, procedures for my interviews, positionings during the research process, research ethics and gave a presentation of my analysis procedures. By engaging in these practices, I have engaged in Glaser and Strauss' (1967) criteria for judging qualitative research, such as grounded theory. Therefore to judge the quality of my study these aspects could be referred to for grounded theory studies (Charmaz, 2006, 2014; Glaser \& Strauss, 1967), such as whether I have given enough details on my research process (Charmaz, 2006, 2014; Corbin \& Strauss, 2008; Glaser \& Strauss, 1967).

A common discussion concerning qualitative research addresses the dilemma of doing close readings of data and the relationshipbuilding aspect, where the researcher wants to understand the participants' perspectives. The researcher also interprets the data, which might be seen as a way to distance oneself from the participants. Charmaz (2014) stated that researchers do not uncritically report the participants' perspectives, rather we act on our data through our interpretations of it. This evokes a conflict in qualitative research, especially when doing close readings of the data while not wanting to be uncritical (Denzin, 2014). This is especially a conflict in grounded theory since the findings are supposed to be useful in practice and described so that "others can see and hear it" (Glaser \& Strauss, 1967, p. 228), and a heightened sensitivity towards the participants perspectives is required (Corbin \& Strauss, 2008; Charmaz, 2006, 
2014). This may be more of a problem when performing research with children. While the students in this study are viewed as experts of their social worlds and therefore have important knowledge to share with us about their social worlds, power imbalance between adults and children might be evoked. This power imbalance might make children communicate with an adult perspective, which according to Näsman \& von Graber (2002) could contribute to children's subordinate position. I have used a research approach that aimed at listening, probing and positioning the participants as experts. Further, I have announced the dilemmas of qualitative research with a researcher who interprets and acts on the data, the positions made throughout the interviews, and the fact that interview data is indeed based in subjective experiences and social constructions, which makes this dilemma difficult to resolve. Hence, as was mentioned earlier, the students' positionings during the data collection and recruiting processes reveals how their agency could be interpreted as a practice where they positioned me. This could be considered a strength of the role chosen for the researcher in this study, as it might uncover how it was possible for students to frame processes and position themselves as possessing knowledge (Fernqvist, 2010).

Finally, when writing my papers, I used many quotes to reveal the participants' perspectives to show how I made my interpretations. I tried to disclose the different positions taken, variations and constructing concepts that made a fit with the categories or processes articulated among the participants. As was described before, there is a tension in the grounded theory approach concerning the relationship between complexity and reduction (Dey, 1999), and this might have affected the amount of variations I disclosed in my analysis. Overall, these strategies aimed at revealing the richness in the data and making the participants visible for themselves in the data (Charmaz, 2014; Corbin \& Strauss, 2008, Glaser \& Strauss, 1967), to make the constructed theories fit the researched practice.

My aim throughout these chapters is to reveal the transferability of my study, which positions the reader of the study as the judge of the quality of my study (Charmaz, 2014, Glaser \& Strauss, 1967). This has been referred to as reader generalizability (Larsson, 2009). Whether my findings could be generalised includes a type of generalisation where the reader is allowed to judge my findings by the reading, interpreting and use of concepts and theories developed to answer 
questions about bullying. The reader and the user of these findings could be students, teachers or anyone who finds the concepts and theories helpful to further understand bullying.

\section{Usefulness and Practical Implications}

Hopefully I have presented my studies in a clear way, and I have identified concepts and processes of students' perspectives of bullying which could be useful for the broader school practice and elsewhere. Even though the processes mentioned do not claim that the students' definitions of situations and the factors involved to guide their bystander reactions will be the same in all circumstances, the process of defining the situation could be a useful tool for school practice. The same could be said about how bullying is understood through the social ordering of belonging and as negotiated identities. These two processes indicate how complicated bullying might be, including how normative identity constructions according to the students' narratives become a part of both their social relationships and bullying. The social orderings and identity positions do not have to be articulated in the same way, and they will not be since these are ongoing processes. However, the question of what social orderings and identity negotiations that are important in certain school contexts and how they are described might give important insights into how bullying could be counteracted and how it is understood in that particular context. With this said, I still want to argue that the students' perspectives on bullying as they were conceptualised and interpreted in this study offer insight into what might be going on among students and how this is linked with bullying and bystander processes in bullying. These perspectives contribute with both nuances and processes on bullying and have strengthened previous research findings.

Overall, the suggested practical implications of the research findings are:

- A focus on the dynamics of the social psychological processes, where group processes, social norms and identity negotiations were crucial for understanding bullying and bystander responses and could be used in 
discussions with students to have them reflect on possible consequences of certain actions and activities.

- Consider the wider social ordering, where identity negotiations based on issues such as gender, ethnicity and sexuality are interlinked with understandings of bullying.

- Attention to how bullying could be understood as a social identity process, where a need to fit in become crucial, which could either make it difficult to define actions against oneself such as bullying, or could be used to exclude and bully others. 


\section{References}

Adler, P.A., \& Adler, P. (1995). Dynamics of inclusion and exclusion in preadolescent cliques. Social Psychology Quarterly, 145-162. Adler, P.A. \& Adler, P. (1998). Peer power: Preadolescent culture and identity. New Brunswick: Rutgers University Press.

Ahlström, B. (2009). Bullying and social objectives: A study of prerequisites for success in Swedish schools. Umeå: Department of Sociology, Umeå University.

Alanen, L. (2009). “Generational Order”. In Qvortrup, J., Corsaro, W.A., \& Honig, M. (Eds.) The Palgrave handbook of childhood studies (pp.157-174). Basingstoke: Palgrave Macmillan

Alvesson, M. \& Sköldberg, K. (2009). Reflexive methodology: New vistas for qualitative research. Los Angeles: SAGE.

Archer, J., \& Coyne, S. M. (2005). An integrated review of indirect, relational, and social aggression. Personality and Social Psychology Review, 9(3), 212-230.

Arfwedson, G., \& Ödman, P. J. (1998). Intervjumetoder och intervjutolkning. En dialog kring ett kvalitativt alternativ $i$ lärarutbildning och skolforskning. Stockholm: HLS Förlag. Arneback, E. (2012). Med kränkningen som måttstock. Om planerade bemötanden av främlingsfientliga uttryck i gymnasieskolan. (Doctoral dissertation). Örebro: Örebro universitet.

Bandura, A. (1997). Self-efficacy: The exercise of control. Macmillan. Bandura, A. (1999). Moral disengagement in the perpetration of inhumanities. Personality and Social Psychology Review, 3, 193209.

Bandura, A. (2002). Selective moral disengagement in the exercise of moral agency. Journal of Moral Education, 31, 101-119.

Barbour, R. (2014). "Analysing focus groups" in Gubrium, J.F. (Ed.), The Sage handbook of interview research: the complexity of the craft, (pp. 313-326). Thousand Oaks: SAGE Publications

Becker, H.S. (1963). Outsiders: Studies in the sociology of deviance.

New York: Macmillan. 
Beckman, L. (2013). Traditional bullying and cyberbullying among Swedish adolescents: Gender differences and associations with mental health. Karlstad: Karlstads universitet.

Beckman, L., Hagquist, C., \& Hellström, L. (2013). Does the association with psychosomatic health problems differ between cyberbullying and traditional bullying? Emotional and Behavioural Difficulties, 17(3-4), 421-434

Bellmore, A., Ma, TL., You, JI., \& Huhges, M. (2012). A two-method investigation of early adolescents' responses upon witnessing peer victimization in school. Journal of Adolescence 35, 1265-1276.

Beran, T. (2009), Correlates of peer victimization and achievement: An exploratory model. Psychology in the schools, 46, 348-361.

Berger, P.L. \& Luckmann, T. (1966). The social construction of reality: a treatise in the sociology of knowledge. New York: Anchor books.

Besag, V. 2006. Understanding girls' friendships, fights and feuds: A practical approach to girls' bullying. Maidenhead: Open University Press.

Bibou-Nakou, I., Tsiantis, J., Assimopoulos, H., Chatzilambou, P., \& Giannakopoulou, D. (2012). School factors related to bullying: A qualitative study on early adolescent students. Social Psychology of Education, 22, 125-145.

Bliding, M. (2004). Inneslutandets och uteslutandets praktik: En studie av barns relationsarbete $i$ skolan, Göteborg: Acta Universitatis Gothoburgensis.

Blumer, H. (1969). Symbolic interactionism: Perspective and method. Englewood Cliffs: Prentice-Hall.

Borntrager, C., Davis, J.L., Bernstein, A., \& Gorman, H. (2009). A Cross-National Perspective on Bullying. Child youth care forum, 38, 121-134.

Bosacki, S.L., Marini, Z.A., \& Dane, A.W. (2006). Voices from the classroom: Pictorial and narrative representations of children's bullying experiences. Journal of Moral Education, 35, 231-245.

Brinkman, B. G., \& Manning, L. (2015). Children's intended responses to gender-based bullying as targets and bystanders. Childhood. doi: 0907568215595095. 
Brown, L. M., Chesney-Lind, M., \& Stein, N. (2007). Patriarchy matters: Toward a gendered theory of teen violence and victimization. Violence Against Women, 13(12), 1249-1273.

Bryant, A. (2002), "Re-grounding Grounded Theory," The Journal of Information Technology Theory and Application, 4(1), 25-42.

Bryant, A. (2009). Grounded Theory and Pragmatism: The Curious Case of Anselm Strauss. Forum Qualitative Sozialforschung / Forum: Qualitative Social Research, 10:3.

Bryant, A., \& Charmaz, K. (2010). "Grounded Theory in Historical Perspective: An Epistemological Account", in Bryant, A., Charmaz, K (Eds.), The Sage Handbook of Grounded Theory. (pp.31-57). Los Angeles: Sage publications.

Burns, S., Maycock, B., Cross, D., \& Brown, G. (2008a). The Power of Peers: Why Some Students Bully Others to Conform.

Qualitative Health Research, 18, 1704-1716.

Burns, S., Maycock, B., Cross, D., \& Brown, G. (2008b). 'Woodpushers are Gay': The Role of Provocation in Bullying. International Journal of Mental Health Promotion, 10(4), 41-51.

Burns, S., Cross, D., \& Maycock, B. (2010). "That Could Be Me Squishing Chips on Someone's Car." How Friends Can Positively Influence Bullying Behaviors. The journal of primary prevention, 31(4), 209-222.

Butera, K. J. (2006). Manhunt: The Challenge of Enticing Men to Participate in a Study on Friendship. Qualitative inquiry, 12(6), 1262-1282.

Cadigan, R.J. (2002). Scrubs: An ethnographic study of peer culture and harassment among sixth graders in an urban middle school. Los Angeles: University of California.

Caravita, S. C. S., Blasio, P. D., \& Salmivalli, C. (2009). Unique and interactive effects of empathy and social status on involvement in bullying. Social Development, 18, 140 - 163.

Cascardi, M., Brown, C., Iannarone, M., \& Cardona, N. (2014). The problem with overly broad definitions of bullying: Implications for the schoolhouse, the statehouse, and the ivory tower. Journal of School Violence, 13(3), 253-276.

Charmaz, K. (2006). Constructing grounded theory: a practical guide through qualitative analysis. London: SAGE. 
Charmaz, K. (2014). Constructing grounded theory. (2nd edition.) Thousand Oaks, CA: Sage Publications.

Charon, J.M. (2009). Symbolic interactionism: An introduction, an interpretation, an integration. Upper Saddle River: Pearson Education.

Cheng, Y., Chen, L., Ho, H., \& Cheng, C. (2011). Definitions of school bullying in Taiwan: A comparison of multiple perspectives. School Psychology International, 32(3), 227-243.

Clarke, A. (2005). Situational analysis: Grounded theory after the postmodern turn. Los Angeles: Sage Publications.

Clarke, A. (2015). "Feminisms, Grounded Theory, and Situational Analysis Revisited", in Clarke, A.E., Friese, C., \& Washburn, R. (Eds), Situational Analysis in Practice: Mapping Research with Grounded Theory, (pp. 119-154). Left Coast Press.

Compton, L., Campbell, M.A., \& Mergler, A. (2014). Teacher, parent and student perceptions of the motives of cyberbullies". Social Psychology of Education, 17(3), 383-400.

Corbin, J.M. \& Strauss, A.L. (2008). Basics of qualitative research: Techniques and procedures for developing grounded theory. Thousand Oaks: SAGE.

Corsaro, W. (2011). The Sociology of Childhood. Thousand Oaks: Pine Forge Press.

Cornish, F., Gillespie, A., \& Zittoun, T. 2014. "Collaborative Analysis of Qualitative Data “. In Flick, U. (Ed.), The SAGE handbook of qualitative data analysis, (pp. 79-93). Los Angeles: SAGE.

Cowie, H. \& Jennifer, D. (2008) New perspectives on bullying. New York: Open University Press.

Craig, W., \& Pepler, D. 1997. Observations of bullying and victimization in the school yard. Canadian Journal of Social Psychology 13, 41-60.

Craig, W., Pepler, D. J, \& Atlas, R. (2000). Observations of Bullying in the Playground and in the Classroom. School Psychology International, 21(22), 21-36.

Craig, W. M, Harel-Fisch, Y., Fogel-Grinvald, H., Dostaler, S., Hetland, J., Simons-Morton, B., et al. (2009). A cross-national profile of bullying and victimization among adolescents in 40 countries. International Journal of Public Health, 54, 216-224. 
Currie, D. H., Kelly, D. M., \& Pomerantz, S. (2007). 'The power to squash people': Understanding girls' relational aggression. British Journal of Sociology of Education, 28(1), 23-37.

Davies, B. (2011). Bullies as guardians of the moral order: Re-thinking the origins of bullying in schools. Children \& Society, 25, 278286

Deegan, M.J. (1986). Jane Addams and the men of the Chicago school, 1892-1918, Transaction Books, New Brunswick.

Denzin, N.K. (2001). The reflexive interview and a performative social practice. Qualitative research, 1(1), 23-46.

Denzin, N. K., \& Lincoln, Y. S. (2011). The SAGE handbook of qualitative research. Thousand Oaks: SAGE.

Denzin, N.K. (2014). "Writing and/as Analysis or Performing the World". In Flick, U. (Ed.), The SAGE handbook of qualitative data analysis, (pp. 569-584). Los Angeles: SAGE.

Dewey, J. (1925). The essential Dewey. Vol. 1, Pragmatism, education, democracy.

Dey, I. (1999). Grounding grounded theory: Guidelines for qualitative inquiry. San Diego: Academic Press.

Dixon, R., Smith. P, Jenks, C. (2004). Bullying and difference: A case study of peer group dynamics in one school. Journal of School violence, 3, 41-58.

Duffy, A. L., \& Nesdale, D. (2009). Peer groups, social identity, and children's bullying behavior. Social Development, 18(1), 121-139.

Duncan, N. 2004. It's important to be nice, but it's nicer to be important: Girls, popularity and sexual competition. Sex education, 4, 137-152.

Duncan, N. (1999). Sexual bullying: Gender conflict and pupil culture in secondary schools. London: Routledge.

Duncan, N., \& Owens, L. (2011). Bullying, social power and heteronormativity: Girls' constructions of popularity. Children \& Society, 25(4), 306-316.

Durfee, A. (2012) Situational ambiguity and gendered patterns of arrest for intimate partner violence. Violence Against Women 18(1): 64-84.

Eder, D. 1985. The cycle of popularity: Interpersonal relations among female adolescents. Sociology of education, 154-165. 
Eder, D., Evans, C.C. \& Parker, S. (1995). School talk: Gender and adolescent culture. New Brunswick: Rutgers University Press.

Ellwood, C., \& Davies, B. (2010). Violence and the moral order in contemporary schooling: A discursive analysis. Qualitative Research in Psychology, 7, 85-98.

Enander, V. (2011) 'Violent women? The challenge of women's use of violence in intimate heterosexual relationships to feminist analyses of partner violence' NORA - Nordic Journal of Feminist and Gender Research, 19, 105-123.

Eriksson Barajas, K. \& Lindgren, A.L. (2009) Den "rättfärdige" mobbaren: Elevers föreställningar om mobbning $\mathrm{i}$ skolbioaktiviteter i Utbildning och demokrati, 18, 111-130.

Eriksson, B., Lindberg, O., Flygare, E., \& Daneback, K. (2002). Skolan-en arena för mobbning. Stockholm: Skolverket.

Eriksson, M., \& Näsman, E. (2012). Interviews with children exposed to violence. Children \& society, 26(1), 63-73.

Erling, A., \& Hwang, C. P. (2004). Swedish 10-year-old children's perceptions and experiences of bullying. Journal of School Violence, 3(1), 33-43.

Espelage, D., \& Swearer, S. (2011). "Expanding the Social-Ecological Framework of Bullying Among Youth: Lessons learned from the Past and Directions for the Future". In Espelage, D.L. \& Swearer, S.M (Eds.), Bullying in American schools: A social-ecological perspective on prevention and intervention (pp. 3-10). Erlbaum: Mahwah, NJ.

Farrell, R.A. \& Swigert, V.L. (1975). Social deviance. Philadelphia: Lippincott.

Farrington, D. P., \& Ttofi, M. M. (2011). Bullying as a predictor of offending, violence and later life outcomes. Criminal Behavior and Mental Health, 21, 90-98.

Farquhar, C. (1999). "Are focus groups suitible for 'sensitive' topics?, In Barbour, R.S. \& Kitzinger, J. (Eds.) Developing focus group research: Politics, theory and practice (pp. 47-63). London: SAGE.

Fernqvist, S. (2010). (Inter) Active Interviewing in Childhood Research: On Children's Identity Work in Interviews. The Qualitative Report, 15(6), 1309-1327. 
Flygare, E., Frånberg, G.M., Gill, P., Johansson, B., Lindberg, O., Osbeck, C., Söderström, A. (2011). Utvärdering av metoder mot mobbning. Stockholm: Skolverket.

Fors, Z. (1995). Makt maktlöshet mobbning. Stockholm: Liber.

Freeman, M. \& Mathison, S. (2009). Researching children's experiences. New York: Guilford Press.

Frisén, A., Jonsson, A-K., Persson, C. (2007). Adolescents' perception of bullying: Who is the victim? Who is the bully? What can be done to stop bullying? Adolescence, 42, 749-761.

Frisén, A., Holmqvist K., \& Oscarsson, D. (2008). 13-year-olds' perception of bullying: Definitions, reasons for victimisation and experience of adults' response. Educational Studies, 34, 105-117.

Frånberg, G. \& Wrethander, M. (2011). Mobbning - en social konstruktion? Lund: Studentlitteratur.

Giles, J. W. and Heyman, G. D. (2005). Young Children's Beliefs About the Relationship Between Gender and Aggressive Behavior. Child Development, 76, 107-121

Gini, G. (2005). Bullying as a social process: The role of group membership in students perception of inter-group aggression at school. Journal of School Psychology, 51-65.

Gini, G., \& Pozzoli, T. (2009). "Gender roles and bullying: Behavior and motives in the peer context". In Urlich, J.h., \& Cosell, B.T.(Eds.), Handbook on Gender Roles: Conflicts, Attitudes and Behaviors, (pp. 93-12). Nova Science Publishers.

Glaser, B.G. (1978). Theoretical sensitivity: Advances in the methodology of grounded theory, Sociological press.

Glaser, B.G. (1998). Doing grounded theory: issues and discussions. Mill Valley: Sociology Press

Glaser, B.G. \& Strauss, A.L. (1967). The discovery of grounded theory: Strategies for qualitative research. New Brunswick: Aldine Transaction.

Goodwin, M.H. (2002). Exclusion in girls' peer groups: Ethnographic analysis of language practices on the playground. Human development, 45(6), 392-415.

Goffman, E. (1963). Stigma: Notes on the management of spoiled identity. Englewood Cliffs, N.J.: Prentice-Hall.

Goffman, E. (1990). The presentation of self in everyday life. London Penguin books. 
Granström, K. (2007). "Olika förklaringar till mobbning" i Thors, Christina (red). Utstött: En bok om mobbning, Stockholm: Lärarförbundets förlag.

Greene, S., \& Hogan, D. (2005). Researching children's experiences: methods and approaches. London: SAGE publications.

Hall, W.A., Long, B., Bermbach, N., Jordan, S., \& Patterson, K. (2005). Qualitative Teamwork Issues and Strategies: Coordination Through Mutual Adjustment. Qualitative Health Research, 15(3), 394- 410.

Hallberg, L. R. (2006). The "core category" of grounded theory: Making constant comparisons. International journal of qualitative studies on health and well-being, 1(3), 141-148.

Hamarus, P., \& Kaikkonen, P. (2008). School bullying as a creator of pupil peer pressure. Educational research, 50, 333-345.

Hammersley, M. (2007). The issue of quality in qualitative research. International Journal of Research \& Method in Education, 30(3), 287-305.

Hammersley, M. (2010). Reproducing or constructing? Some questions about transcription in social research. Qualitative research, 10(5), 553-569.

Hawkins, L., D., Pepler, D. J. and Craig, W. M. (2001). Naturalistic Observations of Peer Interventions in Bullying. Social Development, 10, 512-527.

Heinemann, P.P. (1972). Mobbning - Gruppvåld bland barn och vuxna. Stockholm: Natur och Kultur.

Horton, P. (2011). School Bullying and Power Relations in Vietnam. Linköping: Linköping university, Faculty of Arts and Sciences. Horton, P., Kvist Lindholm, S., \& Nguyen (2015). Bullying the meek: A conceptualization of Vietnamese school bullying. Research Papers in Education, 30(5), 635-645.

Hunter, S. C., Boyle, J. M. E., \& Warden. (2007). Perceptions and correlates of peer-victimization and bullying. British Journal of Educational Psychology, 77, 797-810.

Iadicola, P., \& Shupe, A. (2012). Violence, inequality, and human freedom. Rowman \& Littlefield.

Jamal, F, Bonell, C, Harden, A, Lorenc, T. (2015). The social ecology of girls' bullying practices: Exploratory research in two London schools. Sociology of health \& illness, 37, 731-744. 
James, A. \& Prout, A. (red.) (1997). Constructing and reconstructing childhood: Contemporary issues in the sociological study of childhood. London: Falmer.

James, A., Jenks, C. \& Prout, A. (1998). Theorizing childhood. Cambridge: Polity Press.

James, A. \& James, A.L. (2004). Constructing childhood: Theory, policy, and social practice. Hampshire: Palgrave Macmillan.

Jameton, A. 1984. Nursing practice: The ethical issues. Englewood Cliffs, NJ: Prentice Hall.

Jennifer, D. (2013). "Girls and indirect aggression". In Rivers, I., \& Duncan, N. (Eds.), Bullying: Experiences and discourses of sexuality and gender, (pp. 45-59). London: Routledge.

Johnson, J.M \& Rowlands, T. (2012). "The interpersonal dynamics of in-depth interviewing", in Gubrium, J.F. (Ed.), The Sage handbook of interview research: the complexity of the craft, (pp. 99-113). Thousand Oaks: SAGE Publications.

Kinney, D.A. (1993). From needs to normals: The recovery of identity among adolescents from middle school to high shool. Sociology of Education, 66, 21-40.

Kitzinger, J. (1995). Qualitative research. Introducing focus groups. BMJ: British medical journal, 29 (311:7000), 299-302.

Kitzinger, J \& Barbour, R.S. (1999), "Introduction: the challenge and promise of focus groups", in Barbour, R.S. \& Kitzinger, J. (Eds.) Developing focus group research: Politics, theory and practice (pp. 1-20). London: SAGE.

Kless, S.J. (1992). The attainment of peer status: Gender and power relationships in the elementary school. Sociological Studies of Childe Development, 5, 115-148.

Kowalski, R.M., Limber, S. \& Agatston, P.W. (2012). Cyberbullying: Bullying in the digital age. Malden, Mass: Wiley-Blackwell.

Kraus, W. (2006). The narrative negotiation of identity and belonging, Narrative Inquiry, 16(1), 103-111.

Kristensen, G. K., \& Ravn, M. N. (2015). The voices heard and the voices silenced: Recruitment processes in qualitative interview studies. Qualitative Research, 1468794114567496.

Kvale, S. \& Brinkmann, S. (2009). Den kvalitativa forskningsintervjun. Lund: Studentlitteratur. 
Lapadat, J. C., \& Lindsay, A. C. (1999). Transcription in research and practice: From standardization of technique to interpretive positionings. Qualitative inquiry, 5(1), 64-86.

Lahelma, E. (2004). Tolerance and understanding? Students and teachers reflect on differences at school. Educational Research and Evaluation, 10, 3-19.

Larsson, A. (2008). Mobbningsbegreppets uppkomst och förhistoria:

En begreppshistorisk analys. Pedagogisk forskning i Sverige, 13(1), 19-36.

Larsson, S. (2009). A pluralist view of generalization in qualitative research. International journal of research \& method in education, 32(1), 25-38.

Latané, B., \& Darley, J. M. (1970). The unresponsive bystander: Why doesn't he help? New York: Appleton-Century-Croft.

Lee, N. (2001). Childhood and society: growing up in an age of uncertainty. Maidenhead: Open University.

Leigh Star, S. \& Griesemer, J.R. (1989). Institutional Ecology, 'Translations' and Boundary Objects: Amateurs and Professionals in Berkeley's Museum of Vertebrate Zoology, 1907-39. Social Studies of Science, 19, 387- 420.

Leigh Star, S. (2010). "Living grounded theory: Cognitive and emotional forms of pragmatism", in Bryant, A., Charmaz, K (Ed.), The Sage Handbook of Grounded Theory. (pp.75-93). Los Angeles: Sage publications.

Lillrank, A. (2012). "Managing the Interviewer Self”. In Gubrium, J.F (Ed.), The Sage handbook of interview research: The complexity of the craft, (pp. 281-294). Thousand Oaks: SAGE publications. Lincoln, Y.S., Lynham, S.A., Guba, E.G (2011). "Paradigmatic Controversies, Contraditions, and Emerging Confluences, Revisited”. In Denzin, N.K. \& Lincoln, Y.S. (Ed.), The Sage handbook of qualitative research (pp. 97-128). Thousand Oaks: Sage publications.

Malinowski, B. (1922). Argonauts of the Western Pacific: An account of native enterprise and adventure in the Archipelagoes of Melanesian New Guinea. London: Routledge and Kegan Paul. Mandell, N. (1991). The least-adult role in studying children. In F. C. Waksler (Ed.), Studying the social worlds of children: Sociological readings (pp. 38-59). London: RoutledgeFalmer. 
Marzano, M. (2012). "Informed consent". In Gubrium, J.F (Ed.), The Sage handbook of interview research: The complexity of the craft (pp. 443-456). Thousand Oaks: SAGE publications.

Maxwell, J., \& Chmiel, M. (2014). "Generalization in and from qualitative analysis". In Flick, U (Ed.), The Sage Handbook of Qualitative Data Analysis (pp. 540-553). Sage: London.

Mayall, B. (2000). "Conversations with children: Working with generational issues". In P. Christensen, \& A. James (Eds.), Research with children (pp. 120-135). London: Falmer Press.

Mayall, B. (2008). "Conversations with children: Working with generational issues". In P. Christensen, \& A. James (Ed.), Research with children (pp. 120-135). London: Falmer Press.

Mayall, B. (2013). A history of the sociology of childhood. London: Institute of Education Press.

May Schott, R. (2014). "The social concept of bullying: philosophical reflections on definitions”. In May Schott, R \& Søndergaard, D.M. (Eds.). School Bullying: New Theories in Context (pp. 23-46). Cambridge: Cambridge University Press.

McCarthy, J., \& Deady, R. 2008. Moral distress reconsidered. Nursing Ethics 15: 254-262.

Mead, G.H. (1934). Mind, self and society: From the standpoint of a social behaviorist. Chicago: The University of Chicago.

Mead, G.H. (1938). The philosophy of the act. Chicago: The University of Chicago Press.

Merton, D.E. (1997). The meaning of meanness: Popularity, completion, and conflict among junior high school girls. Sociology of Education, 70, 175-191.

Meyer, E. J. (2008). Gendered harassment in secondary schools: Understanding teachers'(non) interventions. Gender and Education, 20(6), 555-570.

Mishna, F., Scarcello, I., Pepler, D., \& Wiener, J. (2005). Teachers' understanding of bullying. Canadian Journal of Education, 28, 718-738.

Mishna, F., Saini.,M, Solomon, S. (2009). Ongoing and online: Children and youth's perceptions of cyber bullying. Children and Youth Services Review, 31(12), 1222-1228. 
Mishler, E. G. (1991). Representing discourse: The rhetoric of transcription, Journal of Narrative And Life History, 1(4), 255280.

Morgan, D.L. (2012). "Focus Groups and Social Interaction". In Gubrium, J.F. (Ed.), The Sage handbook of interview research: The complexity of the craft (pp. 161-176).Thousand Oaks: SAGE Publications.

Morse, J.M. (2009). Developing grounded theory: The second generation. Walnut Creek, Calif.: Left Coast Press.

Mounce, H.O. (1997). The two pragmatisms: From Peirce to Rorty. London: Routledge.

Murray-Close, D., Crick, N. R. \& Galotti, K. M. (2006). Children's Moral Reasoning Regarding Physical and Relational Aggression. Social Development, 15, 345-372.

Nansel, T. R., Overpeck, M., Pilla, R. S., Ruan, W. J., SimonsMorton, B., \& Scheidt, P. C. (2001). Bullying behaviors among US youth. Journal of the American Medical Association, 285(16), 2094-2101.

Nastasi, B. (2009). Advances in qualitative research. In T. Gutkin \& C.

Reynolds (Ed.), The Handbook of School Psychology (pp. 30-

53). Hoboken, NJ: Wiley.

Naylor, P., Cowie, H., Cossin, F., Bettencourt, R., \& Lemme, F. (2006). Teachers' and pupils' definitions of bullying. British Journal of Educational Psychology, 76(3), 553-576.

Närvanen, A. L., \& Näsman, E. (2007). “Age order and children's agency". In H. Wintersberger (Ed.), Childhood, generational order and the welfare state: Exploring children's social and economic welfare (pp. 225-249). Odense: University Press of Southern Denmark.

Näsman, E. (1995). Vuxnas intresse av att se med barns ögon.

In Dahlgren, \& Hultquist, (Eds.), Seendet och seendets villkor ( $\mathrm{p}$. 279- 304). Stockholm: HLS förlag.

Näsman, E., \& Gerber, C.V. (2002). "Sharing children's thoughts and experiences". In Näsman, E., \& Ross, A. (Ed), Children's Understanding in the new Europe (pp.7-32 ). Stoke-on-Trent: Trentham. 
O'Connell, P., Pepler, D., Craig, W. (1999). Peer involvement in bullying: Insights and challenges for intervention. Journal of Adolescence, 22, 437- 452.

Olweus, D. (1993). Bullying at School: What we know and what we can do. Oxford: Blackwell.

Olweus, D. (2009). "Understanding and researching bullying". In Jimerson, S. R., Swearer, S. M. \& Espelage, D.L. (Eds), Handbook of bullying in school an international perspective (pp. 9-33). London: Routledge.

Olweus, D. (2013). School bullying: Development and some important challenges. Annual review of clinical psychology, 9, 751-780.

Osbeck, C., Holm \& Wernersson (2003). Kränkningar i skolan: Förekomst, former och sammanhang. Göteborg: Göteborgs universitet.

Osbeck, C. (2006). Kränkningens livsförståelse: En religionsdidaktisk studie av livsförståelselärande i skolan. Karlstad: Karlstads universitet, Religionsvetenskap. Doktorsavhandling.

Osbeck, C, \& Söderström, Å. (2014). “Är program lösningen på det svåra antimobbningsarbetet? Skolpersonals och elevers erfarenheter av att arbeta med program mot mobbning". I Johansson, E., \& Thornberg, R. (Eds), Värdepedagogik: Etik och demokrati i förskola och skola (pp. 227-248). Stockholmn: Liber.

Owens, L., Shute, R., \& Slee, P. (2000). "Guess what I just heard!”: Indirect aggression among teenage girls in Australia. Aggressive behavior, 26(1), 67-83.

Patterson, L. J., Allan, A., \& Cross, D. (2015). Adolescent perceptions of bystanders' responses to cyberbullying. New Media \& Society, doi: 1461444815606369.

Patton, D. U., Hong, J. S., Patel, S., \& Kral, M. J. (2015). A systematic review of research strategies used in qualitative studies on school bullying and victimization. Trauma, Violence, \& Abuse, doi: 1524838015588502.

Peirce, C.S. (1940). The philosophy of Peirce: Selected writings. New York.

Pellegrini, A.D. (2002). Bullying, victimization, and sexual harassment during the transition to middle school. Educational Psychologist, 37, 151-163. 
Phillips, C. (2003). Who's who in the pecking order? British Journal of Criminology, 43, 710-728.

Pini, B. (2005). Interviewing men Gender and the collection and interpretation of qualitative data. Journal of sociology, 41(2), 201216.

Potter, J., \& Hepburn, A. (2012). "Eight Challenges for Interview Researchers". In Gubrium, J.F. (Ed.), The Sage handbook of interview research: The complexity of the craft (pp. 555-570). Thousand Oaks, Calif.: SAGE.

Prout, A., \& James, A. (1997) A new paradigm for the sociology of childhood? Provenance, promise and problems. In James A and Prout A (Eds.), Constructing and reconstructing childhood. $2^{\text {nd }}$ (pp. 7-33), London: The Falmer Press.

Prout, A. (2005). The future of childhood: Towards the interdisciplinary study of children. London: RoutledgeFalmer.

Purcell, A. (2012). A qualitative study of perceptions of bullying in Irish primary schools. Educational Psychology in Practice, 28(3), 273-285.

Pöyhönen, V., Juvonen, J., \& Salmivalli, C. (2012). Standing up for the victim, siding with the bully or standing by? Bystander responses in bullying situations. Social Development, 21(4), 722741.

Ravet, J. (2007). Making sense of disengagement in the primary classroom: A study of pupil, teacher and parent perceptions. Research Papers in Education, 22, 333-362.

Razon, R., \& Ross, K. (2012). Negotiating Fluid Identities AllianceBuilding in Qualitative Interviews. Qualitative Inquiry, 18(6), 494-503.

Renold, E. (2005). Girls, boys and junior sexualities: Exploring children's gender and sexual relations in the primary school. London: Routledge.

Rigby, K. (2008). Children and bullying: How parents and educators can reduce bullying at school. Oxford: Blackwell.

Rigby, K., \& Johnson, B. (2005). Student bystanders in Australian schools. Pastoral Care in Education, 23, 10-16.

Ringrose, J. (2008). " Every time she bends over she pulls up her thong". Teen Girls Negotiating Discourses of Competitive, Heterosexualized Aggression. Girlhood Studies, 1(1), 33-59. 
Ringrose, J., \& Renold, R. 2009. Normative cruelties and gender deviants: The performative effects of bully discourses for girls and boys in school. British Educational Research Journal, 4, 124.

Rivers, I. \& Duncan, N. (Eds..) (2013). Bullying: Experiences and discourses of sexuality and gender. London: Routledge.

Rivers, I., Poteat, P., Noret, N., \& Ashurst, N. (2009). Observing Bullying at School: The Mental Health Implications of Witness Status. School Psychology Quarterly, 24(4), 211-223.

Rorty, R. (1999). Philosophy and social hope. London: Penguin. Salmivalli, C., Lagerspetz, K., Bjorkqvist, K., Osterman, K., \& Kaukiainen, A. (1996). Bullying as a Group Process: Participant Roles and Their Relations to Social Status Within the Group. Aggressive Behaviour, 22, 1-15.

Salmivalli, C. (1999). Participant role approach to school bullying: Implications for interventions. Journal of Adolescence, 22, 453459.

Salmivalli, C., \& Voeten, M. (2004). Connections between attitudes, group norms, and behaviour in bullying situations. International Journal of Behavioral Development, 28(3), 246-258.

Salmivalli, C. (2010). Bullying and the peer group: A review. Aggression and violent behavior, 15(2), 112-120.

Sandstrom, K.L. (2014). Symbols, selves, and social reality: A symbolic interactionist approach to social psychology and sociology. (4th ed.) New York, NY: Oxford University Press.

SFS. (2010:800). Skollagen. Stockholm: Regeringen.

Smith, P.K., Salmivalli, C., \& Cowie, H. (2012). Effectiveness of school-based programs to reduce bullying: a commentary. Journal of Experimental Criminology, 8:4, 433-441.

Smith, P. K. (2014). Understanding school bullying: Its nature and prevention strategies. Los Angeles: Sage.

Søndergaard, D. M. (2012). Bullying and social exclusion anxiety in schools. British Journal of Sociology of Education, 33(3), 355372.

Søndergaard, D. M. (2015). The dilemmas of victim positioning. Confero: Essays on Education, Philosophy and Politics, 3(2), 3679. 
Stavrinides, P., Georgiou, St., Nikiforou, M, \& Kiteri, E. (2011).

Longitudinal investigation of the relationship between bullying and psychosocial adjustment. European Journal of Developmental Psychology, 8(6), 730-743.

Strauss, A.L.,Schatzman, L., Ehrlich, D., Bucher, R., \& Sabshin, M. (1963), "The hospital and its negotiated order". In Freidson, E. (Ed.), The hospital in modern society (pp.147-169). New York: The Free P.

Strauss, A.L. (1978). Negotiations: Varieties, contexts, processes, and social order. San Francisco: Jossey-Bass.

Strauss, A.L, Corbin, J. (1998). Basics of qualitative research:

Techniques and Procedures for Developing grounded theory, Sage Publications.

Svahn, J, Evaldsson, AC. 2011. 'You could just ignore me': Situating peer exclusion within the contingencies of girls' everyday interactional practices. Childhood, 18, 491-508.

Swart, E., \& Bredekamp, J. (2009). Non-physical bullying: Exploring the perspectives of Grade 5 girls. South African Journal of Education, 29(3), 405-425.

Swearer, S. M., \& Doll, B. (2001). Bullying in schools: An ecological framework. Journal of Emotional Abuse, 2(2-3), 7-23.

Teräsahjo, T., \& Salmivalli, C. (2003). "She Is Not Actually Bullied."

The Discourse of Harassment in Student Groups. Aggressive Behaviour, 29, 134-154.

Thayer, H.S (1982). "Introduction". In Thayer, H.S. (Ed.),

Pragmatism, the classic writings: Charles Sanders Peirce, William James, Clarence Irving Lewis, John Dewey, George Herbert Mead (pp-11-22), Indianapolis: Hackett Pub. Co.

Thayer-Bacon, B. J. (1996). An examination and redescription of epistemology. Standards and schooling in the United States: An encyclopedia, 1, 397-418.

Thomas, W.I. \& Thomas, D.S. (1928). The child in America: Behaviour problems and programs. New York: NY: Knopf. Thornberg, R. (2010). Schoolchildren's social representations on bullying causes. Psychology in schools, 47, 311-327.

Thornberg, R. \& Knutsen, S. (2011a). Teenagers'Explanations of Bullying. Child Youth Care Forum. 40(3), 177-192. 
Thornberg, R. (2011b). "She's weird" - The social construction of bullying in school: A review of qualitative research. Children \& Society, 25, 258-267.

Thornberg, R. (2012). Informed grounded theory. Scandinavium Journal of Educational research, 56, 243-259.

Thornberg, R., Tenenbaum, L., Varjas, K., Meyers, J., Jungert, T., \& Vanegas, G. (2012). Bystander motivation in bullying incidents: To intervene or not to intervene? Western Journal of Emergency Medicine, 13, 247-252.

Thornberg, R., Halldin, K., Bolmsjö, N., \& Petersson, A. (2013a).

Victimising of school bullying: A grounded theory. Research Papers in Education, 28, 309-332.

Thornberg, R. (2013b). Det sociala livet i skolan: Socialpsykologi för lärare. Stockholm: Liber.

Thornberg, R., \& Jungert, T. (2013c). Bystander behavior in bullying situations: Basic moral sensitivity, moral disengagement and defender self-efficacy. Journal of adolescence, 36(3), 475-483.

Thornberg, R., \& Charmaz, K. (2014). "Grounded Theory and Theoretical Coding". In Flick, U. (Ed.), The SAGE handbook of qualitative data analysis (pp. 153-169), Los Angeles: SAGE.

Thornberg, R. (2015a). School bullying as a collective action: Stigma processes and identity struggling. Children \& Society, 29, 310320.

Thornberg, R. (2015b). The social dynamics of school bullying: The necessary dialogue between the blind men around the elephant and the possible meeting point at the social-ecological square. Confero: Essays on Education, Philosophy and Politics, $3,1-41$.

Thorne, B. (1993). Gender play: Girls and boys in school. Buckingham: Open University Press.

Tilley, S. A. (2003). "Challenging" research practices: Turning a critical lens on the work of transcription. Qualitative inquiry, 9(5), 750-773.

Tokunaga, R.S. (2010). Following you home from school: A critical review and synthesis of research on cyberbullying victimization.

Computures in Human Behaviour, 26(3), 277-287.

Utrikesdepartementet, (2008). "Mänskliga Rättigheter Barnets

Rättigheter: En lättläst skrift”, Stockholm. 08 Tryck. 
Vaillancourt, T, Brittain, H, Bennett, L, Arnocky, S, McDougall, P, Hymel, S, Cunningham, L. (2010). Places to avoid: Populationbased study of student reports of unsafe and high bullying areas at school. Canadian Journal of School Psychology, 25, 40-54.

Varjas, K., Meyers, J., Bellmoff, L., Lopp, E., Birckbichler, L., \& Marshall, M. 2008. Missing voices: Fourth through eighth grade urban students' perceptions of bullying. Journal of School Violence, 7, 97-118.

Vetenskapsrådet. (2002). Forskningsetiska principer inom humanistisk- samhällsvetenskaplig forskning.

Volk, A. A., Dane, A. V., \& Marini, Z. A. (2014). What is bullying? A theoretical redefinition. Developmental Review, 34(4), 327-343.

Walton, G. (2005). Bullying widespread: A critical analysis of research and public discourse on bullying. Journal of school violence, 4(1), 91-118.

Walton, G. (2011). Spinning our wheels: Reconceptualizing bullying beyond behaviour-focused approaches. Discourse: studies in the cultural politics of education, 32(1), 131-144.

Wang, C., Berry, B., \& Swearer, S.M. (2013) The Critical Role of School Climate in Effective Bullying Prevention, Theory Into Practice, 52(4), 296-302.

Wang, J., Iannotti, R. J., \& Nansel, T. R. (2009). School bullying among adolescents in the United States: Physical, verbal, relational, and cyber. Journal of Adolescent Health, 45, 368-375.

Wuest, J. (2000). Negotiating with helping systems: An example of grounded theory evolving through emergent fit. Qualitative Health Research, 10(1), 51-70.

Yoneyama, S., \& Naito, A. (2003). Problems with the paradigm: The school as a factor in understanding bullying (with special reference to Japan). British Journal of Sociology of Education, 24(3), 315-330.

Yoon, J., \& Kerber, K. (2003). Bullying: Elementary teachers' attitudes and intervention strategies. Research in Education, 69(1), 27-35. 



\section{Papers}

The articles associated with this thesis have been removed for copyright reasons. For more details about these see:

http://urn.kb.se/resolve?urn=urn:nbn:se:liu:diva-123925 